\title{
Enabling in vivo Photocatalytic Activation of Rapid Bioorthogonal Chemistry by Repurposing Si-Rhodamine Fluorophores as Cytocompatible Far-red Photocatalysts
}

Chuanqi Wang, ${ }^{1, \ddagger}$ He Zhang, ${ }^{2, \ddagger}$ Tao Zhang ${ }^{3}$, Xiaoyu Zou, ${ }^{2}$ Hui Wang, ${ }^{3}$ Julia E. Rosenberger, ${ }^{1}$ Raghu Vannam, ${ }^{1}$ William S. Trout, ${ }^{1}$ Jonathan B. Grimm, ${ }^{5}$ Luke D. Lavis,${ }^{5}$ Colin Thorpe, ${ }^{1}$ Xinqiao Jia, ${ }^{2,4^{*}}$ Zibo Li, ${ }^{3,}{ }^{*}$ Joseph M. Fox ${ }^{1,2,}$

${ }^{1}$ Department of Chemistry and Biochemistry, University of Delaware, Newark, Delaware 19716, USA

${ }^{2}$ Department of Materials Science and Engineering, University of Delaware, Newark, Delaware 19716, USA

${ }^{3}$ Department of Radiology and Biomedical Research Imaging Center, University of North Carolina at Chapel Hill, Chapel Hill, North Carolina 27599, USA

${ }^{4}$ Delware Biotechnology Institute, Newark, Delaware 19711, USA

5Janelia Research Campus, Howard Hughes Medical Institute, Ashburn Virginia, 20147, USA 


\section{Table of Contents}

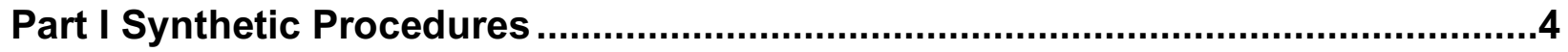

Part II Dihydrotetrazine oxidation experiments.....................................................11

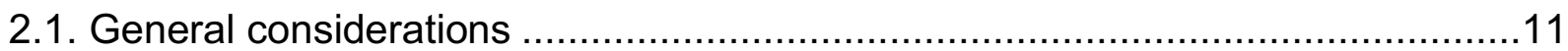

2.2. SiR catalyzed photooxidation of DHTz 6 monitored by UV-Vis spectrophotometer

.

2.2.1. SiR catalyzed photooxidation (Results displayed in Fig 4B, standard conditions, Fig S3):.............................................................................. 12

2.2.2. Light dependent control (Results displayed in Fig 4B, light on/off): ..............12

2.2.3. Superoxide quenching control (Results displayed in Fig $4 B,+S O D)$ :...........12

2.2.4. Singlet oxygen quenching control (Results displayed in Fig $4 B,+$ Met):........12

2.2.5. Comparison of the ability that different photocatalysts catalyze the photooxidatioin of DHTz 6 to Tz 7:...........................................................13

2.3. SiR catalyzed photooxidation of $\mathrm{DHTz} 6$ to produce a thioredoxin-trans-

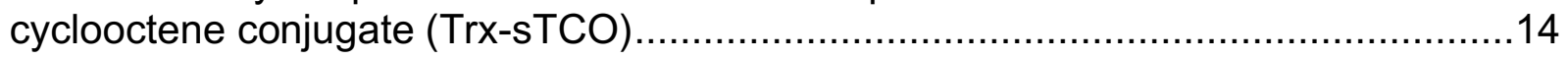

2.3.1. Thioredoxin (Trx) single Cys mutant expression and purification:.................14

2.3.2. Synthesis of Trx-sTCO .................................................................15

2.3.3. Photocatalyzed Labeling of Trx-sTCO with DHTz 6 (Results displayed in Fig

5, with catalyst, Fig S7-9): ...................................................................16

2.3.4. Control of labeling Trx-sTCO with DHTz 6, using no catalyst (Results

displayed in Fig 5, without catalyst, S10-12):..............................................18

2.3.5. Control of labeling Trx-sTCO with DHTz 6, using no light:..........................20

2.3.6. SiR-photocatalyzed reaction of Trx-sTCO with DHTz 6 with prolonged

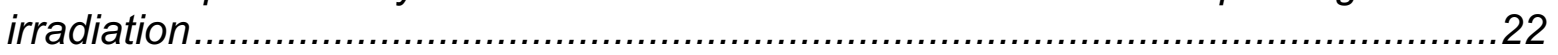

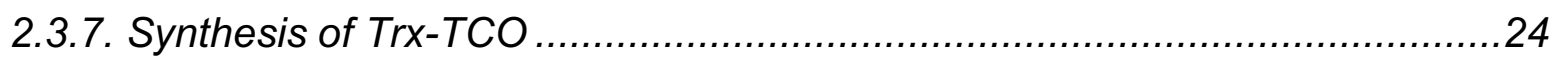

2.3.8. Photocatalyzed Labeling of Trx-TCO with DHTz 6 .................................25

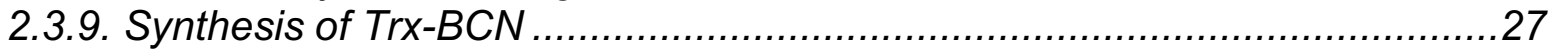

2.3.10. Photocatalyzed Labeling of Trx-BCN with DHTz 6 ...............................28

2.3.11. Oxidation of $D H T z 6$ during reverse phase chromatography ......................30

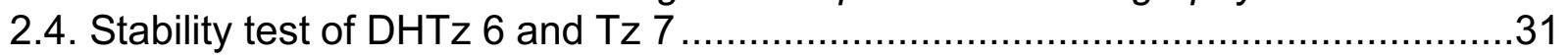

2.4.1. Stability of DHTz 6 in PBS (Results displayed in Fig 2D):......................... 31

2.4.2. Stability of Tz 7 in PBS (Results displayed in Fig 2E):.............................31

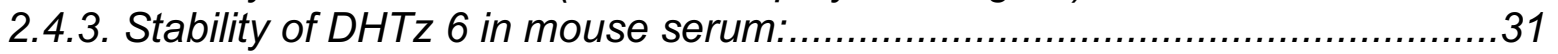

2.5. Stopped-flow kinetic analysis with ax-5-hydroxy-trans-cyclooctene .....................32

2.5.1. Stopped-flow kinetic analysis between Tz 7 and ax-5-hydroxy-trans-

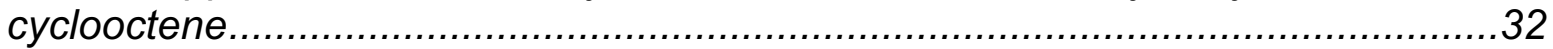

2.5.2. Stopped-flow kinetic analysis between Tz 3 and ax-5-hydroxy-trans-

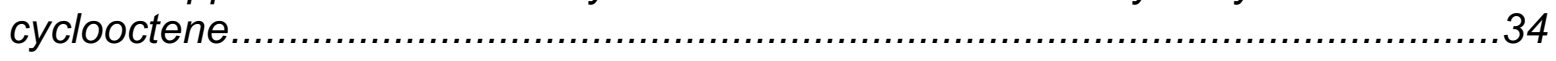

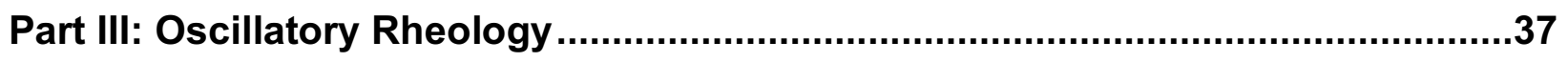

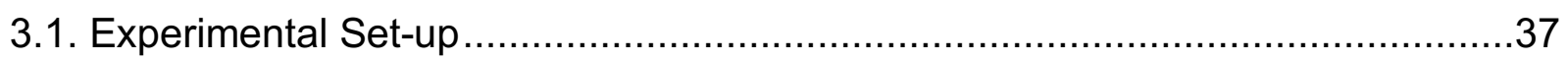

3.2. In-situ gelation (Results displayed in Fig 6C) ............................................3

3.3. Oscillatory rheological measurement on hydrogel precursor solution without light

3.4. Oscillatory rheological measurement on hydrogel precursor solution without 


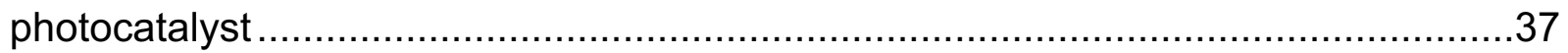

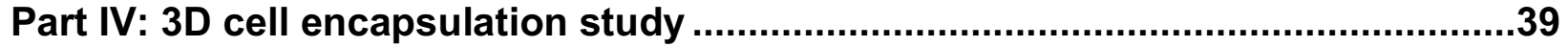

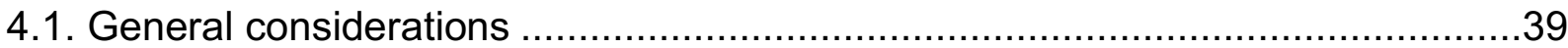

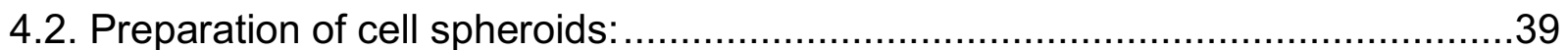

4.3. Cell encapsulation (Results displayed in Fig 6A, Fig S34) .............................40

4.4. Cell viability assay (Results displayed in Fig 6E, Fig S35-37) .........................40

Part V: Hydrogelation studies in live mice ..........................................................45

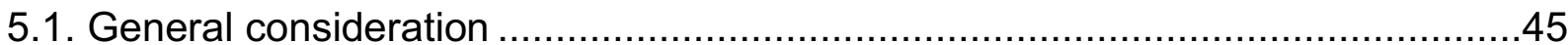

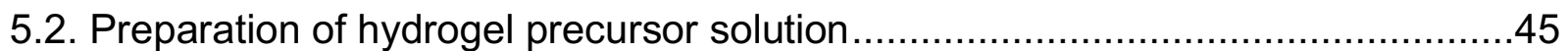

5.3. Study of the fluorescence signal change before and after in vitro gelation..........45

5.4. Study of in vivo gelation ...................................................................... 47

5.4.1. The baseline correction before the injection of In vivo gelation experiments 47

5.4.2. Time-course imaging experiment:.......................................................47

5.4.3. Control experiment without light:............................................................49

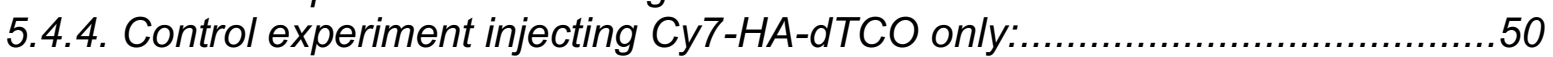

5.5. Fluorescent imaging guided surgical experiments ........................................53

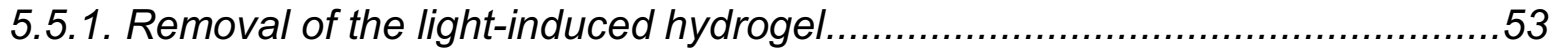

5.5.2. Surgical experiments for control without light...........................................54

Part VI: Mechanistic study of the oxidation of DHT 6 catalyzed by SiR 1d.............55

6.1. Relative rates of photocatalyzed oxidation of DHTz and oxidation of ABDA by singlet oxygen using SiR 1d vs methylene blue. ..............................................55

6.2. Effect of SiR concentration on the rate of $\mathrm{DHTz}$ oxidation. ............................56

6.3. Effect of light power density on the rate of $\mathrm{DHTz}$ oxidation ............................57

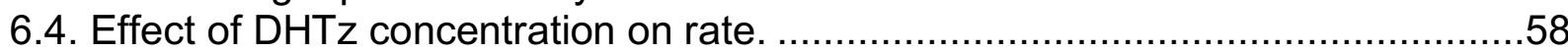

6.5. UV-vis spectra of SiR $1 \mathrm{~d}$ in the presence and absence of $\mathrm{DHTz} 6 \ldots \ldots \ldots \ldots \ldots . . .59$

6.6. Effect of tetrazine or peroxide on $\mathrm{DHTz}$ oxidation rate.................................60

6.7. Effect of oxidation products on $\mathrm{DHTz}$ rate ....................................................61

6.8. Effect of catalase on background DHTz oxidation......................................62

Part VII: Mechanistic studies showing that peroxide is a product of DHTz

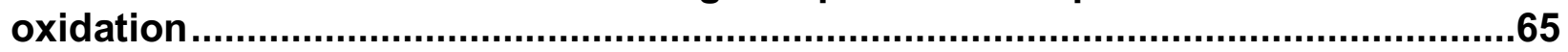

7.1 Oxygen Electrode Experiment (Results displayed in Fig 2B) ...........................65

7.2 Formation of $\mathrm{H} 2 \mathrm{O} 2$ in methylene blue and SiR-photocatalyzed DHTz oxidation. 65

7.3 Effect of Catalase on LNCaP Viability After Photocatalytic DHTz Oxidation ........66

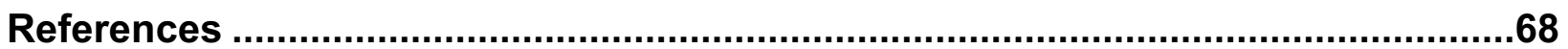

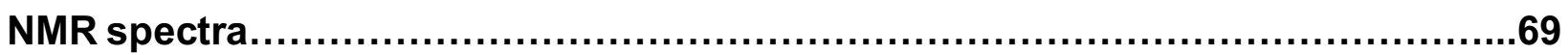




\section{Part I Synthetic Procedures}

\section{General considerations}

All reactions were carried out in glassware that was flame-dried under vacuum and cooled under nitrogen. Flash Chromatography was performed using normal phase Silicycle silica gel $(40-63 D, 60 \AA)$. Other solvents and reagents were purchased commercially from reputable sources without additional purification. NMR spectra were obtained on a Bruker AV600 $\left({ }^{1} \mathrm{H}: 600 \mathrm{MHz},{ }^{13} \mathrm{C}: 150 \mathrm{MHz}\right)$ or an AV400 $\left({ }^{1} \mathrm{H}: 400 \mathrm{MHz},{ }^{13} \mathrm{C}: 100 \mathrm{MHz}\right) \mathrm{NMR}$ spectrometer. ${ }^{1} \mathrm{H}$ NMR peak multiplicities were reported as singlet (s), doublet (d), triplet $(\mathrm{t})$, quartet (q), pentet (pent), multiplet (m), 'broad' (br), and sometimes described as 'apparent' (app). An APT pulse sequence was used for ${ }^{13} \mathrm{C}$ NMR, where the secondary and quaternary carbons appeared 'up' $(u)$, and tertiary and primary carbons appeared 'down' (dn). Exceptions were for methine carbons of alkynes, which usually have the same phase as 'normal' methylenes and quaternary carbons. Stopped-flow kinetics measurements were performed on a SX18MV-R stopped-flow spectrophotometer (Applied Photophysics Ltd.) with temperature control $\left(25^{\circ} \mathrm{C}\right)$. High resolution mass spectrometry was conducted on a Thermo Q-Exactive Orbitrap.

Phosphate-buffered saline (PBS) was purchased directly from Corning, and PBS was passed through a column of Chelex 100 resin to remove any trace metals by the following procedure. All containers and the column were first rinsed with 2 mM EDTA ( $3 x$ ) and then with MilliQ water (3x). The column (Biotage, $50 \mathrm{~g}$ Snap Cartridge) was filled with BioRad Chelex 100 Resin (analytical grade, 50-100 mesh, cat \# 1422822). Commercial PBS buffer (typically $500 \mathrm{~mL}$ ) was passed through the resin; the first $50 \mathrm{~mL}$ was discarded, and the rest was collected in a Nalgene container. A small amount of the solution was transferred to a vial and the $\mathrm{pH}$ of the solution was checked; if necessary, $\mathrm{pH}$ was adjusted with $1 \mathrm{M} \mathrm{HCl}$ or $1 \mathrm{M} \mathrm{NaOH}$ solutions prepared from MilliQ water.

\section{3-((2-hydroxyethyl)amino)picolinonitrile}<smiles>CCN(CC)CCO</smiles>

To a round-bottomed flask with a stir bar, 3-fluoropicolinonitrile $(3.0 \mathrm{~g}, 25 \mathrm{mmol}), 2-$ aminoethanol $(2.0 \mathrm{~g}, 32 \mathrm{mmol})$, triethylamine $(3.7 \mathrm{~g}, 37 \mathrm{mmol})$, and dimethylformamide $(50 \mathrm{~mL})$ were added. The reaction mixture was heated to $85^{\circ} \mathrm{C}$ with stirring for 3 hours, and then cooled to room temperature. Water $(100 \mathrm{~mL})$ was added to the flask and the reaction mixture was extracted with ethyl acetate $(50 \mathrm{~mL} \times 3)$. The organic layers were combined, dried with $\mathrm{Na}_{2} \mathrm{SO}_{4}$, filtered and the solvent was then removed by rotary evaporation. The yellow crude product was purified by column chromatography $(20-80 \%$ ethyl acetate in hexane) to give the title compound as white solid $(3.1 \mathrm{~g}, 77 \%)$.

${ }^{1} \mathrm{H}$ NMR $\left(600 \mathrm{MHz}, \mathrm{CDCl}_{3}\right) \delta 8.00(\mathrm{dd}, J=4.5,1.2 \mathrm{~Hz}, 1 \mathrm{H}), 7.32(\mathrm{dd}, J=8.7,4.4 \mathrm{~Hz}, 1 \mathrm{H})$, $7.13(\mathrm{dd}, J=8.7,1.2 \mathrm{~Hz}, 1 \mathrm{H}), 5.03(\mathrm{~s}, 1 \mathrm{H}), 3.93(\mathrm{q}, J=4.5 \mathrm{~Hz}, 2 \mathrm{H}), 3.42(\mathrm{q}, J=5.4 \mathrm{~Hz}$, $2 \mathrm{H}), 2.20(\mathrm{~d}, J=4.7 \mathrm{~Hz}, 1 \mathrm{H})$. 
${ }^{13} \mathrm{C}$ NMR (101 MHz, CDCl 3 ) $\delta 147.9(\mathrm{C}), 139.4(\mathrm{CH}), 128.0(\mathrm{CH}), 118.5(\mathrm{CH}), 117.7(\mathrm{C})$, $116.3(\mathrm{C}), 60.9\left(\mathrm{CH}_{2}\right), 44.9\left(\mathrm{CH}_{2}\right)$.

FTIR (dry film) $v_{\max }\left(\mathrm{cm}^{-1}\right): 3448,2223,1637,1593,1516,1276,806,747,576,540$.

MS (ESI) calcd. for $\mathrm{C}_{8} \mathrm{H}_{10} \mathrm{~N}_{3} \mathrm{O}^{+}, 164.0824$ found 164.0816 .

2-((2-(6-(pyridin-2-yl)-1,4-dihydro-1,2,4,5-tetrazin-3-yl)pyridin-3-yl)amino)ethanol (4)

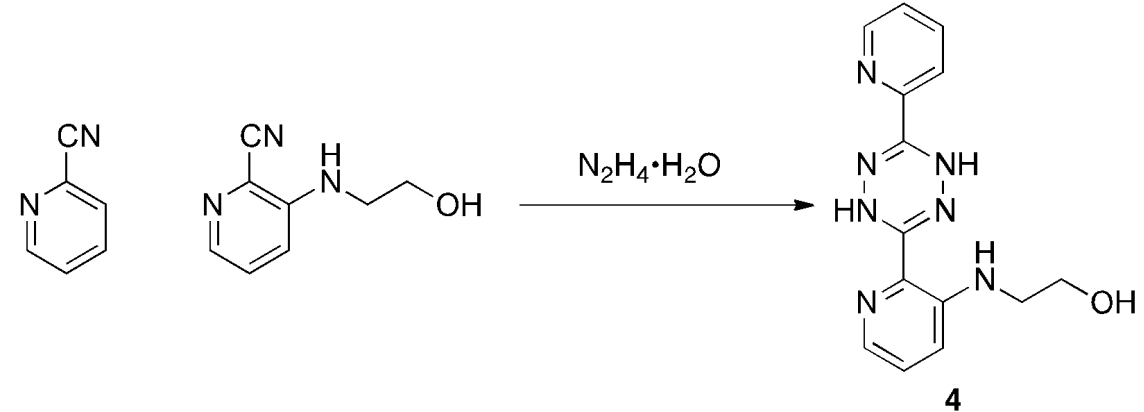

To a round-bottomed flask with a stir bar, 3-((2-hydroxyethyl)amino)picolinonitrile (160 $\mathrm{mg}, 1.0 \mathrm{mmol})$, picolinonitrile $(400 \mathrm{mg}, 4.0 \mathrm{mmol})$, and hydrazine monohydrate $(1.0 \mathrm{~mL})$ were added. The reaction mixture was heated to $90{ }^{\circ} \mathrm{C}$ with stirring overnight, and then cooled to room temperature. Water $(20 \mathrm{~mL})$ was added to the flask and the reaction mixture was extracted with ethyl acetate $(30 \mathrm{~mL} \times 3)$. The organic layers were combined, dried with $\mathrm{Na}_{2} \mathrm{SO}_{4}$, filtered and the solvent was then removed by rotary evaporation. The crude product was purified by column chromatography $(20-80 \%$ diethyl ether in dichloromethane) to give the title compound as yellow-orange solid (140 mg, 47\%).

${ }^{1} \mathrm{H} \mathrm{NMR}\left(600 \mathrm{MHz}, \mathrm{CDCl}_{3}\right) \delta 8.96(\mathrm{~s}, 1 \mathrm{H}), 8.58(\mathrm{~s}, 1 \mathrm{H}), 8.53$ (ddd, $J=4.9,1.7,1.0 \mathrm{~Hz}$, $1 \mathrm{H}), 8.02(\mathrm{dt}, J=8.0,1.1 \mathrm{~Hz}, 1 \mathrm{H}), 7.86(\mathrm{dd}, J=4.4,1.4 \mathrm{~Hz}, 2 \mathrm{H}), 7.72(\mathrm{td}, J=7.7,1.8 \mathrm{~Hz}$, 1H), 7.31 (ddd, $J=7.5,4.9,1.2 \mathrm{~Hz}, 1 \mathrm{H}), 7.12$ (dd, $J=8.4,4.4 \mathrm{~Hz}, 1 \mathrm{H}$ ), 7.02 (dd, $J=8.5$, $1.3 \mathrm{~Hz}, 1 \mathrm{H}$ ), , $3.84(\mathrm{t}, J=5.4 \mathrm{~Hz}, 2 \mathrm{H}), 3.37(\mathrm{q}, J=5.5 \mathrm{~Hz}, 2 \mathrm{H}), 2.44(\mathrm{~s}, 1 \mathrm{H})$.

${ }^{13} \mathrm{C}$ NMR (101 MHz, CDCl 3 ) ठ $149.0(\mathrm{C}), 148.5(\mathrm{CH}), 147.7$ (C), 146.9 (C), 144.9 (C), $136.9(\mathrm{CH}), 135.8(\mathrm{CH}), 128.2(\mathrm{C}), 125.7(\mathrm{CH}), 125.0(\mathrm{CH}), 121.3(\mathrm{CH}), 118.0(\mathrm{CH}), 61.4$ $\left(\mathrm{CH}_{2}\right), 45.0\left(\mathrm{CH}_{2}\right)$.

FTIR (dry film) $V_{\max }\left(\mathrm{cm}^{-1}\right): 3320,2874,1587,1507,1468,1439,1375,1258,1201,1041$, 989, 885, 790, 743, 677, 659.

MS (ESI) calcd. for $\mathrm{C}_{14} \mathrm{H}_{16} \mathrm{~N}_{7} \mathrm{O}^{+}, 298.1416$ found 298.1401 .

\section{4-nitrophenyl(2-((2-(6-(pyridin-2-yl)-1,4-dihydro-1,2,4,5-tetrazin-3-yl)pyridin-3- yl)amino)ethyl)carbonate (5)}



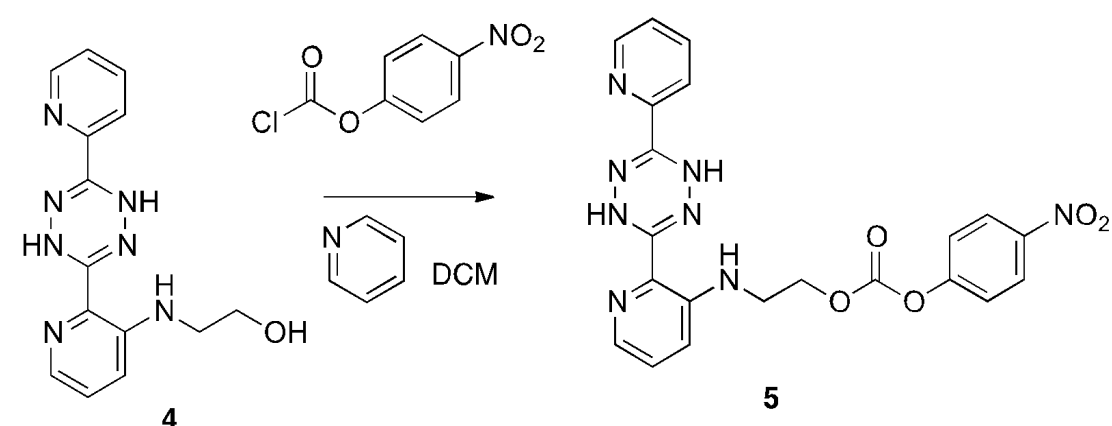

To a round-bottomed flask with a stir bar, 2-((2-(6-(pyridin-2-yl)-1,4-dihydro-1,2,4,5tetrazin-3-yl)pyridin-3-yl)amino)ethanol $(100 \mathrm{mg}, \quad 0.34 \mathrm{mmol}), \quad$ anhydrous dichloromethane $(5 \mathrm{~mL})$, and pyridine $(70 \mu \mathrm{L}, 0.8 \mathrm{mmol})$ were added. A solution of 4nitrophenylchloroformate $(80 \mathrm{mg}, 0.4 \mathrm{mmol})$ in anhydrous dichloromethane $(4 \mathrm{~mL})$ was added to the flask dropwise, and the reaction mixture stirred for $7 \mathrm{~h}$ at room temperature. Saturated aq. $\mathrm{NH} 4 \mathrm{Cl}$ was then added to the mixture and the layers were separated. The organic layer was washed with water, then dried with $\mathrm{Na}_{2} \mathrm{SO} 4$, filtered and the solvent was removed using a rotary evaporator. The crude product was purified by column chromatography (100\% dichloromethane, then $0-20 \%$ ethyl acetate in dichloromethane) to give the title compound as a yellow-orange solid (93 $\mathrm{mg}, 60 \%$ ).

1H NMR (600 MHz, $\left.\mathrm{CDCl}_{3}\right) \delta 8.96(\mathrm{~s}, 1 \mathrm{H}), 8.53$ (ddd, $\left.\mathrm{J}=4.9,1.7,1.0 \mathrm{~Hz}, 1 \mathrm{H}\right), 8.51$ (s, $1 \mathrm{H}), 8.24-8.19(\mathrm{~m}, 2 \mathrm{H}), 8.06(\mathrm{dd}, \mathrm{J}=6.6,2.5 \mathrm{~Hz}, 2 \mathrm{H}), 7.95(\mathrm{dd}, \mathrm{J}=4.4,1.3 \mathrm{~Hz}, 1 \mathrm{H})$, $7.76(\mathrm{td}, \mathrm{J}=7.7,1.7 \mathrm{~Hz}, 1 \mathrm{H}), 7.42-7.32(\mathrm{~m}, 3 \mathrm{H}), 7.21$ (dd, J = 8.4, 4.4 Hz, 1H), 7.09 (dd, $\mathrm{J}=8.5,1.3 \mathrm{~Hz}, 1 \mathrm{H}), 4.52(\mathrm{t}, \mathrm{J}=5.6 \mathrm{~Hz}, 2 \mathrm{H}), 3.65(\mathrm{q}, \mathrm{J}=5.7 \mathrm{~Hz}, 2 \mathrm{H})$.

${ }^{13} \mathrm{C}$ NMR (101 MHz, CDCl 3 ) ठ $155.4(\mathrm{C}), 152.6(\mathrm{C}), 148.8(\mathrm{C}), 148.3(\mathrm{CH}), 147.5(\mathrm{C})$, $146.6(\mathrm{C}), 145.4(\mathrm{C}), 144.2(\mathrm{C}), 136.9(\mathrm{CH}), 136.2(\mathrm{CH}), 128.4(\mathrm{C}), 125.6(\mathrm{CH}), 125.3$ $(\mathrm{CH}), 124.9(\mathrm{CH}), 121.8(\mathrm{CH}), 121.2(\mathrm{CH}), 117.5(\mathrm{CH}), 67.0\left(\mathrm{CH}_{2}\right), 41.29\left(\mathrm{CH}_{2}\right)$.

FTIR (dry film) Umax $\left(\mathrm{cm}^{-1}\right): 3337,3294,1766,1588,1524,1379,1349,1268,1259,1219$, 794.

MS (ESI) calcd. for $\mathrm{C}_{21} \mathrm{H}_{19} \mathrm{~N}_{8} \mathrm{O}_{5}{ }^{+}, 463.1478$ found 463.1471 .

2-((2-(6-(pyridin-2-yl)-1,4-dihydro-1,2,4,5-tetrazin-3-yl)pyridin-3-yl)amino)ethyl$2,5,8,11,14,17,20,23,26,29,32,35$-dodecaoxaheptatriacontan-37-ylcarbamate (6)

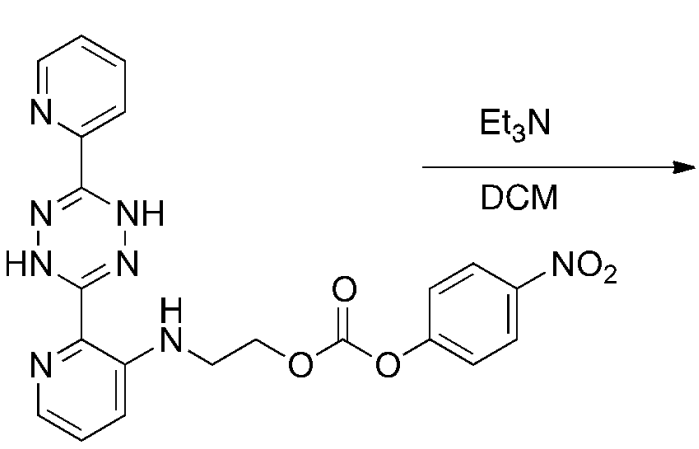

5

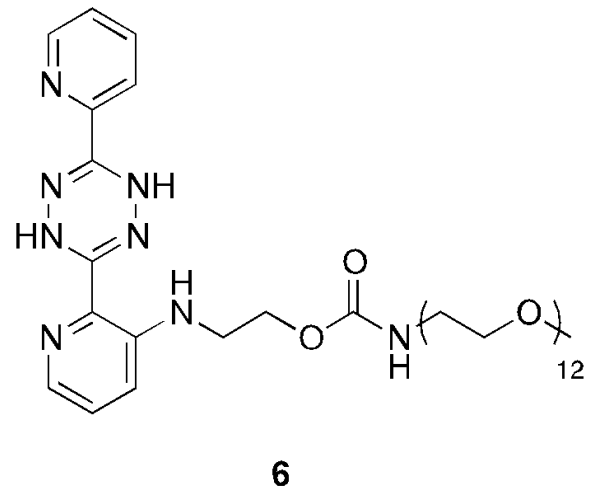


To a round-bottomed flask with a stir bar, anhydrous dichloromethane (3 $\mathrm{mL})$, triethylamine $(70 \mu \mathrm{L}, 0.5 \mathrm{mmol})$, and 4-nitrophenyl(2-((2-(6-(pyridin-2-yl)-1,4-dihydro1,2,4,5-tetrazin-3-yl)pyridin-3-yl)amino)ethyl)carbonate (46 $\mathrm{mg}, 0.10 \mathrm{mmol}$ ) were added. m-PEG12-amine $(56 \mathrm{mg}, 0.10 \mathrm{mmol})$ in anhydrous dichloromethane $(2 \mathrm{~mL})$ was then added dropwise. The reaction mixture stirred overnight at room temperature. The solvent was then removed by rotary evaporation, and the crude reaction mixture was then purified by column chromatography $(0-10 \%$ methanol in dichloromethane) to give the title compound as a yellow-orange oil ( $55 \mathrm{mg}, 64 \%$ ).

${ }^{1} \mathrm{H} \mathrm{NMR}\left(600 \mathrm{MHz}, \mathrm{CDCl}_{3}\right) \delta 8.94(\mathrm{~s}, 1 \mathrm{H}), 8.56(\mathrm{dt}, J=5.0,1.2 \mathrm{~Hz}, 1 \mathrm{H}), 8.54(\mathrm{~s}, 1 \mathrm{H}), 8.04$ $(\mathrm{d}, J=8.0 \mathrm{~Hz}, 1 \mathrm{H}), 7.97-7.85(\mathrm{~m}, 2 \mathrm{H}), 7.75(\mathrm{td}, J=7.7,1.8 \mathrm{~Hz}, 1 \mathrm{H}), 7.41-7.30(\mathrm{~m}$, $1 \mathrm{H}), 7.18(\mathrm{dd}, J=8.5,4.3 \mathrm{~Hz}, 1 \mathrm{H}), 7.09(\mathrm{dd}, J=8.5,1.3 \mathrm{~Hz}, 1 \mathrm{H}), 5.54(\mathrm{~s}, 1 \mathrm{H}), 4.28(\mathrm{~s}$, $2 \mathrm{H}), 3.67-3.58(\mathrm{~m}, 40 \mathrm{H}), 3.58-3.51(\mathrm{~m}, 4 \mathrm{H}), 3.47(\mathrm{q}, J=6.1 \mathrm{~Hz}, 2 \mathrm{H}), 3.39(\mathrm{t}, J=5.4$ $\mathrm{Hz}, 2 \mathrm{H}), 3.37(\mathrm{~s}, 3 \mathrm{H})$.

${ }^{13} \mathrm{C}$ NMR (151 MHz, $\left.\mathrm{CDCl}_{3}\right) \delta 156.6(\mathrm{C}), 148.9(\mathrm{C}), 148.4(\mathrm{CH}), 147.8(\mathrm{C}), 146.8(\mathrm{C})$, $144.7(\mathrm{C}), 136.9(\mathrm{CH}), 135.8(\mathrm{CH}), 128.1(\mathrm{C}), 125.7(\mathrm{CH}), 124.9(\mathrm{CH}), 121.3(\mathrm{CH}), 117.8$ $(\mathrm{CH}), 72.1\left(\mathrm{CH}_{2}\right), 70.71\left(\mathrm{CH}_{2}\right), 70.67\left(17 \mathrm{CH}_{2}\right), 70.64\left(\mathrm{CH}_{2}\right), 70.63\left(\mathrm{CH}_{2}\right), 70.4\left(\mathrm{CH}_{2}\right), 70.2$ $\left(\mathrm{CH}_{2}\right), 62.9\left(\mathrm{CH}_{2}\right), 59.2\left(\mathrm{CH}_{3}\right), 42.0\left(\mathrm{CH}_{2}\right), 41.1\left(\mathrm{CH}_{2}\right)$.

FTIR (dry film) Umax $\left(\mathrm{cm}^{-1}\right)$ : 3436, 2917, 1704, 1641, 1588, 1468, 1377, 1254, 1000, 951 , 540 .

MS (ESI) calcd. for $\mathrm{C}_{40} \mathrm{H}_{67} \mathrm{~N}_{8} \mathrm{O}_{14}{ }^{+}$, 883.4776, found 883.4738.

UV-vis: $\varepsilon_{(354, \max )}=7600 \mathrm{M}^{-1} \mathrm{~cm}^{-1}, \varepsilon_{(417)}=600 \mathrm{M}^{-1} \mathrm{~cm}^{-1}$.

\section{2-((2-(6-(pyridin-2-yl)-1,2,4,5-tetrazin-3-yl)pyridin-3-yl)amino)ethyl}

2,5,8,11,14,17,20,23,26,29,32,35-dodecaoxaheptatriacontan-37-ylcarbamate (7)

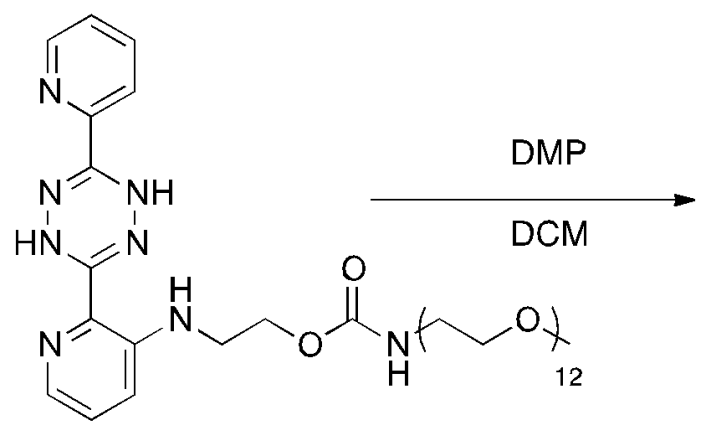

6

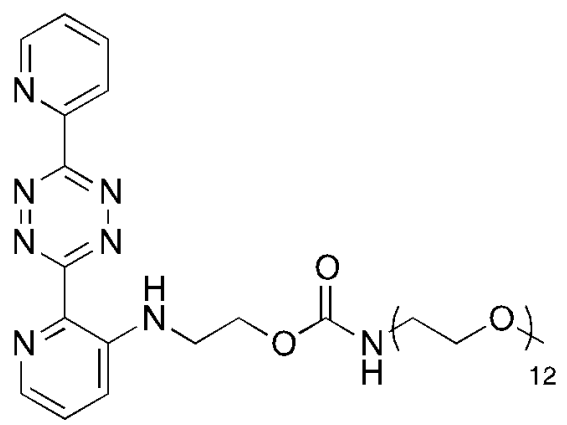

7

A round-bottomed flask was charged with a stir bar and Dess-Martin periodinane $(6.0 \mathrm{mg}$, $14 \mu \mathrm{mol})$, and nitrogen was used to purge the flask. 2-((2-(6-(pyridin-2-yl)-1,4-dihydro1,2,4,5-tetrazin-3-yl)pyridin-3-yl)amino)ethyl-2,5,8,11,14,17,20,23,26,29,32,35-

dodecaoxaheptatriacontan-37-ylcarbamate $(7 \mathrm{mg}, 8 \mu \mathrm{mol})$ in anhydrous dichloromethane $(1 \mathrm{~mL})$ was added dropwise. The reaction mixture stirred for 5 minutes at room temperature. The solvent was then removed by rotary evaporation, and then purified by column chromatography $(0-10 \%$ methanol in dichloromethane) to give the title compound as a red-orange oil $(5.7 \mathrm{mg}, 81 \%)$. 
${ }^{1} \mathrm{H}$ NMR $\left(600 \mathrm{MHz}, \mathrm{CD}_{3} \mathrm{CN}\right) \delta 8.62(\mathrm{dt}, J=7.9,1.1 \mathrm{~Hz}, 1 \mathrm{H}), 8.32(\mathrm{~s}, 1 \mathrm{H}), 8.23(\mathrm{dd}, J=$ 3.9, $1.6 \mathrm{~Hz}, 1 \mathrm{H}$ ), 8.08 (td, $J=7.8,1.8 \mathrm{~Hz}, 1 \mathrm{H}), 7.64$ (ddd, $J=7.6,4.7,1.2 \mathrm{~Hz}, 1 \mathrm{H}), 7.45$ (qd, $J=8.7,2.7 \mathrm{~Hz}, 2 \mathrm{H}), 4.30(\mathrm{t}, J=5.6 \mathrm{~Hz}, 2 \mathrm{H}), 3.67-3.59(\mathrm{~m}, 2 \mathrm{H}), 3.58-3.44(\mathrm{~m}$, $42 \mathrm{H}), 3.44(\mathrm{~d}, J=5.6 \mathrm{~Hz}, 2 \mathrm{H}), 3.29(\mathrm{~s}, 3 \mathrm{H}), 3.22(\mathrm{q}, J=5.7 \mathrm{~Hz}, 2 \mathrm{H})$.

${ }^{13} \mathrm{C}$ NMR $\left(101 \mathrm{MHz}, \mathrm{CD}_{3} \mathrm{CN}\right) \delta 166.1(\mathrm{C}), 162.7(\mathrm{C}), 151.7(\mathrm{CH}), 151.5(\mathrm{C}), 147.9(\mathrm{C})$, 139.2 (CH), $138.6(\mathrm{CH}), 131.1(\mathrm{C}), 128.5(\mathrm{CH}), 127.4(\mathrm{CH}), 124.9(\mathrm{CH}), 121.0(\mathrm{CH}), 72.5$ $\left(\mathrm{CH}_{2}\right), 71.04\left(\mathrm{CH}_{2}\right), 71.02\left(\mathrm{CH}_{2}\right), 71.00\left(13 \mathrm{CH}_{2}\right), 70.97\left(\mathrm{CH}_{2}\right), 70.9\left(\mathrm{CH}_{2}\right), 70.8\left(\mathrm{CH}_{2}\right)$, $70.4\left(\mathrm{CH}_{2}\right), 63.6\left(\mathrm{CH}_{2}\right), 58.9\left(\mathrm{CH}_{3}\right), 42.9\left(\mathrm{CH}_{2}\right), 41.47\left(\mathrm{CH}_{2}\right)$.

MS (ESI) calcd. for $\mathrm{C}_{40} \mathrm{H}_{65} \mathrm{~N}_{8} \mathrm{O}_{14}{ }^{+}, 881.4620$ found 881.4589 .

UV-vis: $\varepsilon_{(354)}=2800 \mathrm{M}^{-1} \mathrm{~cm}^{-1}, \varepsilon_{(417, \mathrm{max})}=9400 \mathrm{M}^{-1} \mathrm{~cm}^{-1}$.

\section{2-((2-(6-(pyridin-2-yl)-1,4-dihydro-1,2,4,5-tetrazin-3-yl)pyridin-3-yl)amino)ethyl hydrazinecarboxylate (15)}

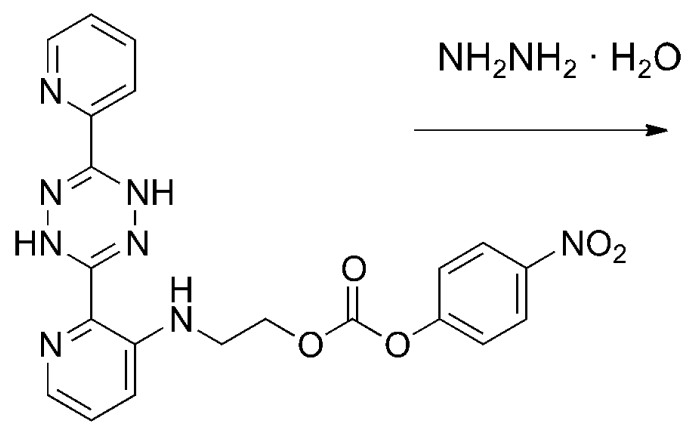

5

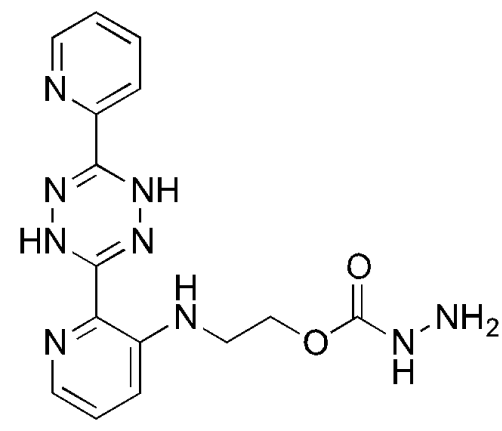

15

To a round-bottomed flask with a stir bar, dichloromethane $(3 \mathrm{~mL})$ and compound 5 (17 $\mathrm{mg}, 37 \mu \mathrm{mol})$ were added. Hydrazine monohydrate $(10 \mathrm{mg}, 5 \mathrm{mmol})$ was then added dropwise. The reaction mixture was allowed to stir at room temperature for an hour. After washing with $3 \% \mathrm{NaHCO}_{3}$ solution $(5 \times 10 \mathrm{~mL})$, the organic layer was dried with $\mathrm{Na}_{2} \mathrm{SO}_{4}$, filtered and the solvent was removed using a rotary evaporator to give an orange solid (13 mg, 94\%). The crude product was used without further purification.

${ }^{1} \mathrm{H} \mathrm{NMR}\left(600 \mathrm{MHz}, \mathrm{CDCl}_{3}\right) \delta 8.95(\mathrm{~s}, 1 \mathrm{H}), 8.56(\mathrm{dt}, J=4.9,1.3 \mathrm{~Hz}, 1 \mathrm{H}), 8.54(\mathrm{~s}, 1 \mathrm{H}), 8.04$ (dt, $J=7.9,1.1 \mathrm{~Hz}, 1 \mathrm{H}), 7.91$ (dt, $J=4.4,2.2 \mathrm{~Hz}, 2 \mathrm{H}), 7.74(\mathrm{td}, J=7.7,1.7 \mathrm{~Hz}, 1 \mathrm{H}), 7.33$ (ddd, $J=7.4,4.9,1.2 \mathrm{~Hz}, 1 \mathrm{H}), 7.17(\mathrm{dd}, J=8.4,4.4 \mathrm{~Hz}, 1 \mathrm{H}), 7.05(\mathrm{~d}, J=8.5 \mathrm{~Hz}, 1 \mathrm{H})$, $6.26(\mathrm{~s}, 1 \mathrm{H}), 4.34(\mathrm{t}, J=5.7 \mathrm{~Hz}, 2 \mathrm{H}), 3.81(\mathrm{~s}, 2 \mathrm{H}), 3.47(\mathrm{q}, J=5.7 \mathrm{~Hz}, 2 \mathrm{H})$.

${ }^{13} \mathrm{C} \mathrm{NMR}\left(101 \mathrm{MHz}, \mathrm{CDCl}_{3}\right) \delta 158.7(\mathrm{C}), 148.9(\mathrm{C}), 148.5(\mathrm{CH}), 147.7(\mathrm{C}), 146.8(\mathrm{C})$, 144.6 (C), $137.0(\mathrm{CH}), 135.9(\mathrm{CH}), 128.2(\mathrm{C}), 125.7(\mathrm{CH}), 125.0(\mathrm{CH}), 121.4(\mathrm{CH}), 117.8$ $(\mathrm{CH}), 63.6\left(\mathrm{CH}_{2}\right), 41.9\left(\mathrm{CH}_{2}\right)$.

IR (dry film) $V_{\max }\left(\mathrm{cm}^{-1}\right): 3739,3324,2920,2851,1720,1587,1504,1440,1375,1263$, 1205, 1153, 1042, 989, 881, 787, 738, 677.

MS (ESI) calcd. for $\mathrm{C}_{15} \mathrm{H}_{18} \mathrm{~N}_{9} \mathrm{O}_{2+}, 356.1583$ found 356.1562 . 


\section{HA-DHTz}

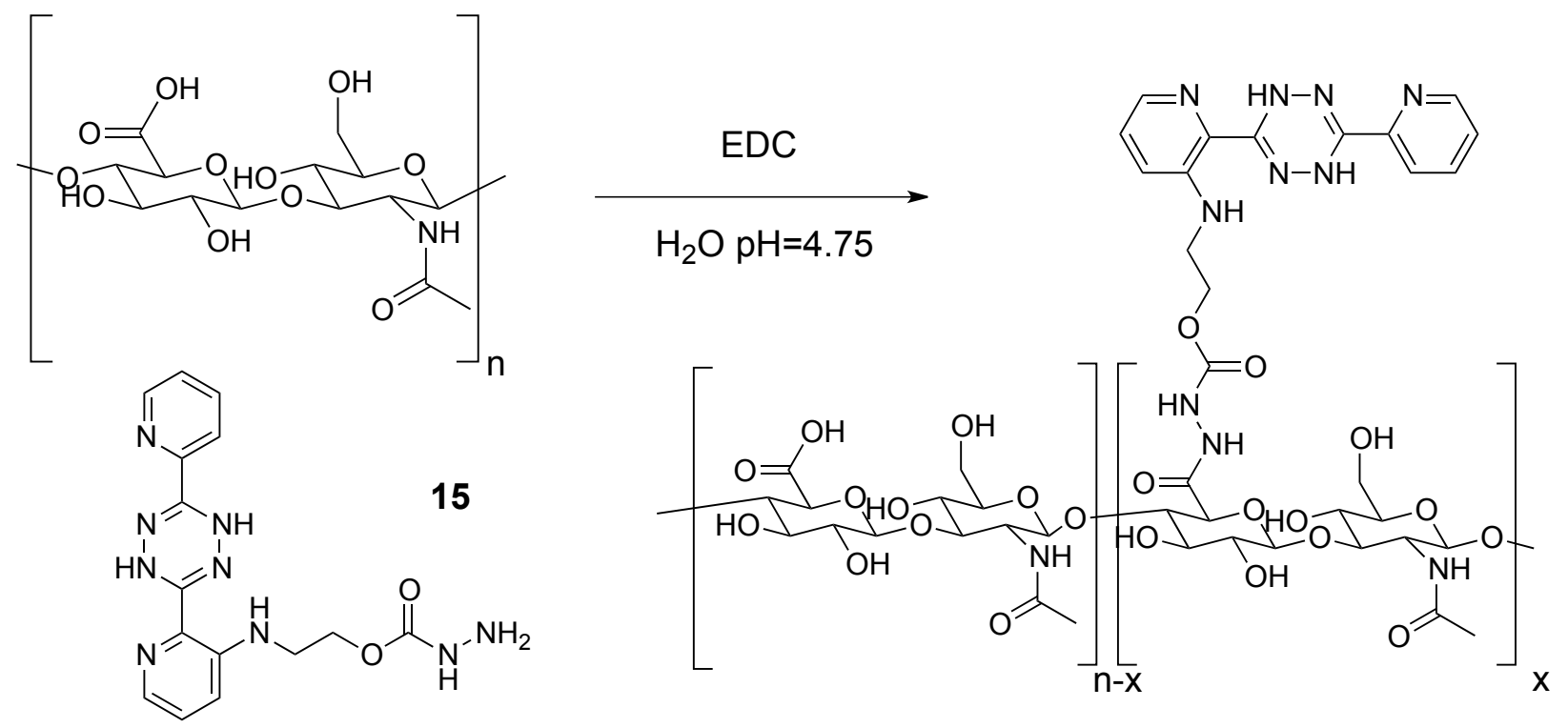

Hyaluronic acid (HA, sodium salt, $40 \mathrm{kDa}, 120 \mathrm{mg}, 0.30 \mathrm{mmol}$ disaccharide repeats) was dissolved in $\mathrm{DI} \mathrm{H}_{2} \mathrm{O}(40 \mathrm{~mL})$ at a concentration of $3 \mathrm{mg} / \mathrm{mL}$. To this solution, 1-ethyl-3-[3(dimethylamino)propyl]-carbodiimide hydrochloride (EDC, $29 \mathrm{mg}, 0.19 \mathrm{mmol}$ ) was added. DHTz-hydrazide 15 (43 mg, $0.12 \mathrm{mmol}$ ) was dissolved in DMSO (1 mL). The solution was then added dropwise to the HA solution, and methanol $(4 \mathrm{~mL})$ was added into HA solution to prevent $\mathrm{DHT}$ precipitation. The resulting mixture was stirred at room temperature for 6 hours with $\mathrm{pH}$ monitoring and periodic adjustment to $\mathrm{pH} 4.75$ by adding $0.1 \mathrm{M} \mathrm{HCl}$ aqueous solution. The resulting solution was diluted with $\mathrm{DI} \mathrm{H}_{2} \mathrm{O}$ to a final volume of 100 $\mathrm{mL}$ and was exhaustively dialyzed (Spectra $1 \mathrm{kDa} \mathrm{MWCO}$ ) against $0.1 \mathrm{M} \mathrm{NaCl}$ solution containing $1 \mathrm{mM}$ mercaptoethanol (added to prevent DHTz oxidation) for 2 days, then against $\mathrm{DI} \mathrm{H} \mathrm{H}_{2} \mathrm{O}$ for 1 day. The purified solution was lyophilized to afford $98 \mathrm{mg}(0.25 \mathrm{mmol}$, $82 \%) \mathrm{HA}-\mathrm{DHTz}$ as a light yellow fluffy solid. The degree of substitution by DHTz was determined to be $7 \%$ by UV-vis absorbance. The product was stored at $-20{ }^{\circ} \mathrm{C}$ prior to use.

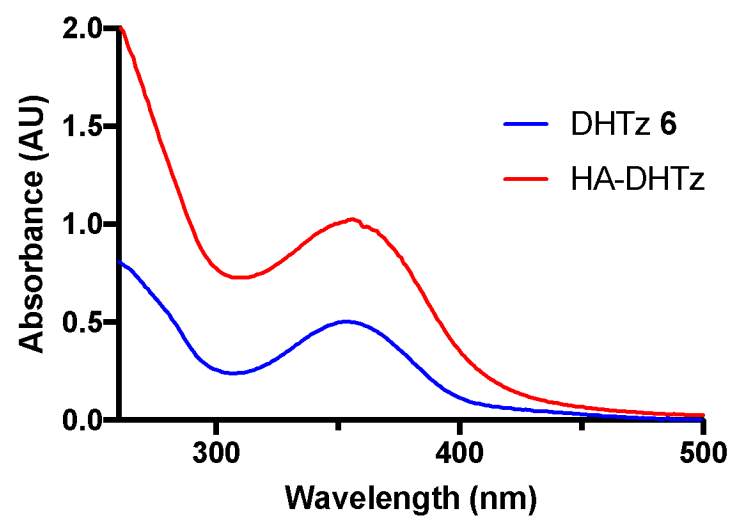

Fig S1. UV-Vis spectrum of DHTz $6(67 \mu \mathrm{M})$ and HA-DHTz $(0.7 \mathrm{mg} / \mathrm{mL})$. 


\section{HA-dTCO}
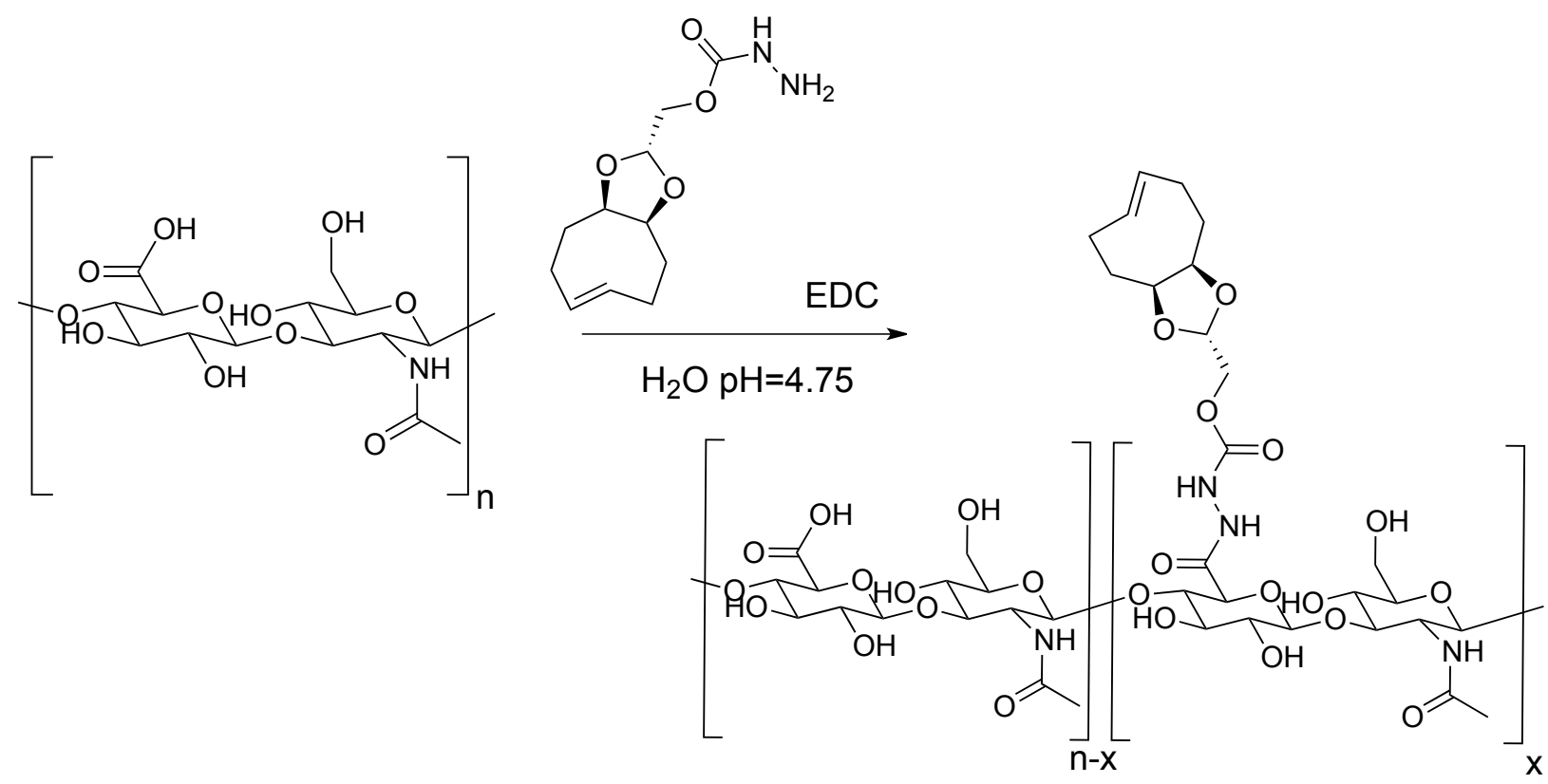

Hyaluronic acid (HA, sodium salt, $130 \mathrm{kDa}, 200 \mathrm{mg}, 0.50 \mathrm{mmol}$ disaccharide repeats) was dissolved in $\mathrm{DI} \mathrm{H}_{2} \mathrm{O}(20 \mathrm{~mL})$ at a concentration of $10 \mathrm{mg} / \mathrm{mL}$. To this solution EDC (46 mg, $0.30 \mathrm{mmol}$ ) was added. dTCO-hydrazide ${ }^{1}(48 \mathrm{mg}, 0.20 \mathrm{mmol}$ ) was dissolved in DMSO $(1 \mathrm{~mL})$ and then added dropwise to the HA solution. The resulting mixture was stirred at room temperature for 3 hours with $\mathrm{pH}$ monitoring and periodic adjustment to $\mathrm{pH}$ 4.75 by adding $0.1 \mathrm{M} \mathrm{HCl}$ aqueous solution. The resulting solution was diluted with DI $\mathrm{H}_{2} \mathrm{O}$ to a final volume of $150 \mathrm{~mL}$ and was exhaustively dialyzed (Spectra $10 \mathrm{kDa}$ MWCO) against $0.1 \mathrm{M} \mathrm{NaCl}$ solution for 2 days, then against $\mathrm{DI} \mathrm{H}_{2} \mathrm{O}$ for 1 day. The purified solution was lyophilized to afford $167 \mathrm{mg}(0.42 \mathrm{mmol}, 84 \%)$ of HA-dTCO as a white fluffy solid. The degree of substitution by dTCO was determined to be $20 \%$ based on the ${ }^{1} \mathrm{H}$ NMR integration ( $1.9 \mathrm{ppm}\left(-\mathrm{COCH}_{3}\right.$ in $\left.\mathrm{HA}\right), 5.5-5.7 \mathrm{ppm}(-\mathrm{CH}=\mathrm{CH}-$ in dTCO$)$ ). The product was stored at $-20^{\circ} \mathrm{C}$ prior to use. 


\section{Part II Dihydrotetrazine oxidation experiments}

\subsection{General considerations}

UV-Vis measurements were conducted in quartz cuvettes using Hewlett Packard 8453 spectrophotometer at $25^{\circ} \mathrm{C}$ in a UV-cell with stirring capability and a top mounted, 660 $\mathrm{nm}$ high-power ( $3 \times 900 \mathrm{~mW})$ LED source. The LED was a 'deep red' Cree XLamp XP-E "3 up" High Power LED Star (CREEXPE-DRD-3) and purchased from LED Supply (https://www.ledsupply.com/leds/cree-xlamp-xpe-high-power-led-star). The LED was mounted on a heat sink with a driver as displayed below. The driver used was P/N 03023D-E-1000P (https://www.ledsupply.com/led-drivers/buckpuck-dc-led-drivers).
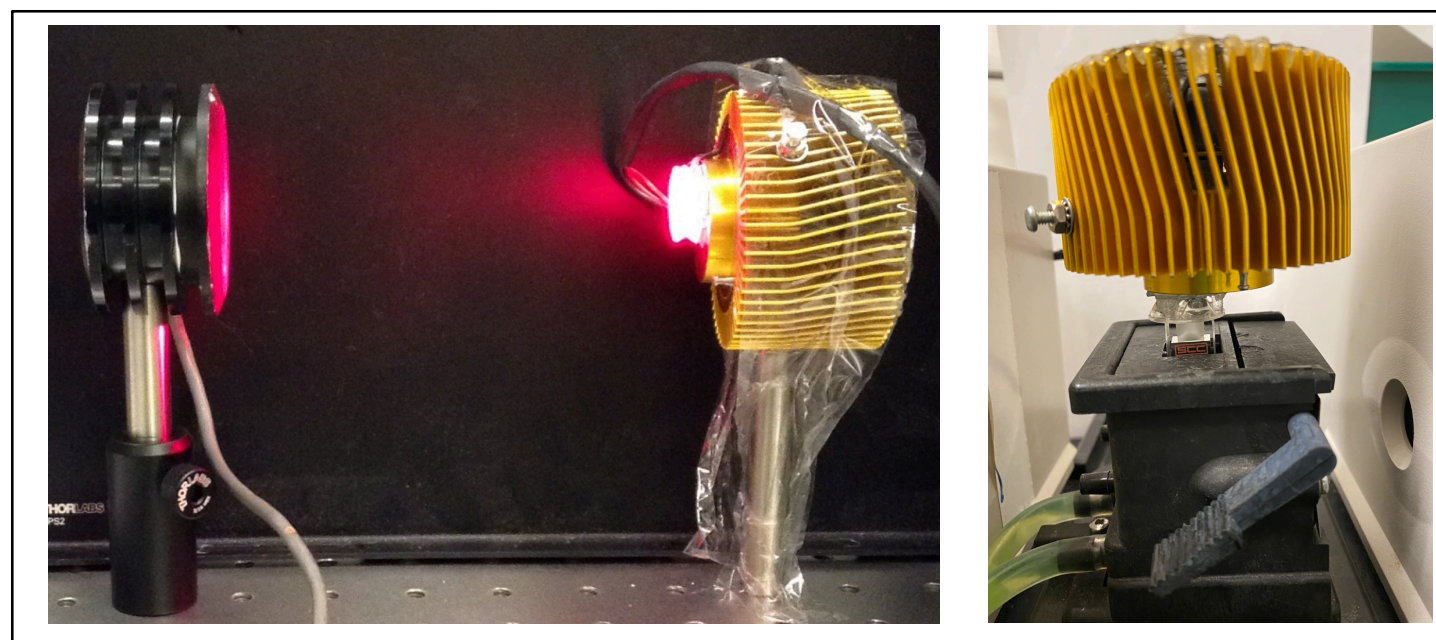

Fig S2. (left) LED light source with optical power sensor. (right) LED source top mounted on a UV-vis spectrometer.

For UV-vis experiments, the light intensity was estimated by measuring the light intensity $2.5 \mathrm{~cm}$ from the light source along the emission axis, which was equal to the distance from the LED to the center of the cuvette holder. To measure the intensity of light emitted by the LEDs, a Coherent FieldMax-Top Optical Power Meter equipped with a PM10 sensor was used. Based on the measurement, the power density applied in all the UVvis experiments were $450 \mathrm{~mW} / \mathrm{cm}^{2}$.

Glassware was cleaned by rinsing twice with phosphate buffered saline (PBS, $\mathrm{pH}=7.4$ ) containing EDTA (2 mM), followed by triple rinsing with PBS buffer free of EDTA. PBS buffer was passed through a column of Chelex 100 resin to remove any trace metals. The $\mathrm{pH}$ of the buffer was then adjusted to 7.4 using $1 \mathrm{M}$ solutions of either $\mathrm{HCl}$ or $\mathrm{NaOH}$. DHTz stability was variable and shorter when buffer was used that was not first treated with Chelex. 
2.2. SiR catalyzed photooxidation of DHTz 6 monitored by UV-Vis spectrophotometer
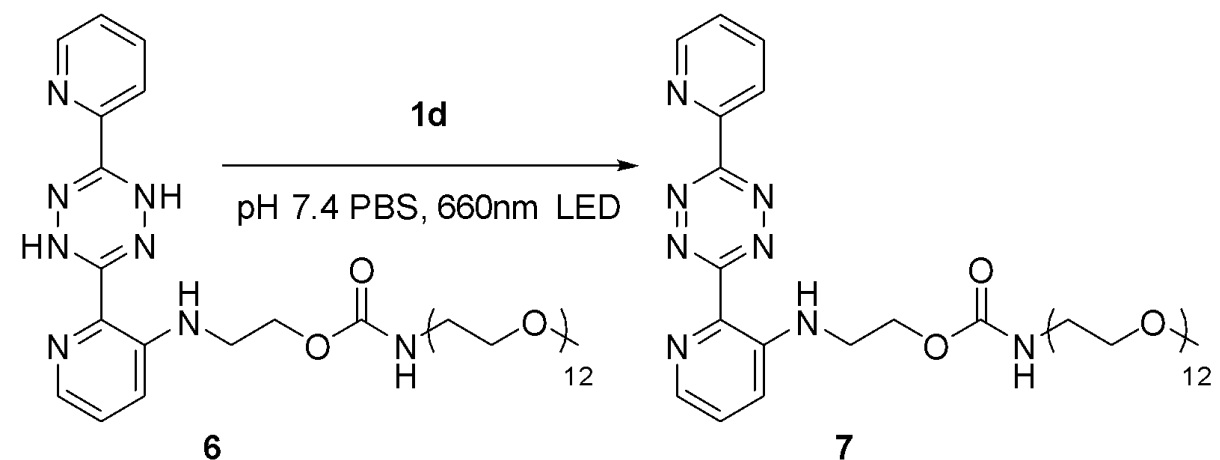

2.2.1. SiR catalyzed photooxidation (Results displayed in Fig 4B, standard conditions, Fig S3):

In a cuvette, a PBS solution $(2 \mathrm{~mL})$ of DHTz $6(35 \mu \mathrm{M})$ and SiR 1c $(1 \mu \mathrm{M})$ was prepared from stock solutions. A LED source described in $\mathbf{S 2 . 1}\left(660 \mathrm{~nm}, 450 \mathrm{~mW} / \mathrm{cm}^{2}\right)$ was used to irradiate from the top of the cuvette. The oxidation of DHTz 6 to Tz 7 was monitored by recording the absorbance at $354 \mathrm{~nm}$ every 10 seconds.

2.2.2. Light dependent control (Results displayed in Fig 4B, light on/off):

In a cuvette, a PBS solution $(2 \mathrm{~mL})$ of DHTz $6(35 \mu \mathrm{M})$ and SiR 1c $(1 \mu \mathrm{M})$ was prepared from stock solutions. A LED source described in $\mathbf{S 2 . 1}\left(660 \mathrm{~nm}, 450 \mathrm{~mW} / \mathrm{cm}^{2}\right)$ was used to irradiate from the top of the cuvette. The light was then turned off for $30 \mathrm{sec}$, and then turned back on. The process was repeated one more time after $40 \mathrm{sec}$, and then the light was left on until no further change in absorbance was observed. The oxidation of DHTz 6 to Tz 7 was monitored by recording the absorbance at $354 \mathrm{~nm}$ every 10 seconds.

2.2.3. Superoxide quenching control (Results displayed in Fig 4B, $+S O D)$ :

In a cuvette, a PBS solution (2 mL) of DHTz $6(35 \mu \mathrm{M})$ and SiR 1c $(1 \mu \mathrm{M})$ and superoxide dismutase $(1 \mu \mathrm{M})$ was prepared from stock solutions. A LED source described in $\mathbf{S 2 . 1}$ $\left(660 \mathrm{~nm}, 450 \mathrm{~mW} / \mathrm{cm}^{2}\right)$ was used to irradiate from the top of the cuvette. The oxidation of DHTz 6 to Tz 7 was monitored by recording the absorbance at $354 \mathrm{~nm}$ every 10 seconds.

2.2.4. Singlet oxygen quenching control (Results displayed in Fig $4 \mathrm{~B},+\mathrm{Met}$ ):

In a cuvette, a PBS solution $(2 \mathrm{~mL})$ of DHTz $6(35 \mu \mathrm{M})$ and SiR 1c $(1 \mu \mathrm{M})$ and methionine $(70 \mathrm{mM})$ was prepared from stock solutions. A LED source described in $\mathbf{S 2 . 1}(660 \mathrm{~nm}$, $450 \mathrm{~mW} / \mathrm{cm}^{2}$ ) was used to irradiate from the top of the cuvette. The oxidation of DHTz 6 to Tz 7 was monitored by recording the absorbance at $354 \mathrm{~nm}$ every 10 seconds. 

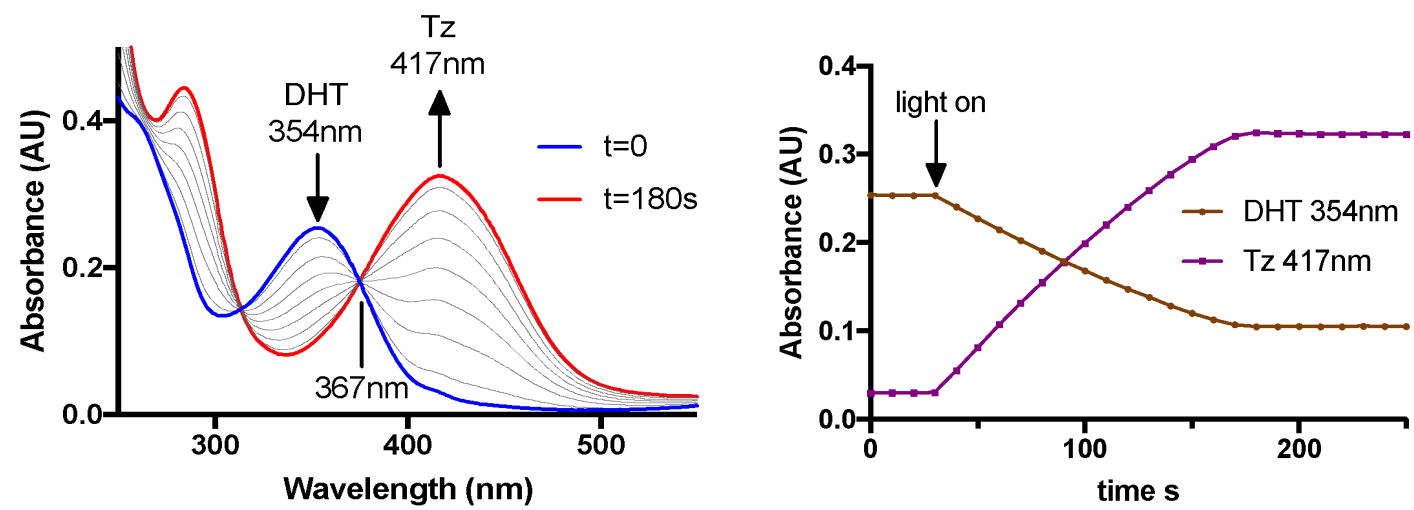

Fig S3. (Experiment described in S2.2.1) SiR 1d $(1 \mu \mathrm{M})$ catalyzed photooxidaton from DHTz $6(35 \mu \mathrm{M})$ to Tz 7 irradiated by light from LED source described in $\mathbf{S 2 . 1}(660 \mathrm{~nm}$, $450 \mathrm{~mW} / \mathrm{cm}^{2}$ ). (left): The UV-Vis spectrum from 250 to $550 \mathrm{~nm}$. Data was recorded every $20 \mathrm{sec}$. (right): Time-course monitoring of the UV-Vis absorptions at 354 and $417 \mathrm{~nm}$. Data was recorded every 10 seconds.

2.2.5. Comparison of the ability that different photocatalysts catalyze the photooxidation of DHTz 6 to Tz 7:

In a cuvette, a PBS solution $(2 \mathrm{~mL})$ of DHTz $6(50 \mu \mathrm{M})$ and one of the photocatalysts 1ae $(0.5 \mu \mathrm{M})$ or MB $(0.5 \mu \mathrm{M})$ was prepared from stock solutions. A LED source described in S2.1 $\left(660 \mathrm{~nm}, 450 \mathrm{~mW} / \mathrm{cm}^{2}\right)$ was used to irradiate from the top of the cuvette. The oxidation of DHTz 6 to Tz 7 was monitored by recording the absorbance at $354 \mathrm{~nm}$ and $417 \mathrm{~nm}$ every second.

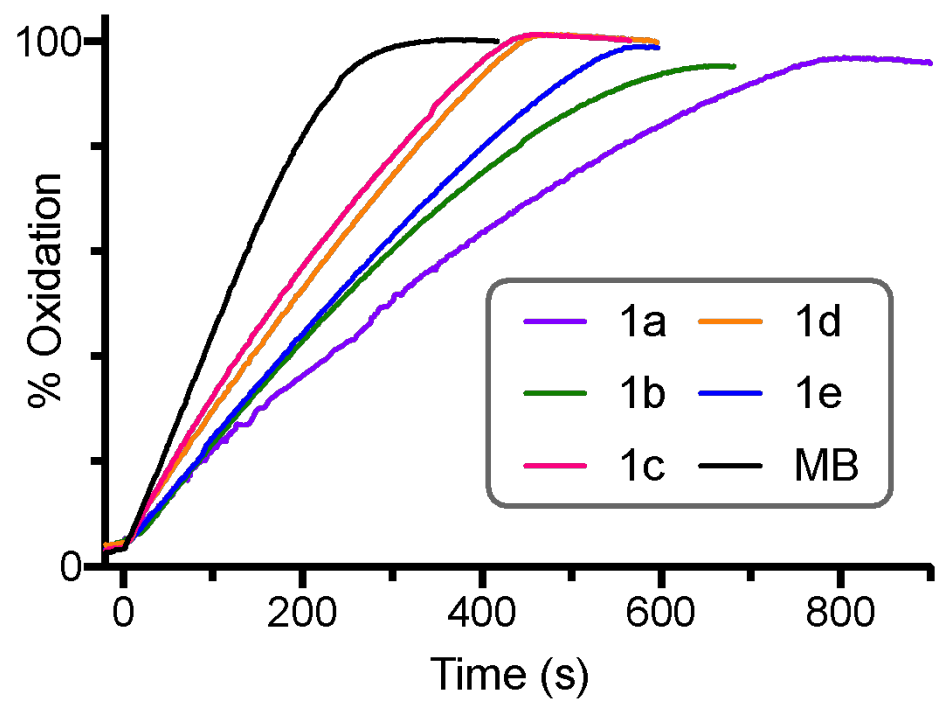

Fig S4. Comparison of the rate that different photocatalysts (1a-e and MB, $0.5 \mu \mathrm{M}$ ) catalyze the photooxidatioin of DHTz 6 to Tz 7, utilizing $660 \mathrm{~nm}$ light $\left(450 \mathrm{~mW} / \mathrm{cm}^{2}\right)$ from the LED source described in S2.1. Data was recorded every second. 


\subsection{SiR catalyzed photooxidation of DHTz 6 to produce a thioredoxin-trans- cyclooctene conjugate (TrX-sTCO)}

\subsubsection{Thioredoxin (Trx) single Cys mutant expression and purification:}

Homo sapiens thioredoxin-1 expression vector was mutated to change all cysteines, excluding the catalytic Cys32, to serine (resulting mutations are $C 35,62,69,73 S$ ). The resulting plasmid contained an $\mathrm{N}$-terminal $\mathrm{His}_{10}$ tag and a TEV protease cleavage site for facile removal of the histidine tag. The construct will be abbreviated as Trx-C32 and was a gift from Sharon Rozovsky's lab at the University of Delaware. The plasmid was transformed and expressed in BL21(DE3) cells. Cells were grown at $37^{\circ} \mathrm{C}$ in $25 \mathrm{~mL}$ of Luria-Bertani medium containing $0.1 \%$ ampicillin overnight. Cells were then added to $1 \mathrm{~L}$ of Terrific Broth containing $0.1 \%$ ampicillin and phosphate buffered saline. Cultures were shaken at $37^{\circ} \mathrm{C}$ and induced by the addition of $1.0 \mathrm{mM}$ isopropyl $\beta-D-1-$ thiogalactopyranoside when the absorbance at $600 \mathrm{~nm}$ reached $0.6 \mathrm{AU}$. Cells were grown for $16 \mathrm{~h}$ at $16^{\circ} \mathrm{C}$ and collected by centrifugation (at $8000 \mathrm{rpm}$ for 10 minutes at $4^{\circ} \mathrm{C}$ ). Cell pellets were resuspended in $50 \mathrm{mM}$ phosphate buffer, $\mathrm{pH} 7.4$, containing $300 \mathrm{mM} \mathrm{NaCl}$, and $30 \mathrm{mM}$ imidazole. Cells were disrupted by two passes through a French pressure cell (at 10,000 psi), and the resulting homogenate was briefly sonicated to shear DNA. The suspension was clarified by two centrifugations (at $14,000 \mathrm{rpm}$ for 15 minutes at $4^{\circ} \mathrm{C}$ ), and the supernatant was loaded onto $5 \mathrm{~mL}$ nickel affinity resin (Sigma HIS-Select Nickel

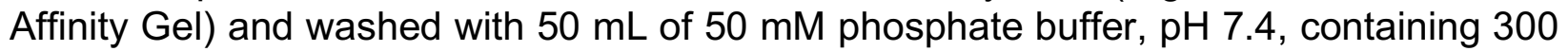
$\mathrm{mM} \mathrm{NaCl}$ and $30 \mathrm{mM}$ imidazole. The construct was then eluted from the column with 20 $\mathrm{mL}$ of $50 \mathrm{mM}$ phosphate buffer, $\mathrm{pH} 7.4$, containing $300 \mathrm{mM} \mathrm{NaCl}$ and $400 \mathrm{mM}$ imidazole, and then dialyzed against $4 \mathrm{~L}$ of $50 \mathrm{mM}$ phosphate buffer, $\mathrm{pH} 7.5$, containing $100 \mathrm{mM}$ $\mathrm{NaCl}$ and $1 \mathrm{mM}$ DTT. Cleavage of the histidine tag was conducted by incubating a 1:20 molar ratio of TEV protease to Trx-C32 at $4{ }^{\circ} \mathrm{C}$ overnight. Trx-C32 was exchanged four times into fresh $50 \mathrm{mM}$ phosphate buffer, $\mathrm{pH} 7.5$, containing $100 \mathrm{mM} \mathrm{NaCl}$ before centrifuging $\left(14,000 \mathrm{rpm}\right.$ for 15 minutes at $\left.4^{\circ} \mathrm{C}\right)$. The supernatant was loaded onto $5 \mathrm{~mL}$ nickel affinity resin and Trx-C32 was eluted with $50 \mathrm{mM}$ phosphate buffer, $\mathrm{pH} 7.5$, containing $100 \mathrm{mM} \mathrm{NaCl}$. The protein was concentrated to $4 \mathrm{~mL}$ and aliquots were stored at $-80^{\circ} \mathrm{C}$ until use.

Trx-C32 protein sequence

GMVKQIESKTAFQEALDAAGDKLVVVDFSATWCGPSKMIKPFFHSLSEKYSNVIFLEVD VDDSQDVASESEVKSMPTFQFFKKGQKVGEFSGANKEKLEATINELV

\section{Trx-C32 nucleotide sequence}

ATGGTGAAACAGATCGAGAGCAAAACTGCTTTTCAAGAAGCTCTGGACGCTGCAG GTGATAAACTTGTAGTAGTTGACTTCTCAGCCACGTGGTGTGGGCCTAGCAAAATG ATCAAGCCTTTCTTTCATTCCCTCTCTGAAAAGTATTCCAACGTGATATTCCTTGAA GTAGATGTGGATGACAGTCAGGATGTTGCTTCAGAGTCTGAAGTCAAAAGCATGCC AACATTCCAGTTTTTTAAGAAGGGACAAAAGGTGGGTGAATTTTCTGGAGCCAATA AGGAAAAGCTTGAAGCCACCATTAATGAATTAGTCTAA 


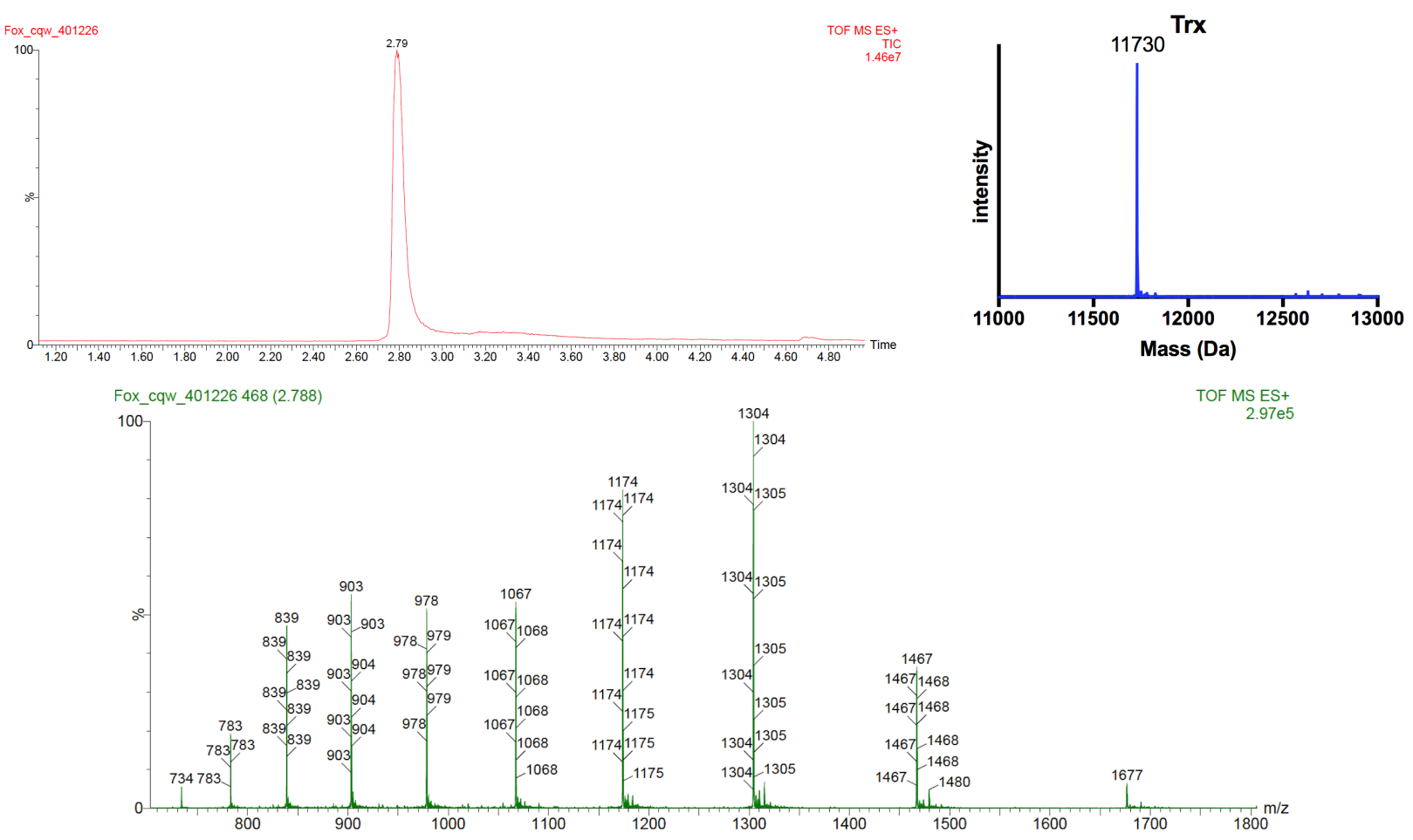

Fig S5. LC-MS-ESI TIC trace (top left), ESI Mass spectrum (bottom) and Deconvoluted ESI mass spectrum (top right) of thioredoxin single Cys mutant (Trx). The mass of the protein was calculated to be 11730.3 using the protparam tool: https://web.expasy.org/protparam/

\subsubsection{Synthesis of Trx-sTCO}

To $200 \mu \mathrm{L}$ of a $560 \mu \mathrm{M}$ solution of thioredoxin (Trx) in PBS buffer was added an aqueous solution of dithiothreitol (DTT) $(10 \mu \mathrm{L}, 200 \mathrm{mM} ; 10 \mathrm{mM}$ final concentration). After $30 \mathrm{~min}$, the reaction mixture was passed through a size exclusion desalting column, the fractions were collected and analyzed by UV-Vis to determine concentration, and LC-MS to determine purity, the fractions were then directly used for the next step.

To $100 \mu \mathrm{L}$ of the fraction collected $(110 \mu \mathrm{M}$, determined by UV), (rel-1R,8S,9R,4E)Bicyclo [6.1.0]non-4-ene-9-ylmethyl-N-2maleimidoethyl carbamate (sTCO-Mal) was added (10 uL, $8 \mathrm{mM}$ in $\mathrm{MeOH} ; 800 \mu \mathrm{M}$ final concentration). After $30 \mathrm{~min}$, the reaction mixture was passed through a size exclusion desalting column, the fraction was collected and analyzed by UV-Vis to determine concentration, and LC-MS to determine purity. The fractions were then stored at $-80^{\circ} \mathrm{C}$ until ready to use. 

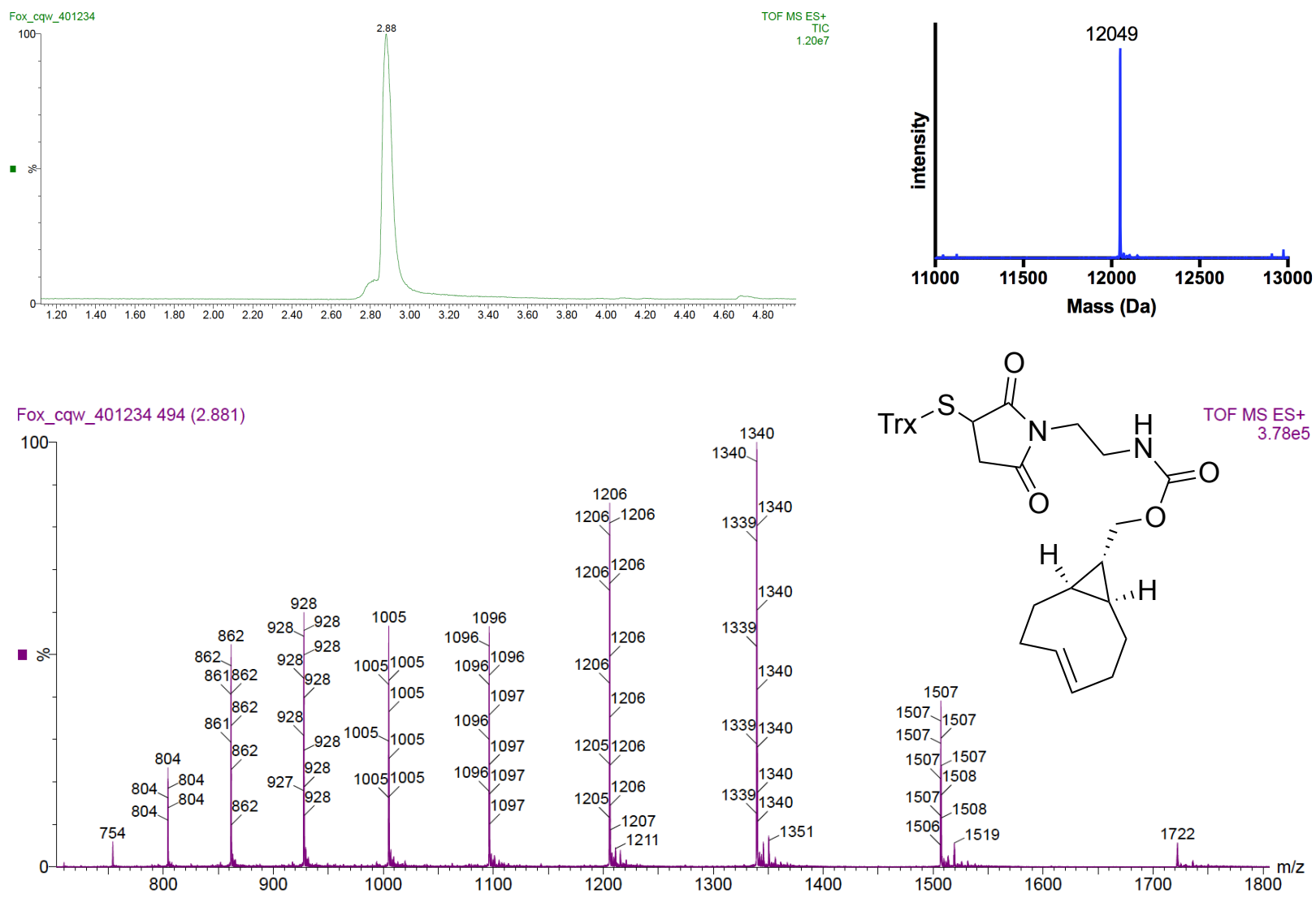

Fig S6. LC-MS-ESI TIC trace (top left), ESI Mass spectrum (bottom) and deconvoluted ESI mass spectrum (top right) of Trx-sTCO.

\subsubsection{Photocatalyzed Labeling of Trx-sTCO with DHTz 6 (Results displayed in Fig 5,} with catalyst, Fig S7-9):

Labeling reactions were carried out at $50 \mathrm{~mW} / \mathrm{cm}^{2}$ for $15 \mathrm{~min}$-the time required to oxidize $20 \mu \mathrm{M}$ of DHTz 6 under the reaction conditions. As an excess of DHTz 6 was utilized, not all of the DHTz was consumed during protein labeling experiments.

A PBS solution of Trx-sTCO $(20 \mu \mathrm{M})$, DHTz $6(25 \mu \mathrm{M})$ and SiR $1 \mathbf{d}(1 \mu \mathrm{M})$ was prepared in an Eppendorf tube from stock solutions. LED light $(660 \mathrm{~nm})$ was used to irradiate the tube for $15 \mathrm{~min}$ with a power density of $50 \mathrm{~mW} / \mathrm{cm}^{2}$. The reaction was stopped after complete consumption of Trx-sTCO, but prior to complete consumption of DHTz 6 which was present in excess. After irradiation, a solution of (4-(6-methyl-1,2,4,5-tetrazin-3$\mathrm{yl})$ phenyl)methanol was added to the tube to a final concentration of $400 \mu \mathrm{M}$ to quench any unreacted Trx-sTCO. The reaction mixture was then directly injected into the LCMS(ESI-QToF) for analysis. The LC-MS results indicated that all of the Trx-sTCO had reacted with Tz 7 during the light irradiation: no free Trx-sTCO was detected, nor was the adduct of Trx-sTCO with (4-(6-methyl-1,2,4,5-tetrazin-3-yl)phenyl)methanol detected. 


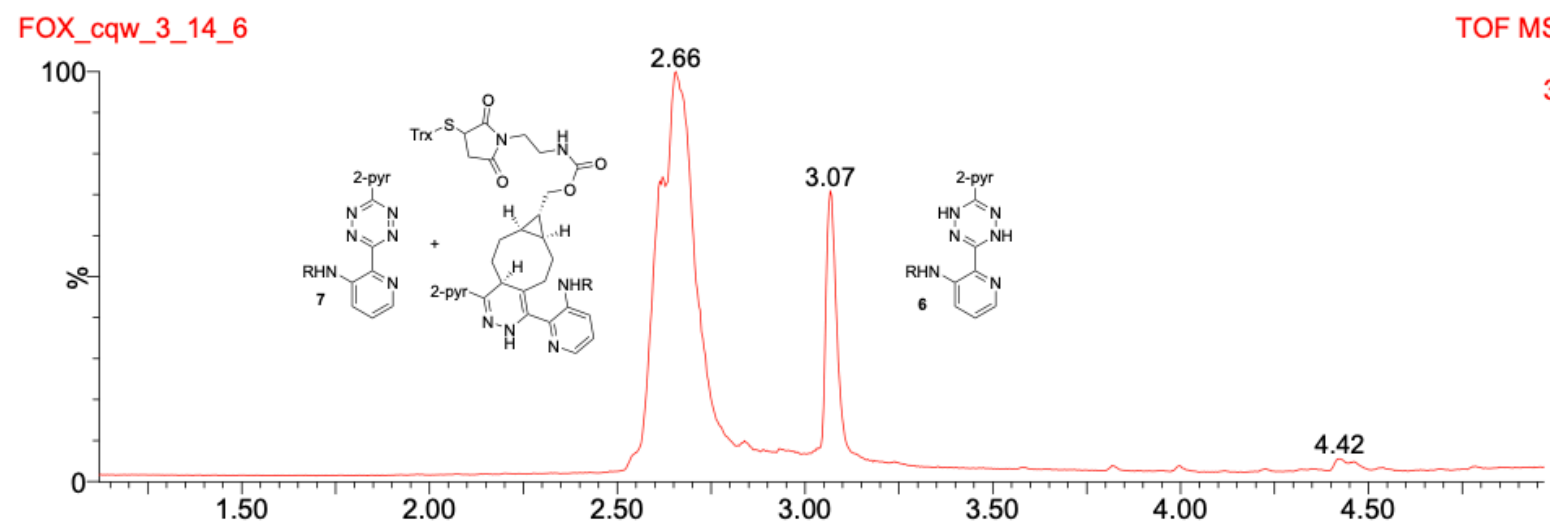

Fig S7. LC-MS-ESI TIC trace of experiment described in S2.3.2. Note: as unreacted DHTz 6 is partially oxidized to Tz 7 during UPLC analysis, the ratio of 6:7 detected by LCMS cannot be used as an indication of their relative concentrations (Fig S27).

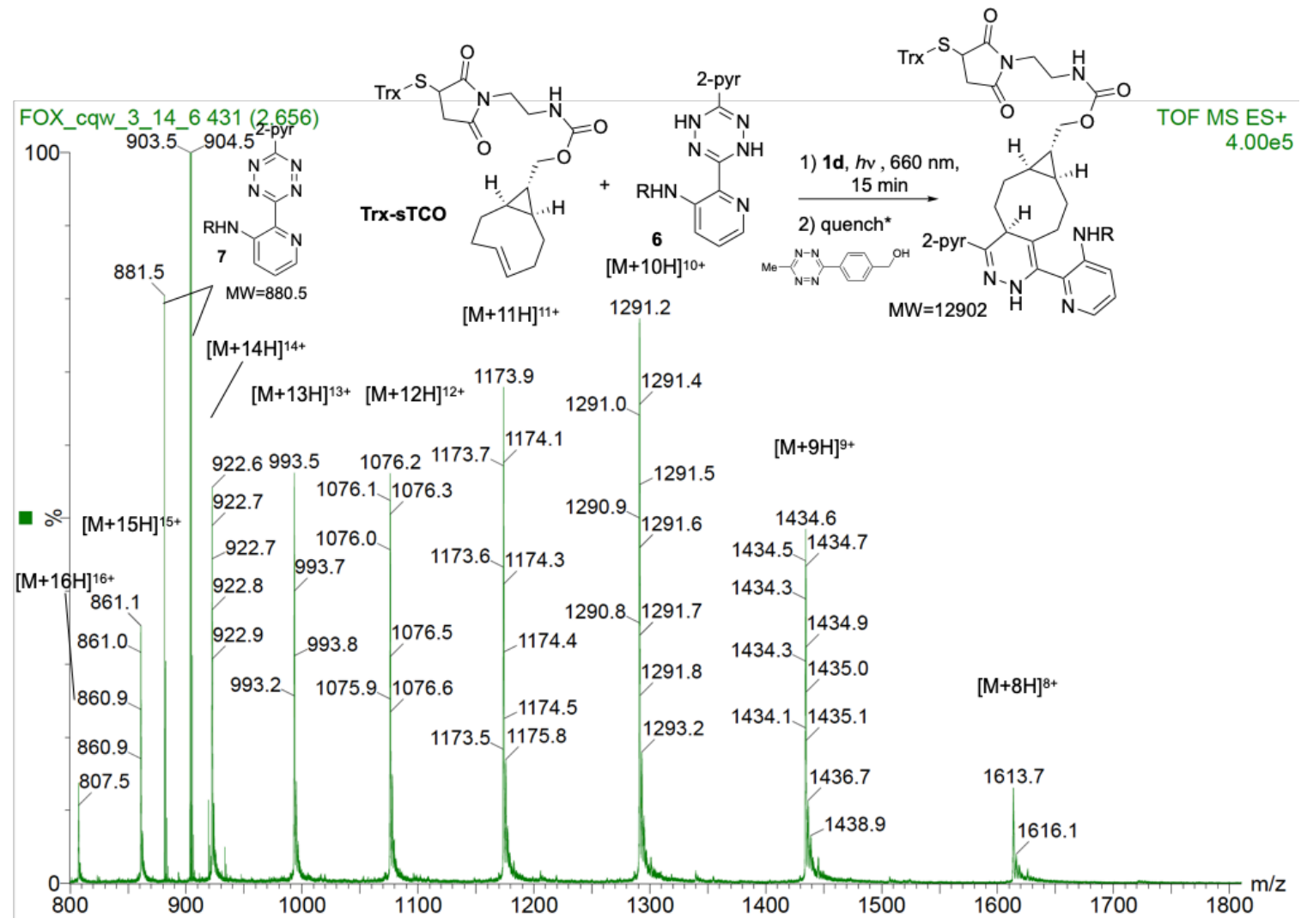

Fig S8. ESI Mass spectrum of experiment described in S2.3.2. After irradiation, (4-(6methyl-1,2,4,5-tetrazin-3-yl)phenyl)methanol was added to capture any unreacted TrxsTCO. In this spectrum, neither the quenching adduct nor Trx-sTCO was observed, indicating that all of TrX-sTCO had reacted with tetrazine 7. 


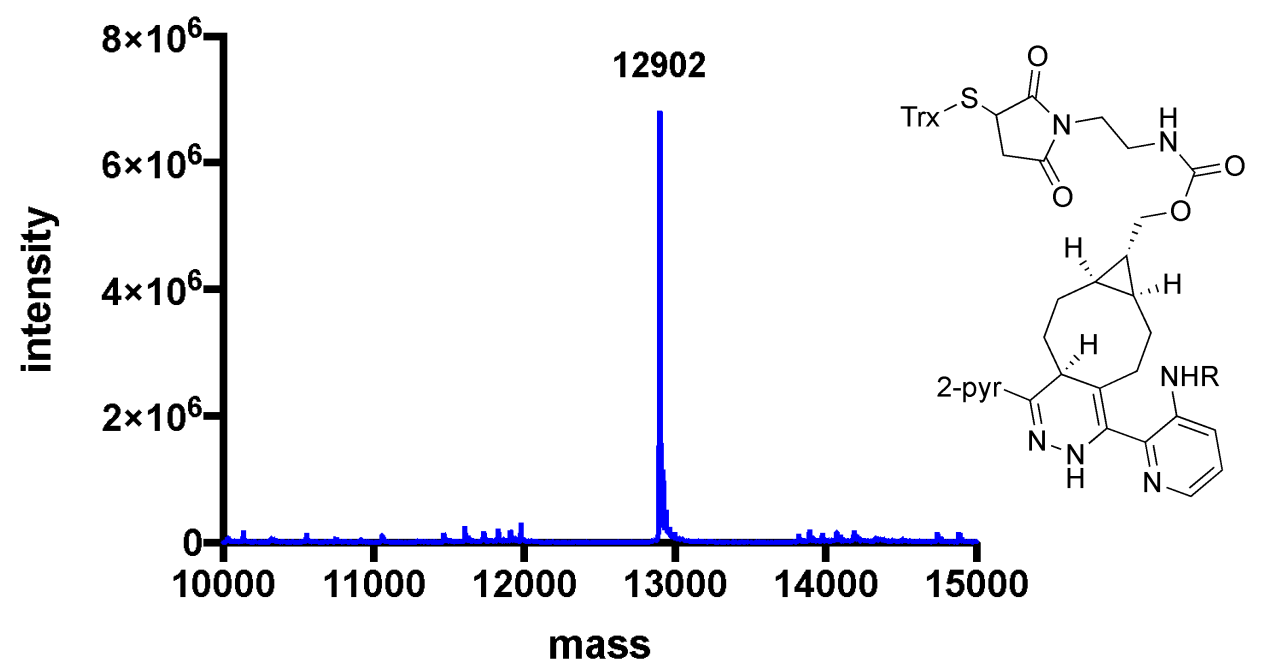

Fig S9. Deconvoluted ESI mass of the experiment described in S2.3.2., contains a single peak at $12902 \mathrm{Da}$, indicating complete reaction between Trx-sTCO and Tz 7.

2.3.4. Control of labeling Trx-sTCO with DHTz 6, using no catalyst (Results displayed in Fig 5, without catalyst, S10-12):

A PBS solution of Trx-sTCO $(20 \mu \mathrm{M})$ and DHTz $6(25 \mu \mathrm{M})$ was prepared in an Eppendorf tube from stock solutions. LED light $(660 \mathrm{~nm})$ was used to irradiate the tube for 15 min with a power density of $50 \mathrm{~mW} / \mathrm{cm}^{2}$. After irradiation, a solution of (4-(6-methyl-1,2,4,5tetrazin-3-yl)phenyl)methanol was added to the tube to a final concentration of $400 \mu \mathrm{M}$. The reaction mixture was then directly injected to LC-MS (ESI-QToF) for analysis. The LC-MS results indicated that the adduct of Trx-sTCO with Tz 7 was not formed during the irradiation without photocatalyst, as all of the Trx-sTCO had been quenched by (4-(6methyl-1,2,4,5-tetrazin-3-yl)phenyl)methanol. No free Trx-sTCO was detected.

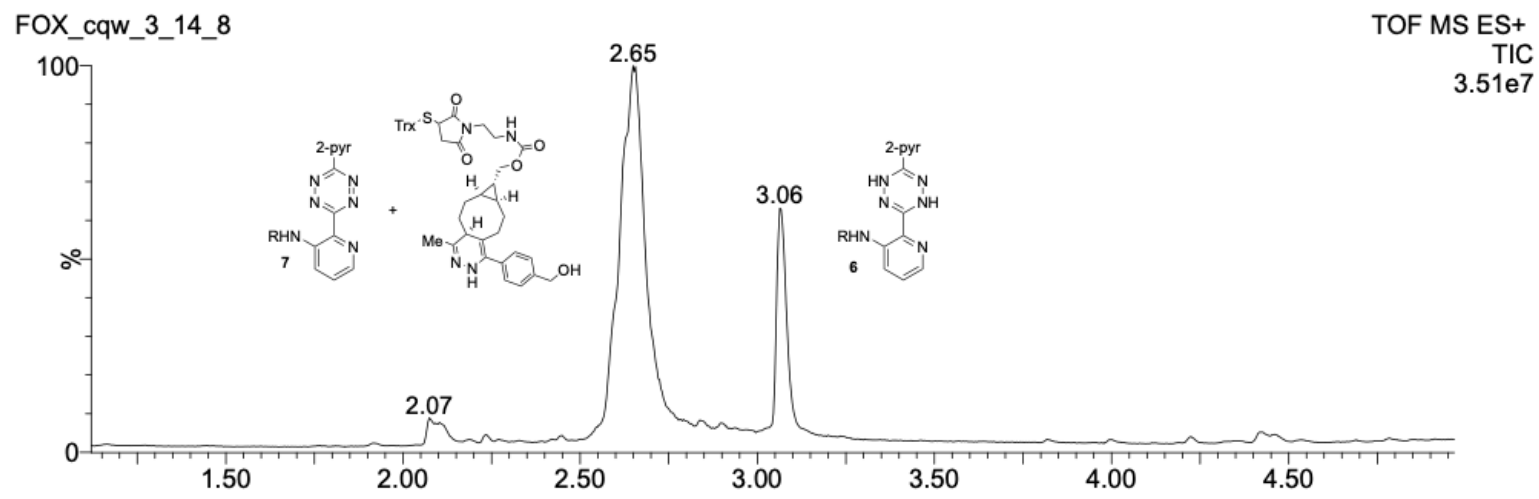

Fig S10. LC-MS TIC trace for experiment described in S2.3.3. Note: unreacted DHTz 6 is partially oxidized to Tz 7 during UPLC analysis (Fig S27), and the observation of Tz 7 is attributed to the oxidation of DHTz 6 to Tz 7 during UPLC analysis. 


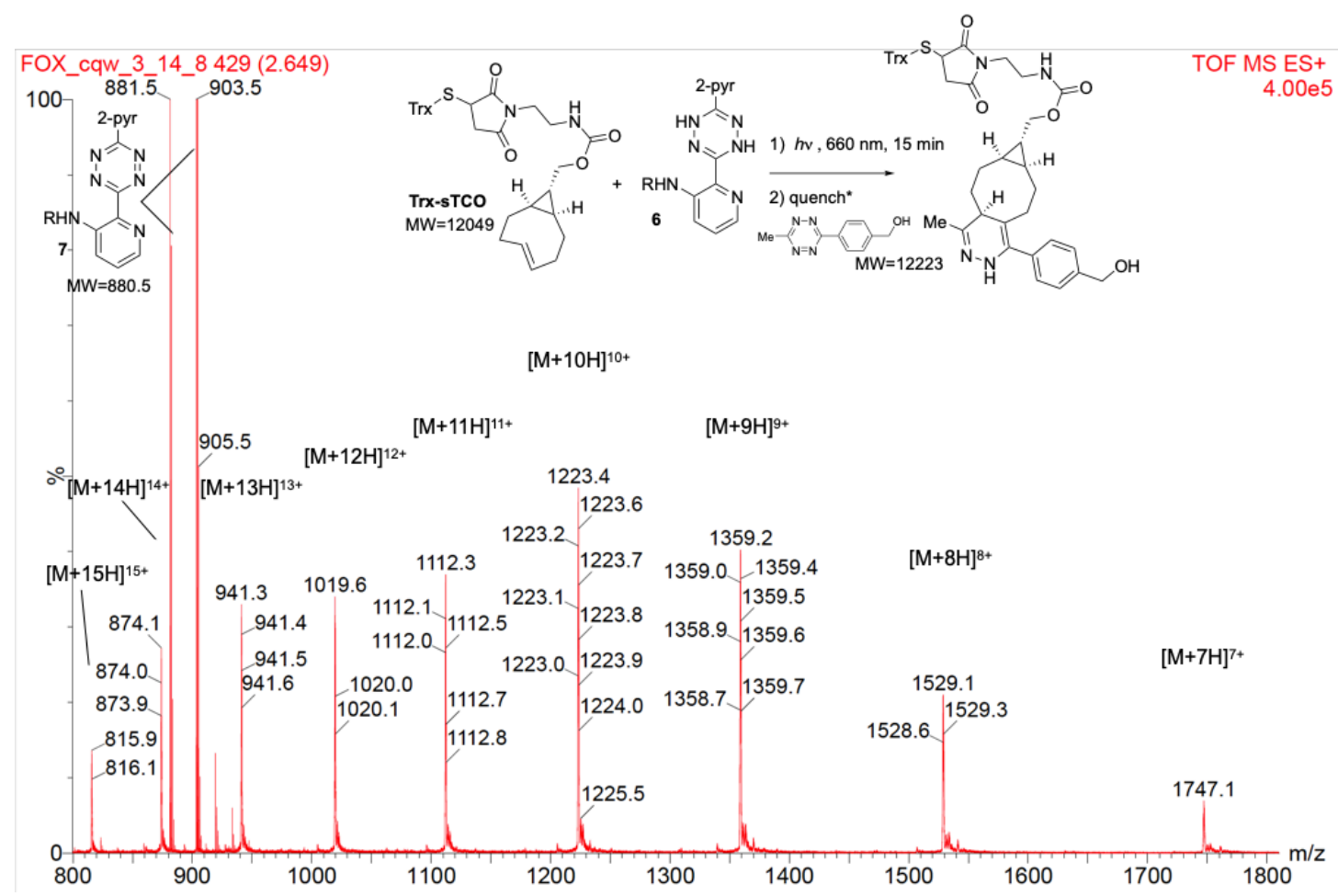

Fig S11. ESI-QToF Mass spectrum of the experiment described in S2.3.3. In this spectrum, only the quenching adduct was observed, indicating that no tetrazine 7 was formed and reacted with Trx-sTCO during the irradiation. Note: unreacted DHTz 6 is partially oxidized to Tz 7 during UPLC analysis (Fig S27), and the observation of Tz 7 is attributed to the oxidation of DHTz 6 to Tz 7 during UPLC analysis.

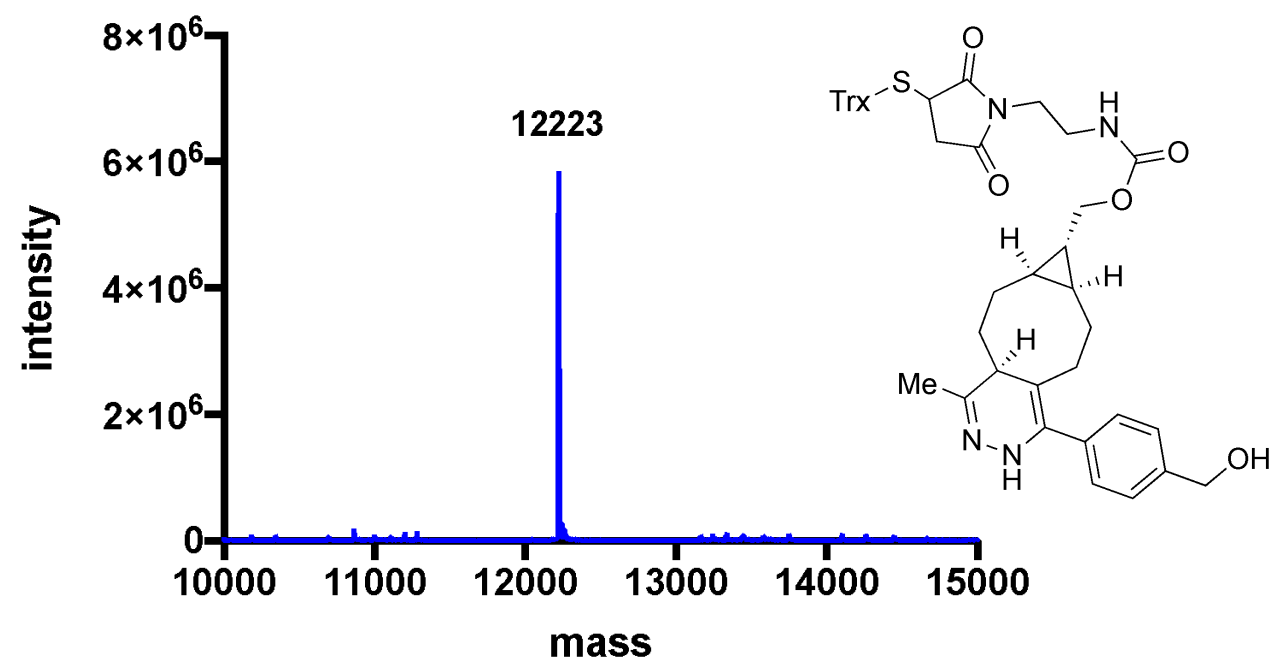

Fig S12. Deconvoluted ESI mass spectrum for experiment described in S2.3.3. contains a single peak at $12223 \mathrm{Da}$, indicating all Trx-sTCO was quenched by (4-(6-methyl-1,2,4,5tetrazin-3-yl)phenyl)methanol, and that no Trx-sTCO had reacted with Tz 7. 


\subsubsection{Control of labeling Trx-sTCO with DHTz 6, using no light:}

A PBS solution of Trx-sTCO $(20 \mu \mathrm{M})$ and DHTz $6(25 \mu \mathrm{M})$ and SiR 1d $(1 \mu \mathrm{M})$ was prepared in an Eppendorf tube from stock solutions. The solution was incubated at ambient light for $15 \mathrm{~min}$. After incubation, a solution of (4-(6-methyl-1,2,4,5-tetrazin-3$\mathrm{yl})$ phenyl)methanol was added to the tube to a final concentration of $400 \mu \mathrm{M}$. The reaction mixture was then directly injected to LC-MS (ESI-QToF) for analysis. The LC-MS results indicated that the adduct of Trx-sTCO with Tz 7 was not formed during the dark incubation, as all of the Trx-sTCO had been quenched by (4-(6-methyl-1,2,4,5-tetrazin-3yl)phenyl)methanol. No free Trx-sTCO was detected.

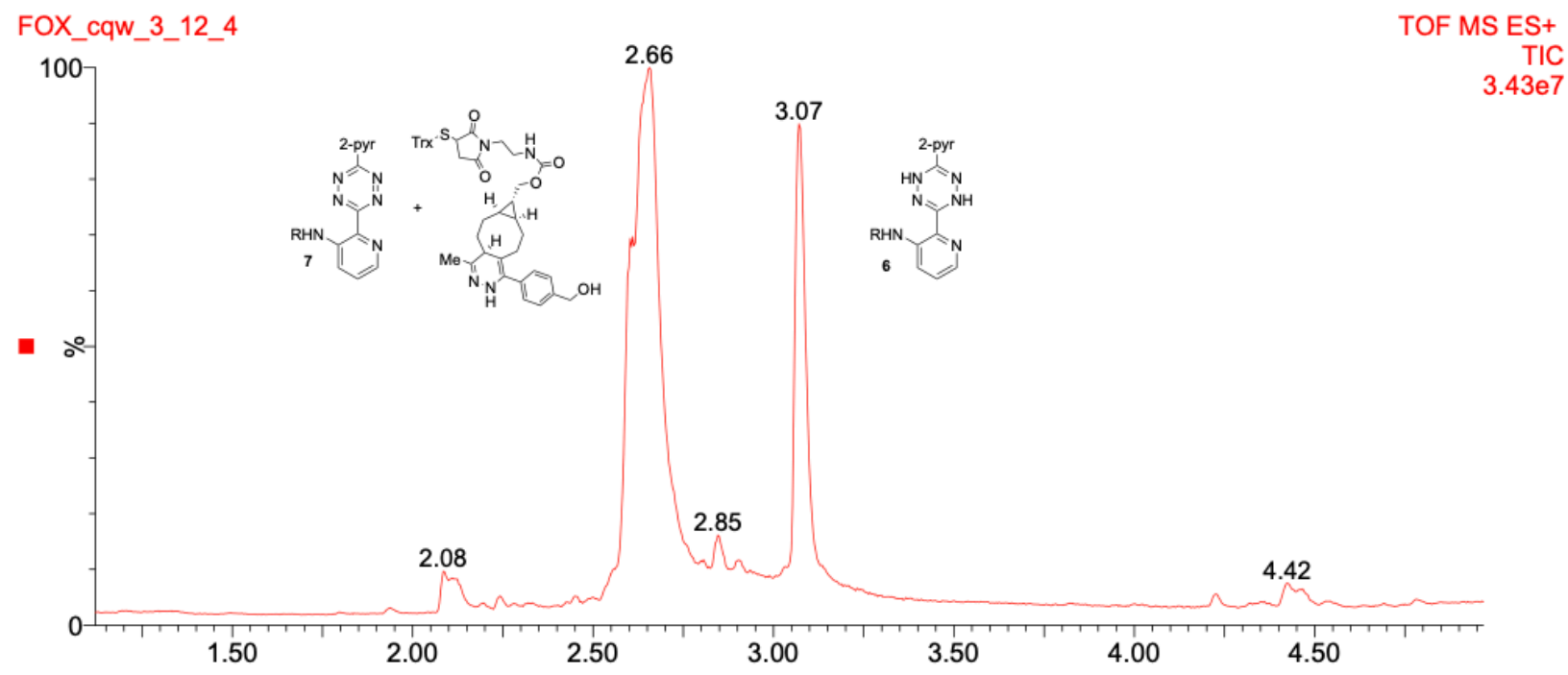

Fig S13. LC-MS TIC trace for experiment described in S2.3.4. Note: unreacted DHTz 6 is partially oxidized to Tz 7 during UPLC analysis (Fig S27), and the observation of Tz 7 is attributed to the oxidation of DHTz 6 to Tz 7 during UPLC analysis 


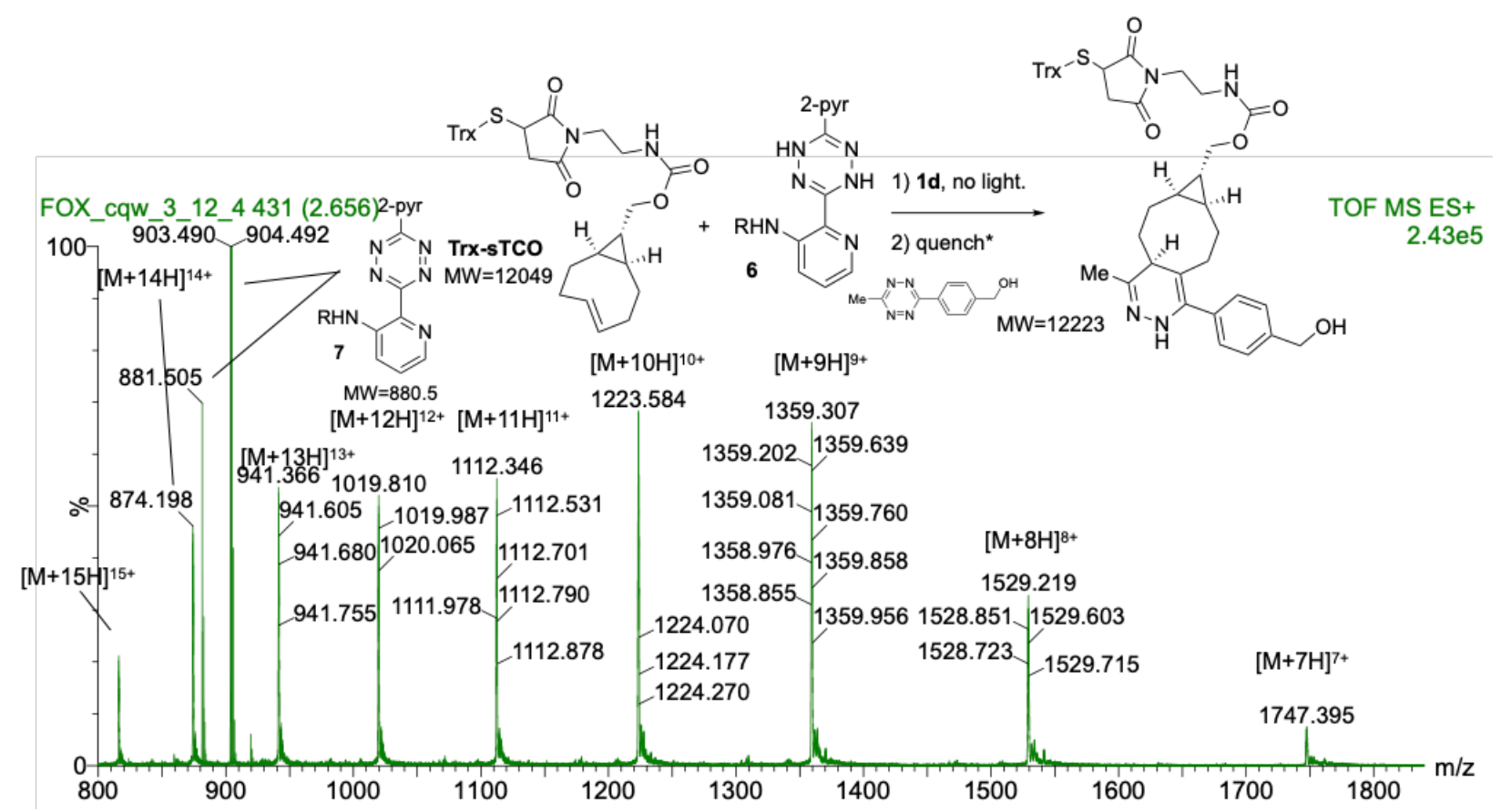

Fig S14. ESI-QToF Mass spectrum of the experiment described in S2.3.4. In this spectrum, only the quenching adduct was observed, indicating that no tetrazine 7 was formed and reacted with Trx-sTCO during the dark incubation. Note: unreacted DHTz 6 is partially oxidized to Tz 7 during UPLC analysis (Fig S27), and the observation of Tz 7 is attributed to the oxidation of DHTz 6 to Tz 7 during UPLC analysis.

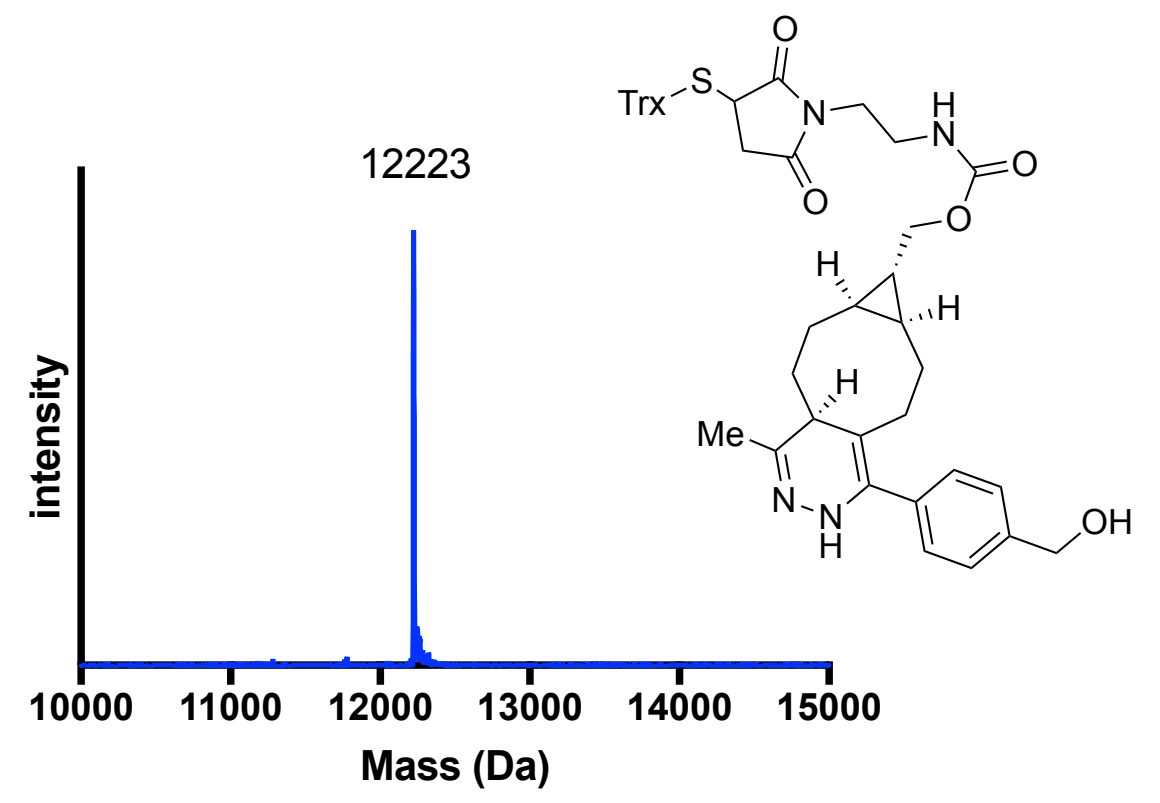

Fig S15. Deconvoluted ESI mass spectrum for experiment described in S2.3.4. contains a single peak at $12223 \mathrm{Da}$, indicating all Trx-sTCO was quenched by (4-(6-methyl-1,2,4,5tetrazin-3-yl)phenyl)methanol, and that no Trx-sTCO had reacted with Tz 7. 


\subsubsection{SiR-photocatalyzed reaction of Trx-sTCO with DHTz 6 with prolonged irradiation}

The following experiment was carried out to study protein stability upon prolonged irradiation of Diels-Alder conjugate 8 in the presence of SiR photocatalyst 1d. A PBS solution of Trx-sTCO $(20 \mu \mathrm{M})$ and DHTz $6(25 \mu \mathrm{M})$ and SiR $1 \mathbf{d}(1 \mu \mathrm{M})$ was prepared in an Eppendorf tube from stock solutions. LED light $\left(660 \mathrm{~nm}, 50 \mathrm{~mW} / \mathrm{cm}^{2}\right)$ was used to irradiate the tube. Aliquots of the reaction mixture were taken at different time points (30 min, 1 h, 2 h, 4 h), and a solution of (4-(6-methyl-1,2,4,5-tetrazin-3-yl)phenyl)methanol was added to each aliquot to a final concentration of $400 \mu \mathrm{M}$. The reaction mixture was then directly injected to LC-MS (ESI-QToF) for analysis. LC-MS analysis indicated that all of DHTz 6 had been consumed at $30 \mathrm{~min}$. The mass spectra showed that initially minor products due to oxidation become more pronounced after $1 \mathrm{~h}, 2 \mathrm{~h}$ and $4 \mathrm{~h}$.

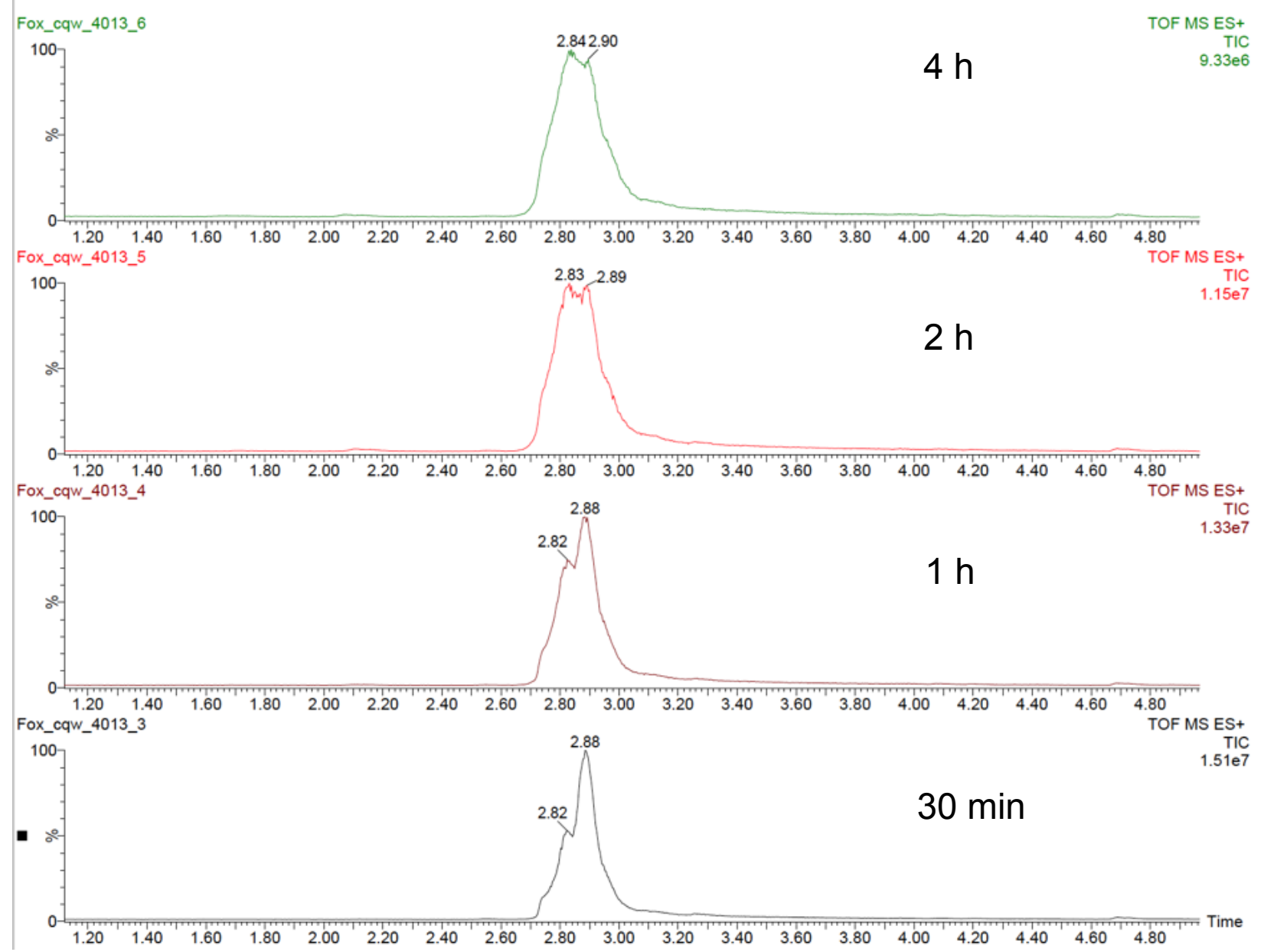

Fig S16. LC-MS TIC trace for experiment described in S2.3.5. 


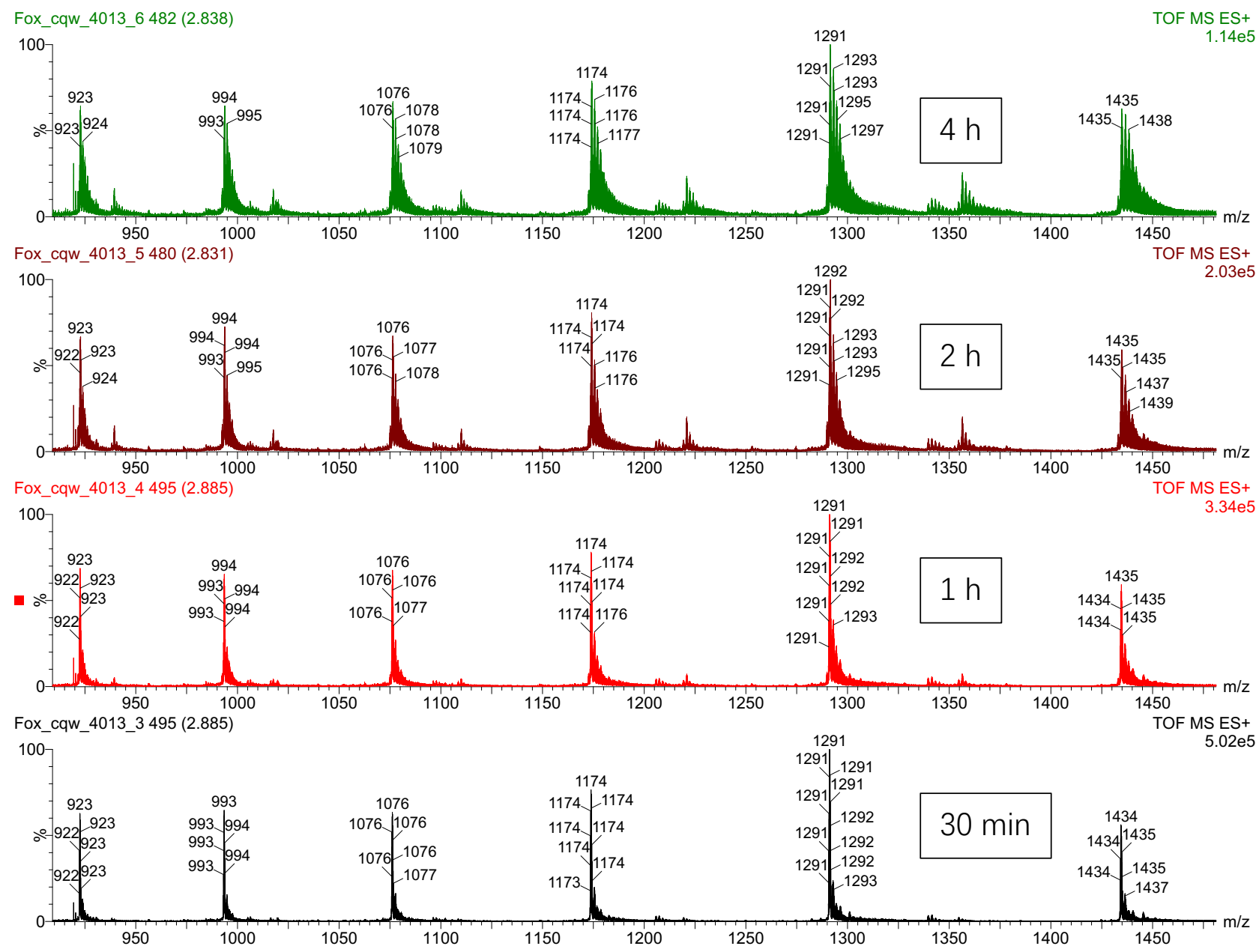

Fig S17. ESI-QToF Mass spectrum of the experiment described in S2.3.6.

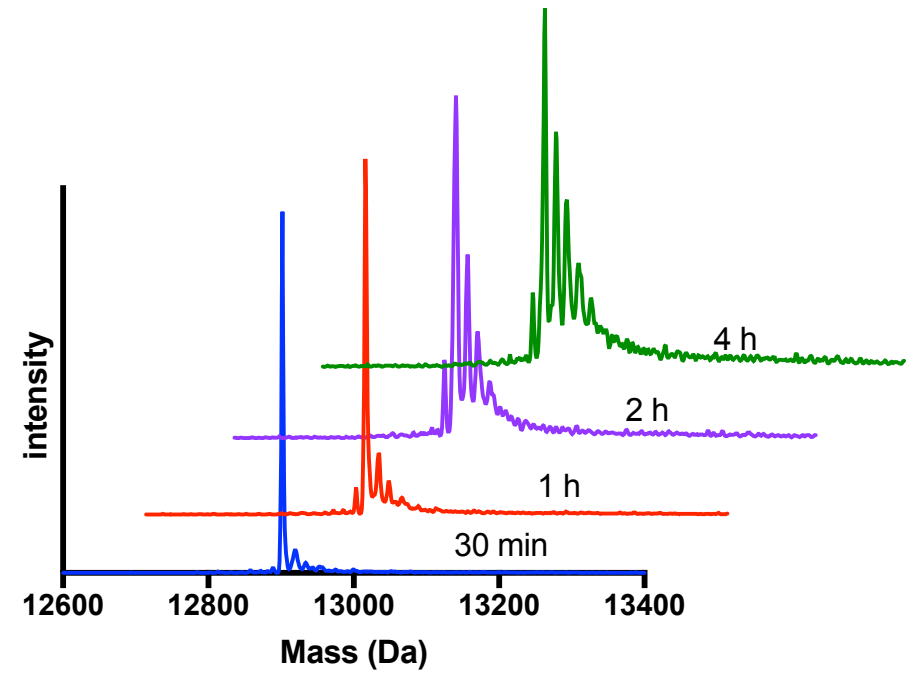

Fig S18. Deconvoluted ESI mass spectrum for experiment described in S2.3.6. 


\subsubsection{Synthesis of Trx-TCO}

To $200 \mu \mathrm{L}$ of a $560 \mu \mathrm{M}$ solution of thioredoxin (Trx) in PBS buffer was added an aqueous solution of dithiothreitol (DTT) $(10 \mu \mathrm{L}, 200 \mathrm{mM} ; 10 \mathrm{mM}$ final concentration). After $30 \mathrm{~min}$, the reaction mixture was passed through a size exclusion desalting column, the fractions were collected and analyzed by UV-Vis to determine concentration, and LC-MS to determine purity, the fractions were then directly used for the next step.

To $100 \mu \mathrm{L}$ of the fraction collected $(110 \mu \mathrm{M}$, determined by UV), TCO-PEG3-maleimide (Sigma-Aldrich, 790443 ) was added (10 uL, $8 \mathrm{mM}$ in MeOH; $800 \mu \mathrm{M}$ final concentration). After $30 \mathrm{~min}$, the reaction mixture was passed through a size exclusion desalting column, the fraction was collected and analyzed by UV-Vis to determine concentration, and LCMS to determine purity. The fractions were then stored at $-80^{\circ} \mathrm{C}$ until ready to use.
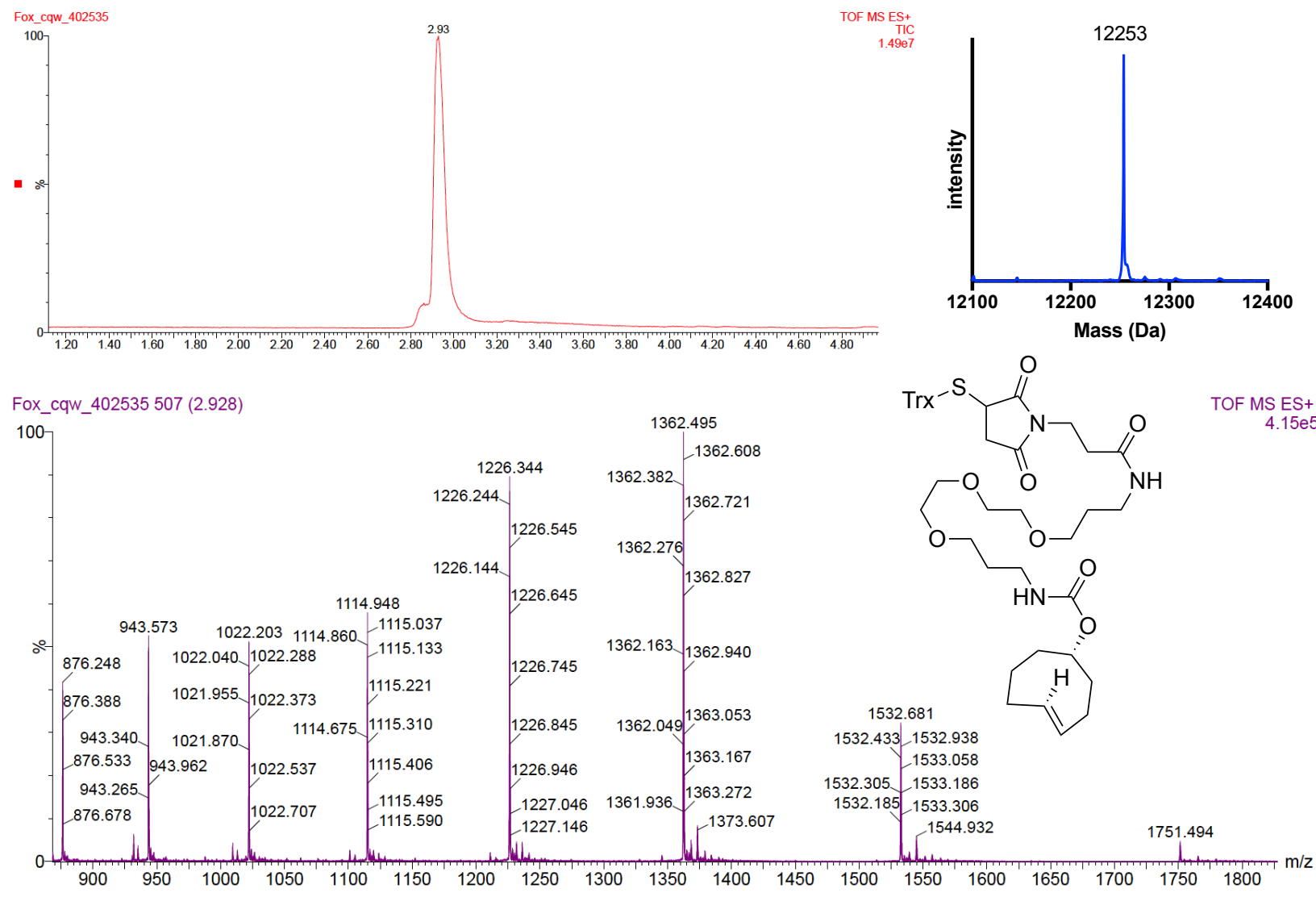

Fig S19. LC-MS-ESI TIC trace (top left), ESI Mass spectrum (bottom) and deconvoluted ESI mass spectrum (top right) of Trx-TCO. 


\subsubsection{Photocatalyzed Labeling of Trx-TCO with DHTz 6}

A PBS solution of Trx-TCO $(20 \mu \mathrm{M})$, DHTz $6(25 \mu \mathrm{M})$ and SiR $1 \mathrm{~d}(1 \mu \mathrm{M})$ was prepared in an Eppendorf tube from stock solutions. LED light $(660 \mathrm{~nm})$ was used to irradiate the tube for 15 min with a power density of $50 \mathrm{~mW} / \mathrm{cm}^{2}$. After irradiation, a solution of (4-(6-methyl1,2,4,5-tetrazin-3-yl)phenyl)methanol was added to the tube to a final concentration of $400 \mu \mathrm{M}$ to quench any unreacted Trx-TCO. The reaction mixture was then directly injected into the LC-MS(ESI-QToF) for analysis. The LC-MS results indicated that all of the Trx-TCO had reacted with Tz 7 during the light irradiation: no free Trx-TCO was detected, nor was the adduct of Trx-TCO with (4-(6-methyl-1,2,4,5-tetrazin-3yl)phenyl)methanol detected.
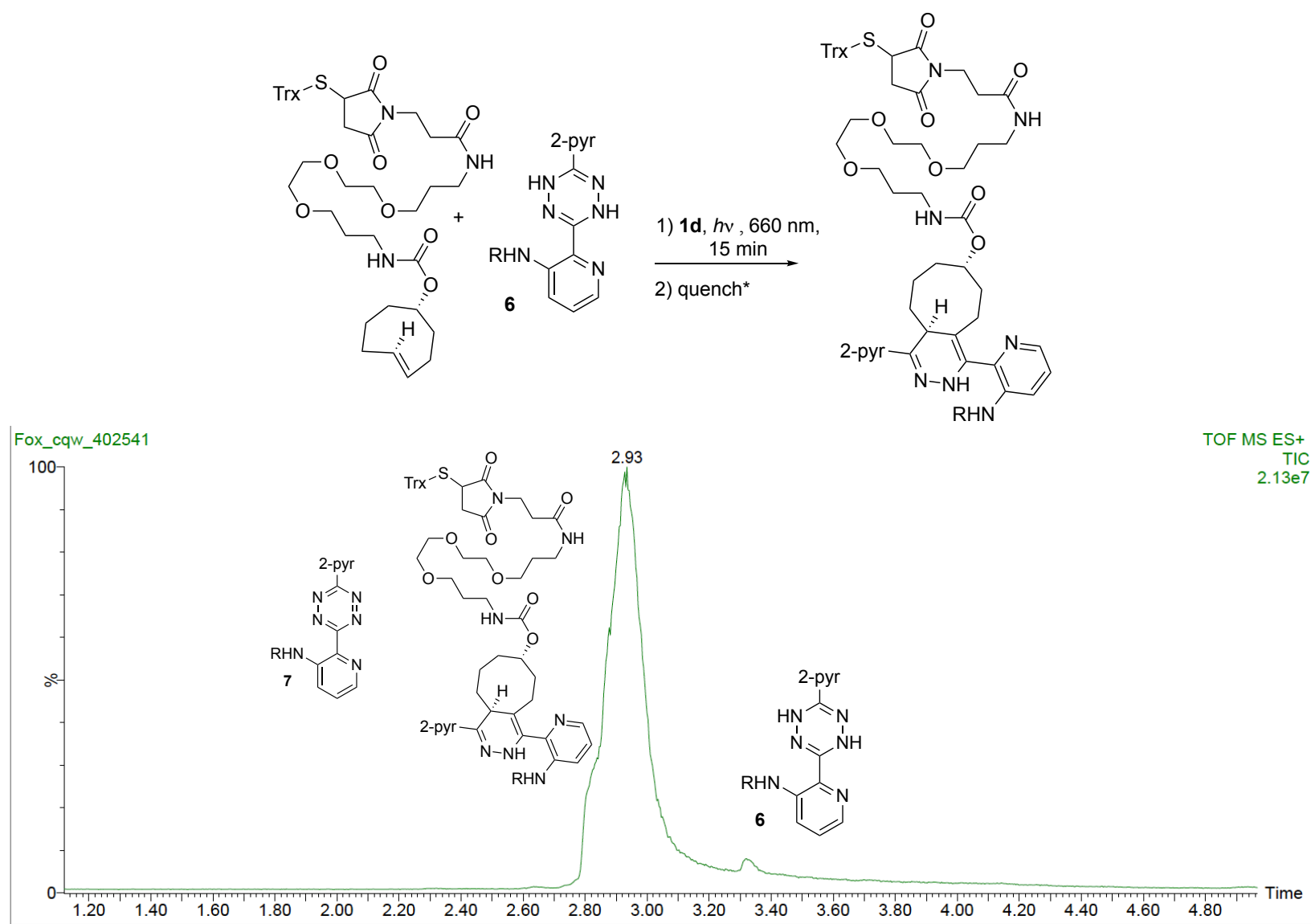

Fig S20. LC-MS TIC trace for photocatalyzed labeling of Trx-TCO with DHTz 6. Note: unreacted DHTz 6 is partially oxidized to Tz 7 during UPLC analysis (Fig S27), and the observation of Tz 7 is attributed to the oxidation of DHTz 6 to Tz 7 during UPLC analysis. 


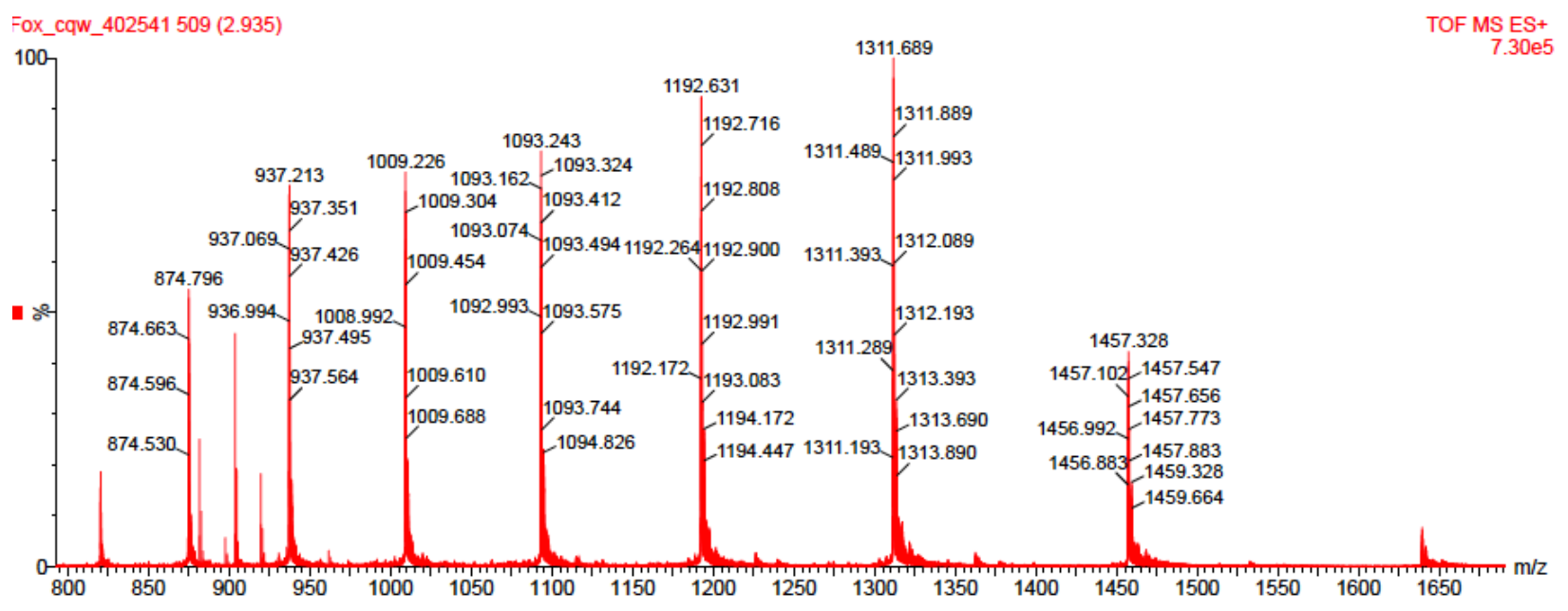

Fig S21. ESI-QToF mass spectrum of photocatalyzed labeling of Trx-TCO with DHTz 6. Note: unreacted DHTz 6 is partially oxidized to Tz 7 during UPLC analysis (Fig S27), and the observation of Tz 7 is attributed to the oxidation of DHTz 6 to Tz 7 during UPLC analysis.
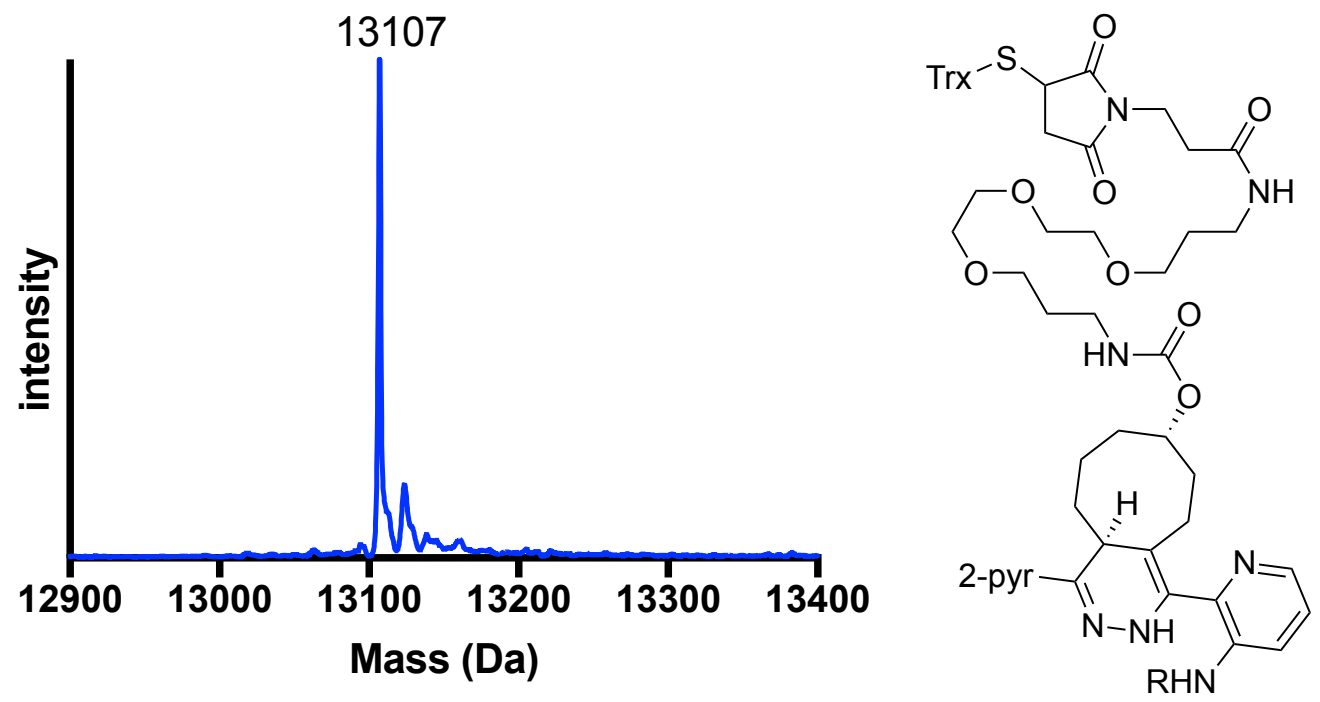

Fig S22. Deconvoluted ESI mass spectrum of photocatalyzed labeling of Trx-TCO with DHTz 6 contains a major peak at $13107 \mathrm{Da}$, with a minor peak of M+18 corresponding to the addition of water to the Diels-Alder adduct. 


\subsubsection{Synthesis of Trx-BCN}

To $200 \mu \mathrm{L}$ of a $560 \mu \mathrm{M}$ solution of thioredoxin (Trx) in PBS buffer was added an aqueous solution of dithiothreitol (DTT) $(10 \mu \mathrm{L}, 200 \mathrm{mM} ; 10 \mathrm{mM}$ final concentration). After $30 \mathrm{~min}$, the reaction mixture was passed through a size exclusion desalting column, the fractions were collected and analyzed by UV-Vis to determine concentration, and LC-MS to determine purity, the fractions were then directly used for the next step.

To $100 \mu \mathrm{L}$ of the fraction collected $(110 \mu \mathrm{M}$, determined by UV), BCN-PEG3-MAL (ConjuProbe, CP-6043) was added (10 uL, $8 \mathrm{mM}$ in MeOH; $800 \mu \mathrm{M}$ final concentration). After $30 \mathrm{~min}$, the reaction mixture was passed through a size exclusion desalting column, the fraction was collected and analyzed by UV-Vis to determine concentration, and LC-MS to determine purity. The fractions were then stored at $-80^{\circ} \mathrm{C}$ until ready to use.

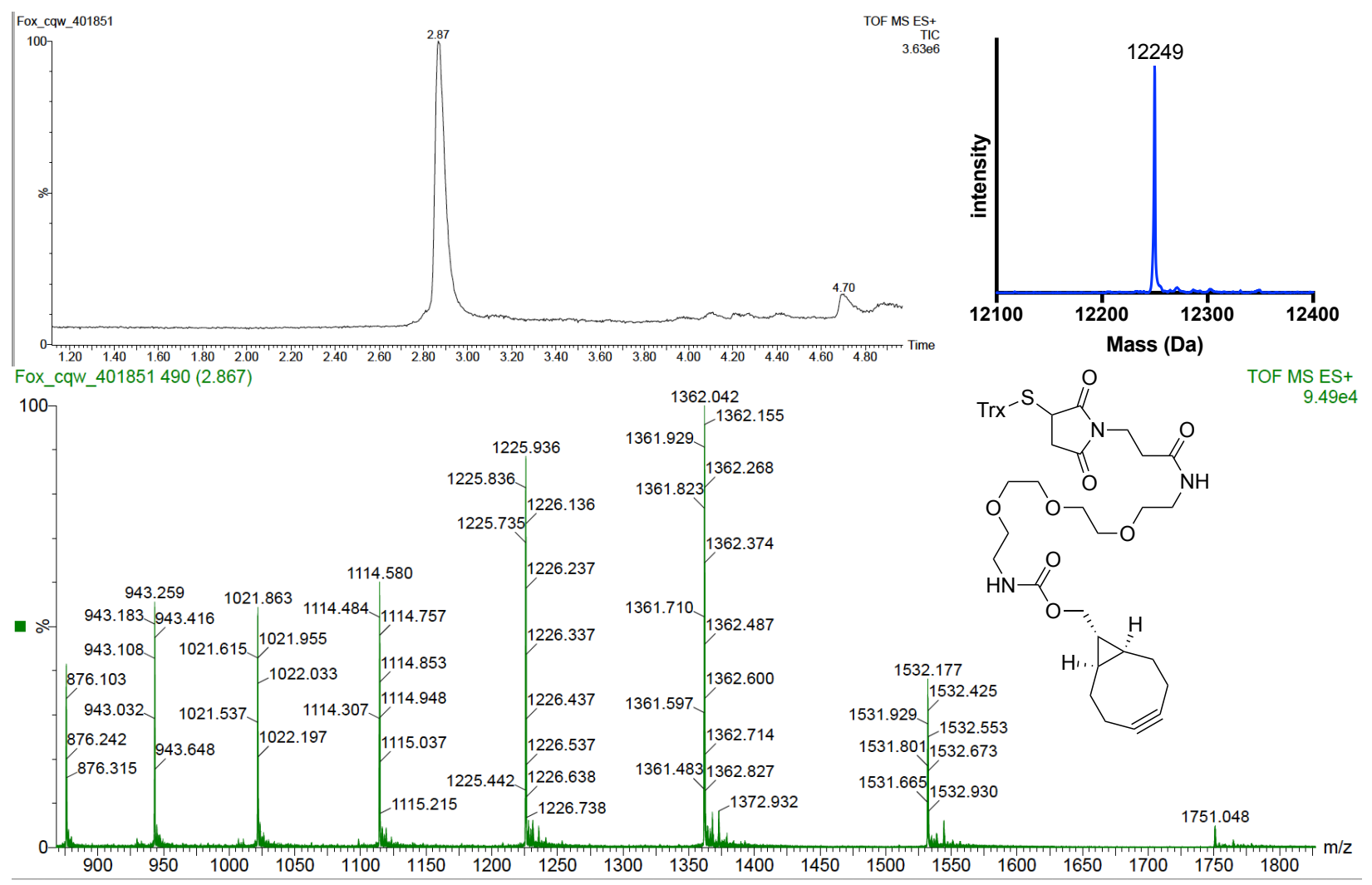

Fig S23. LC-MS-ESI TIC trace (top left), ESI Mass spectrum (bottom) and deconvoluted ESI mass spectrum (top right) of Trx-BCN. 


\subsubsection{Photocatalyzed Labeling of Trx-BCN with DHTz 6}

A PBS solution of Trx-BCN $(20 \mu \mathrm{M})$, DHTz $6(25 \mu \mathrm{M})$ and SiR $1 \mathrm{~d}(1 \mu \mathrm{M})$ was prepared in an Eppendorf tube from stock solutions. LED light $(660 \mathrm{~nm})$ was used to irradiate the tube for $15 \mathrm{~min}$ with a power density of $50 \mathrm{~mW} / \mathrm{cm}^{2}$. After irradiation, a solution of (4-(6-methyl1,2,4,5-tetrazin-3-yl)phenyl)methanol was added to the tube to a final concentration of $400 \mu \mathrm{M}$ to quench any unreacted Trx-BCN. The reaction mixture was then directly injected into the LC-MS(ESI-QToF) for analysis. The LC-MS results indicated that all of the Trx-BCN had reacted with Tz 7 during the light irradiation: no free Trx-BCN was detected, nor was the adduct of Trx-BCN with (4-(6-methyl-1,2,4,5-tetrazin-3yl)phenyl)methanol detected.

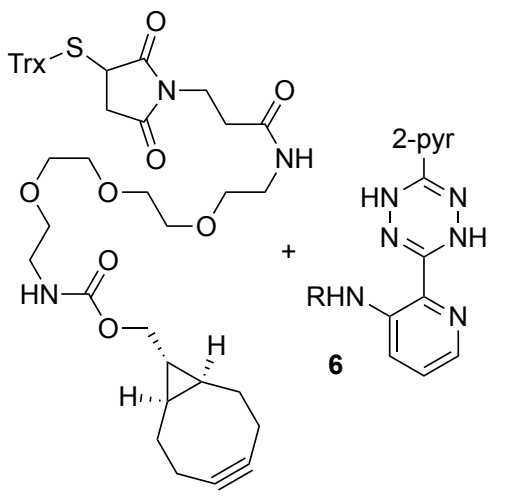

1) $1 \mathrm{~d}, h v, 660 \mathrm{~nm}$,

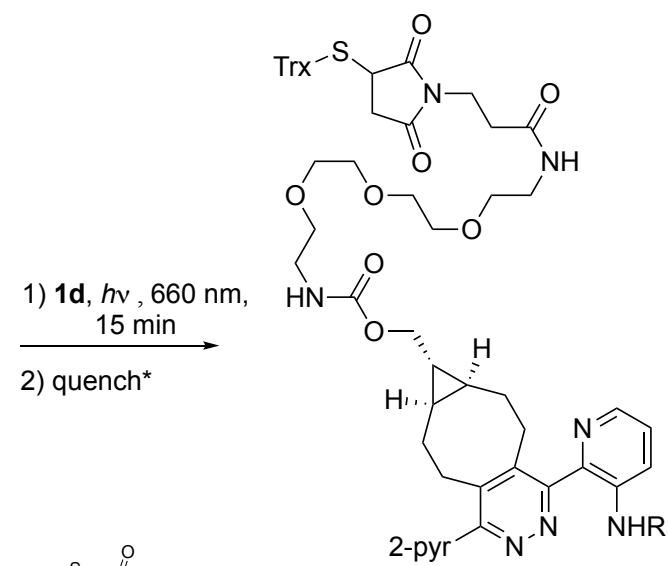

Fox_cqw_401981

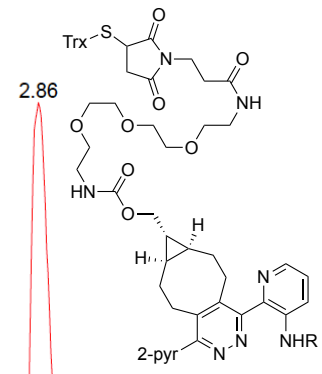

2) quench*

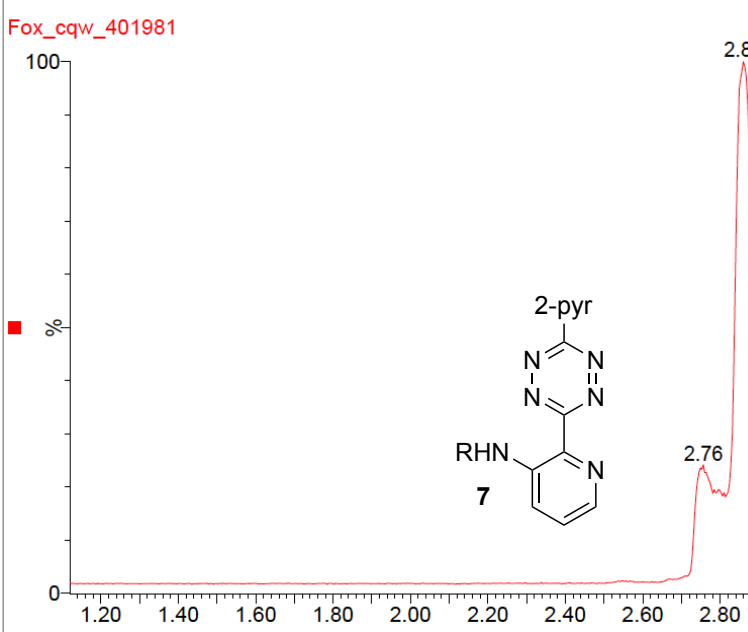

-

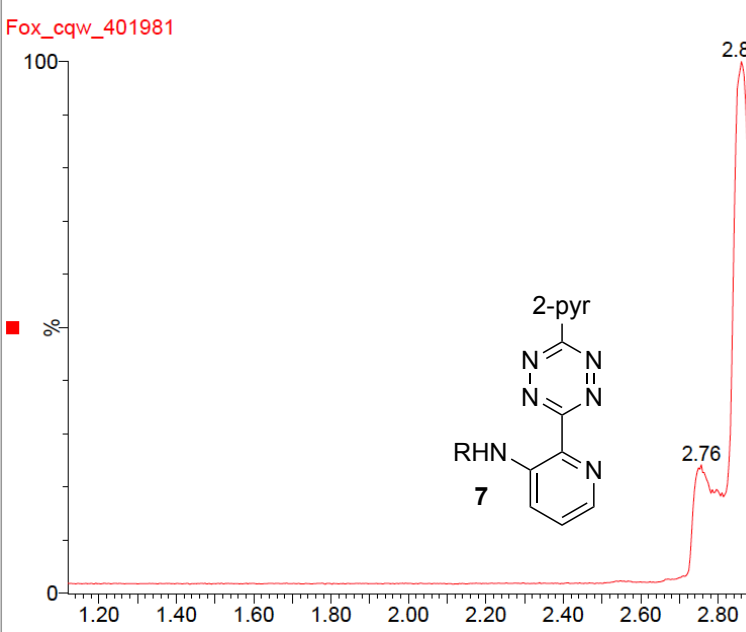

2) quench*
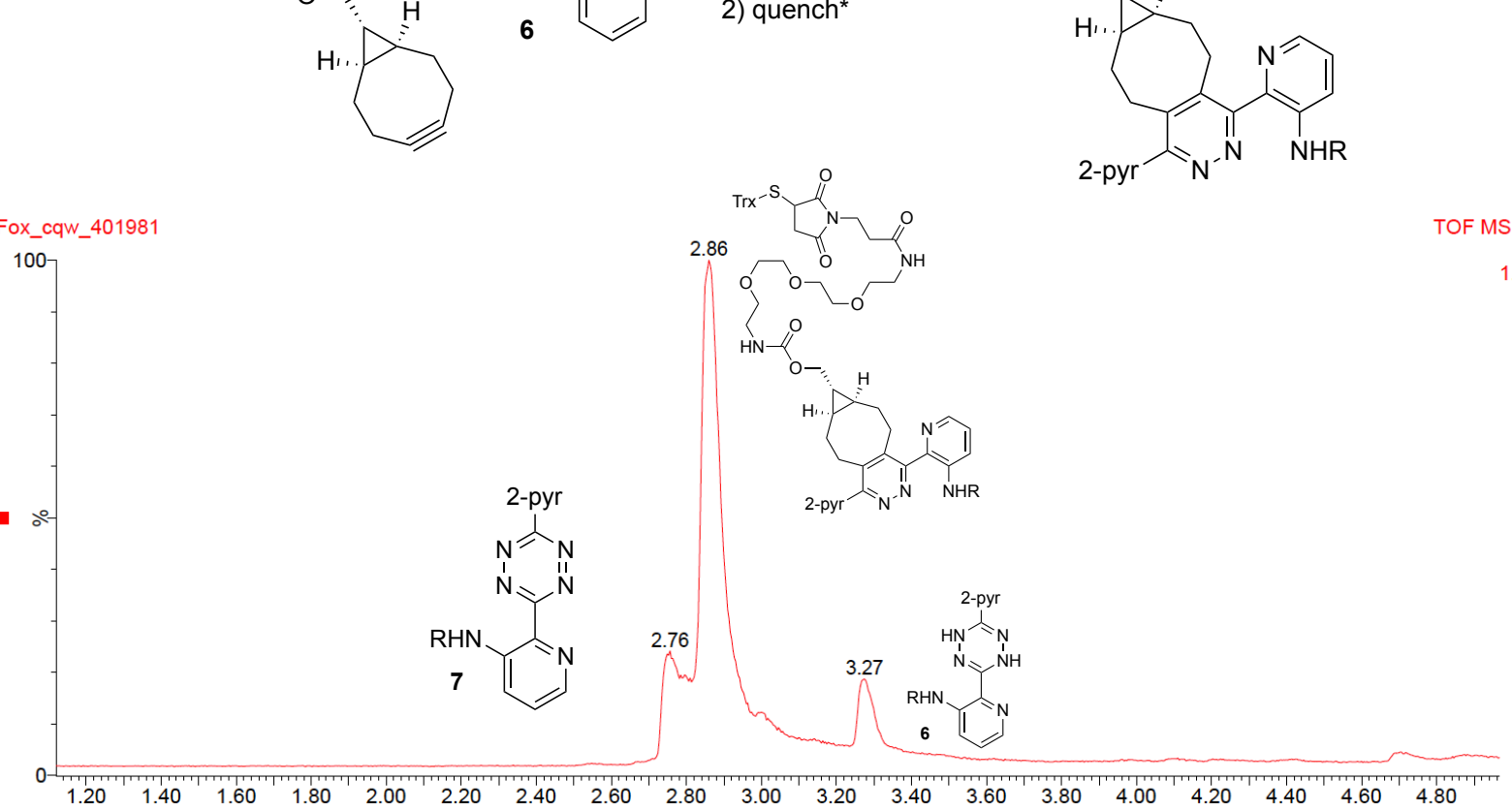

Fig S24. LC-MS TIC trace for photocatalyzed labeling of Trx-BCN with DHTz 6. Note: unreacted DHTz 6 is partially oxidized to Tz 7 during UPLC analysis (Fig S27), and the observation of Tz 7 is attributed to the oxidation of DHTz 6 to Tz 7 during UPLC analysis. 


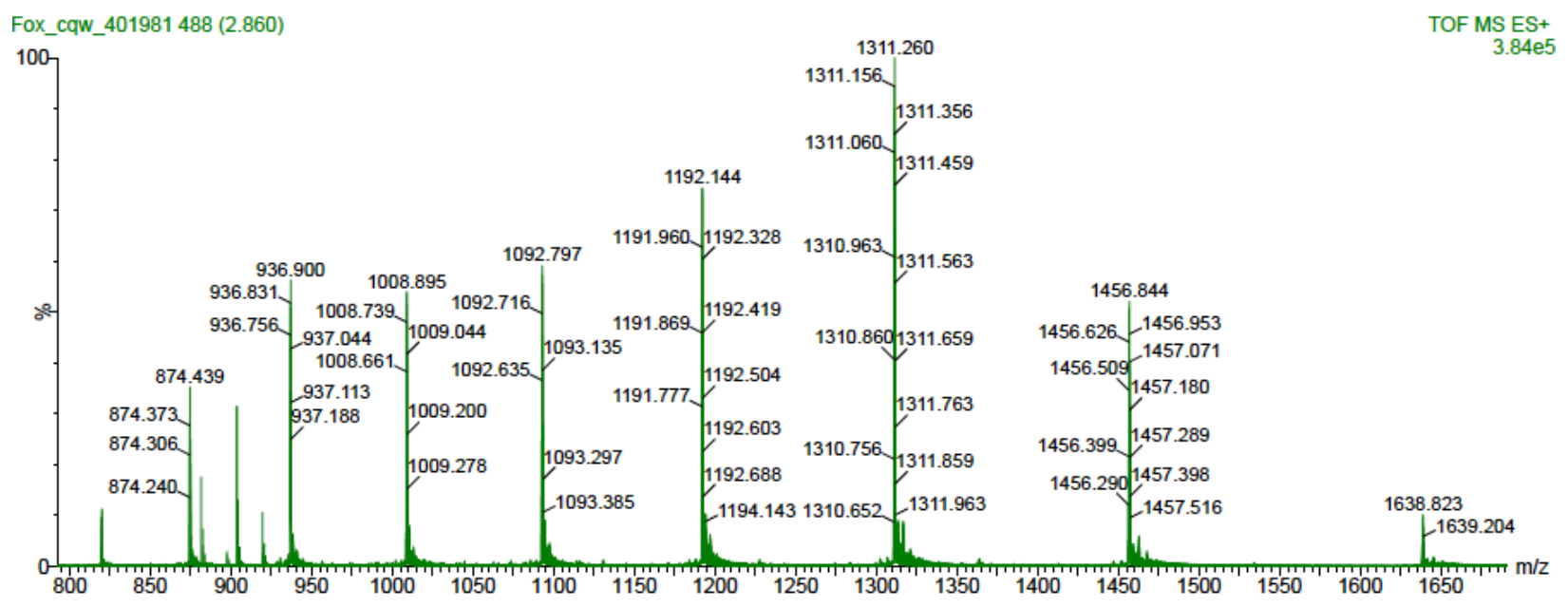

Fig S25. ESI-QToF mass spectrum of photocatalyzed labeling of Trx-BCN with DHTz 6. Note: unreacted DHTz 6 is partially oxidized to Tz 7 during UPLC analysis (Fig S27), and the observation of Tz 7 is attributed to the oxidation of DHTz 6 to Tz 7 during UPLC analysis.
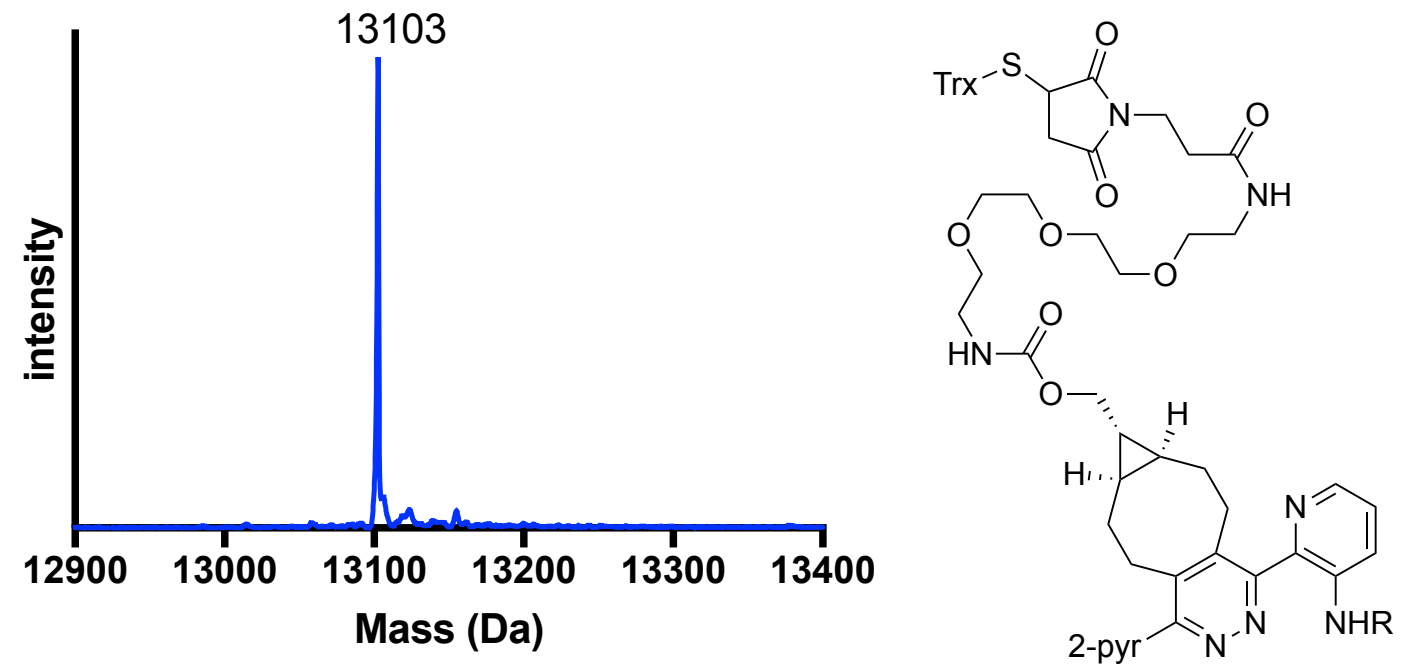

Fig S26. Deconvoluted ESI mass spectrum of photocatalyzed labeling of Trx-BCN with $\mathrm{DHTz} 6$ contains a single peak at $13103 \mathrm{Da}$, indicating all Trx-BCN was quenched by (4-(6-methyl-1,2,4,5-tetrazin-3-yl)phenyl)methanol, and that no Trx-BCN had reacted with Tz 7. 


\subsubsection{Oxidation of DHTz 6 during reverse phase chromatography}

Two samples of DHTz 6 ( $25 \mu \mathrm{M}$ and $5 \mu \mathrm{M}$ in PBS. Both freshly prepared from the same stock solution) were injected to LC-MS for analysis. In both cases an extra peak for Tz 7 was observed, which indicates that DHTz 6 was partially oxidized during the chromatography.
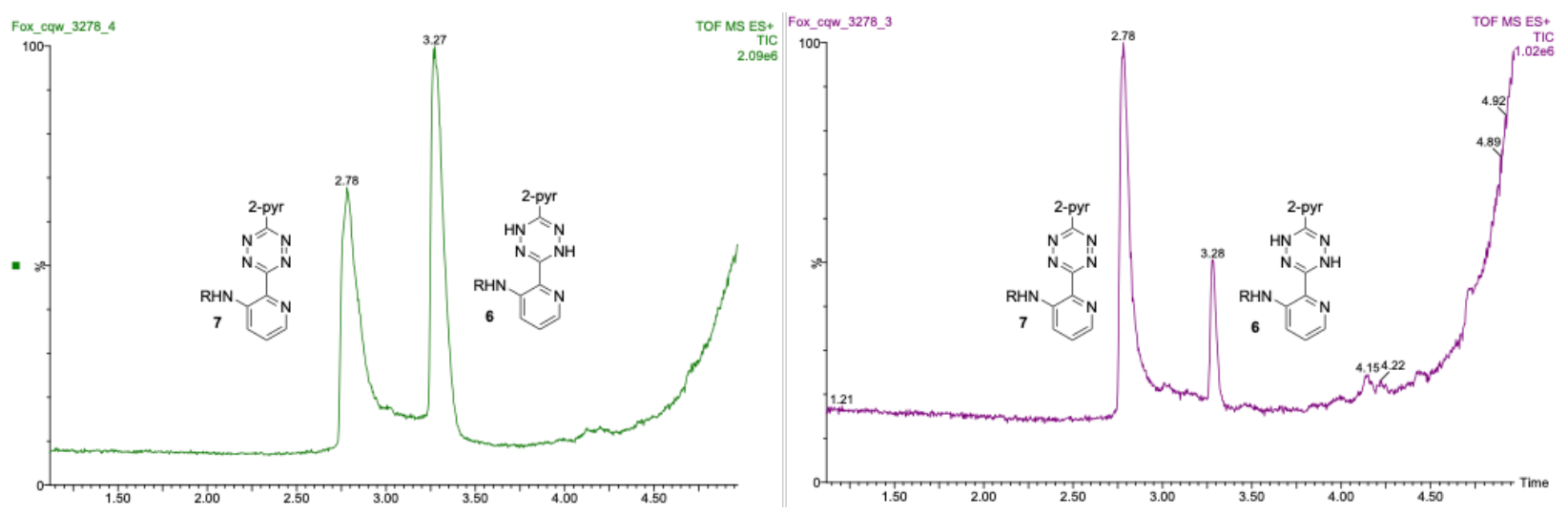

Fig S27. LC-MS TIC trace for experiment described in S2.3.5. (left, $25 \mu \mathrm{M}$. right $5 \mu \mathrm{M}$.) 


\subsection{Stability test of DHTz 6 and Tz 7}

2.4.1. Stability of DHTz 6 in PBS (Results displayed in Fig 2D):

A PBS solution $(2 \mathrm{~mL})$ of DHTz $6(35 \mu \mathrm{M})$ was monitored in ambient light by UV-Vis every hour over 24 hours. The percentage of oxidation after one day, which calculated based on absorbance at 354 and $417 \mathrm{~nm}$, was $5 \%$.

\subsubsection{Stability of Tz 7 in PBS (Results displayed in Fig 2E):}

A PBS solution $(2 \mathrm{~mL})$ of Tz $7(35 \mu \mathrm{M})$ was monitored in ambient light by UV-Vis every 4 hours over 24 hours. The percent retaining after one day, which calculated based on absorbance at $450 \mathrm{~nm}$, was $80 \%$.

\subsubsection{Stability of DHTz 6 in mouse serum:}

A PBS solution $(2 \mathrm{~mL})$ containing $10 \%$ mouse serum and DHTz $6(35 \mu \mathrm{M})$ was monitored in ambient light by UV-Vis at $0,1,2$ and 3 days. The percent of oxidation, calculated based on absorbance at 354 and $417 \mathrm{~nm}$, was $20 \%, 40 \%$ and $50 \%$ at days 1,2 and 3 respectively.

\section{5um DHTz in serum (10\%)}

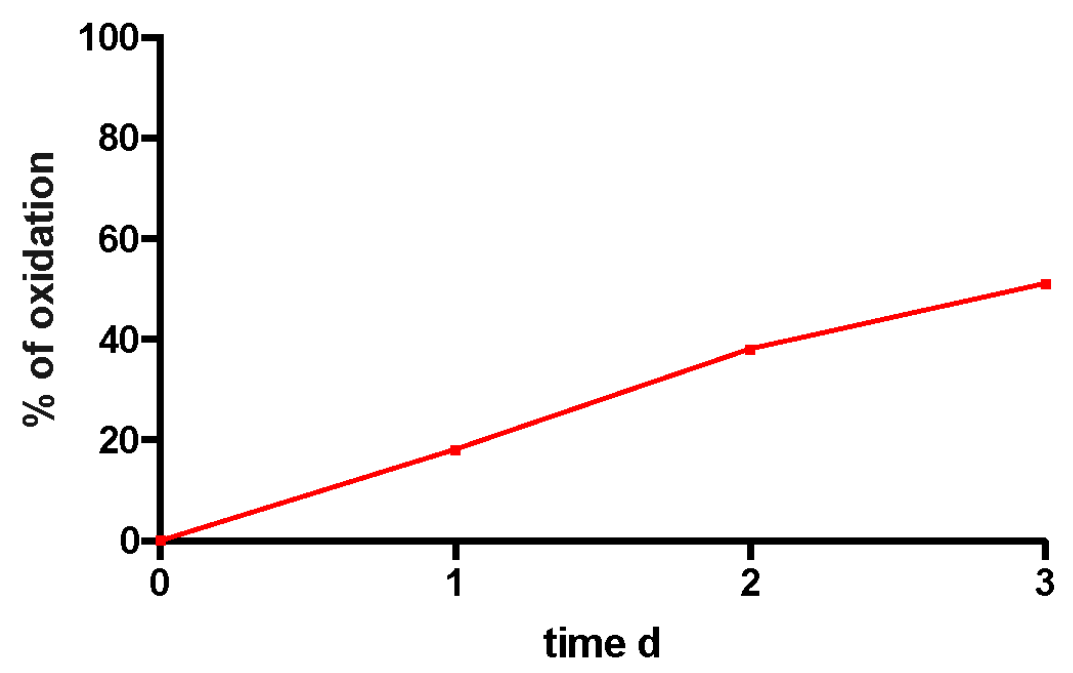

Fig S28. Stability of DHTz 6 in ambient light was monitored by UV-Vis at $0,1,2$ and 3 days. The percentage of oxidation, calculated based on absorbance at 354 and $417 \mathrm{~nm}$, was $20 \%, 40 \%$ and $50 \%$ at days 1,2 and 3 respectively. 


\subsection{Stopped-flow kinetic analysis with ax-5-hydroxy-trans-cyclooctene}

\subsubsection{Stopped-flow kinetic analysis between $T z 7$ and ax-5-hydroxy-trans- cyclooctene}

The reaction between ax-5-hydroxy-trans-cyclooctene and Tz 7 was measured under pseudo-first order conditions with a large excess of TCO in water by following the exponential decay of the tetrazine at $417 \mathrm{~nm}$ over time using an SX 18MV-R stopped flow spectrophotometer (Applied Photophysics Ltd.). The concentration of solutions of ax-5hydroxy-trans-cyclooctene were measured by titration with a freshly prepared $0.493 \mathrm{mM}$ solution of 3,6-di(2-pyridyl)tetrazine in 1:1 PBS : MeOH. A syringe containing Tz 7 (0.10 $\mathrm{mM}, \mathrm{PBS})$ and a second syringe containing ax-5-hydroxy-trans-cyclooctene $(6.46 \mathrm{mM}$, $3.23 \mathrm{mM}$, or $1.62 \mathrm{mM}$ PBS) were loaded to the thermostatted stopped-flow spectrophotometer at $25^{\circ} \mathrm{C}$. An equal volume of the two solutions were then mixed by the stopped flow instrument to create solutions with final concentrations of $0.050 \mathrm{mM} 7$ and 3.23, 1.62, 0,81 mM ax-5-hydroxy-trans-cyclooctene, respectively. Data was recorded for 50-200 milliseconds depending on the concentration of ax-5-hydroxy-transcyclooctene, and each experiment was performed in triplicate. $k_{o b s}$ was determined by nonlinear regression analysis of the data points using Prism software. The average of the $k_{\text {obs }}$ was then plotted against the concentration of ax-5-hydroxy-trans-cyclooctene to obtain the bimolecular rate constant $k_{2}$ from the slope of the plot. 

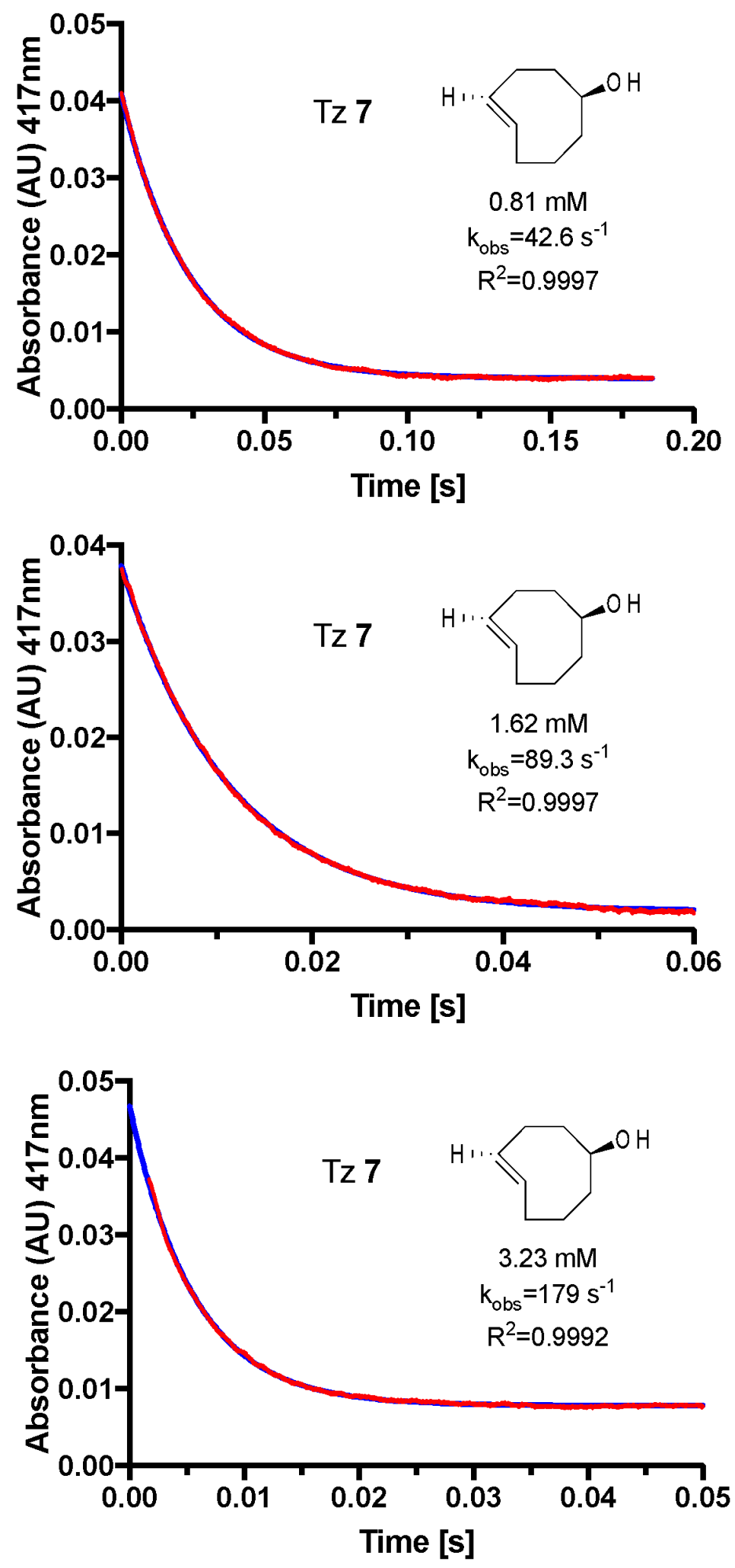

Fig S29. Stopped-flow kinetics of Tz $7(0.05 \mathrm{mM})$ and ax-5-hydroxy-trans-cyclooctene (0.81 mM (top), $1.62 \mathrm{mM}$ (center), $3.23 \mathrm{mM}$ (bottom)). The data was shown as red dots, and the fitted curve generated by Prism software was shown in blue. 


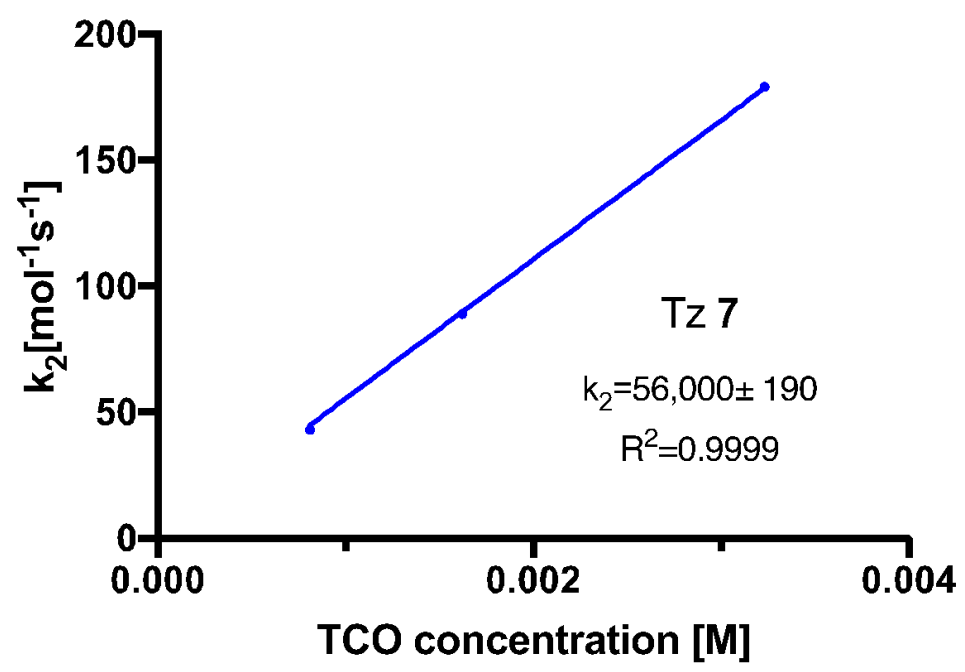

Fig S30. Bimolecular rate determination of Tz 7 and $5-\mathrm{OH}$ TCO by plotting $\mathrm{k}_{\mathrm{obs}}$ vs ax-5hydroxy-trans-cyclooctene concentration.

\subsubsection{Stopped-flow kinetic analysis between Tz 3 and ax-5-hydroxy-trans- cyclooctene}

The reaction between ax-5-hydroxy-trans-cyclooctene and Tz 3 was measured under pseudo-first order conditions with a large excess of TCO in water by following the exponential decay of the tetrazine at $325 \mathrm{~nm}$ over time using an SX 18MV-R stopped flow spectrophotometer (Applied Photophysics Ltd.). The concentration of solutions of ax-5hydroxy-trans-cyclooctene were measured by titration with a freshly prepared $0.1 \mathrm{mM}$ solution of 3,6-di(2-pyridyl)tetrazine in 1:1 PBS : MeOH. A syringe containing Tz 3 (0.2 $\mathrm{mM}, \mathrm{PBS})$ and a second syringe containing ax-5-hydroxy-trans- $(6.46 \mathrm{mM}, 3.23 \mathrm{mM}$, or $1.62 \mathrm{mM}$ PBS) were loaded to the thermostatted stopped-flow spectrophotometer at $25{ }^{\circ} \mathrm{C}$. An equal volume of the two solutions were then mixed by the stopped flow instrument to create solutions with final concentrations of $0.10 \mathrm{mM} 7$ and $3.23,1.62,0,81$ $\mathrm{mM}$ ax-5-hydroxy-trans-cyclooctene, respectively. Data was recorded for 50-200 milliseconds depending on the concentration of ax-5-hydroxy-trans-cyclooctene, and each experiment was performed in triplicate. $k_{\text {obs }}$ was determined by nonlinear regression analysis of the data points using Prism software. The average of the $k_{\text {obs }}$ was then plotted against the concentration of ax-5-hydroxy-trans-cyclooctene to obtain the bimolecular rate constant $k_{2}$ from the slope of the plot. 

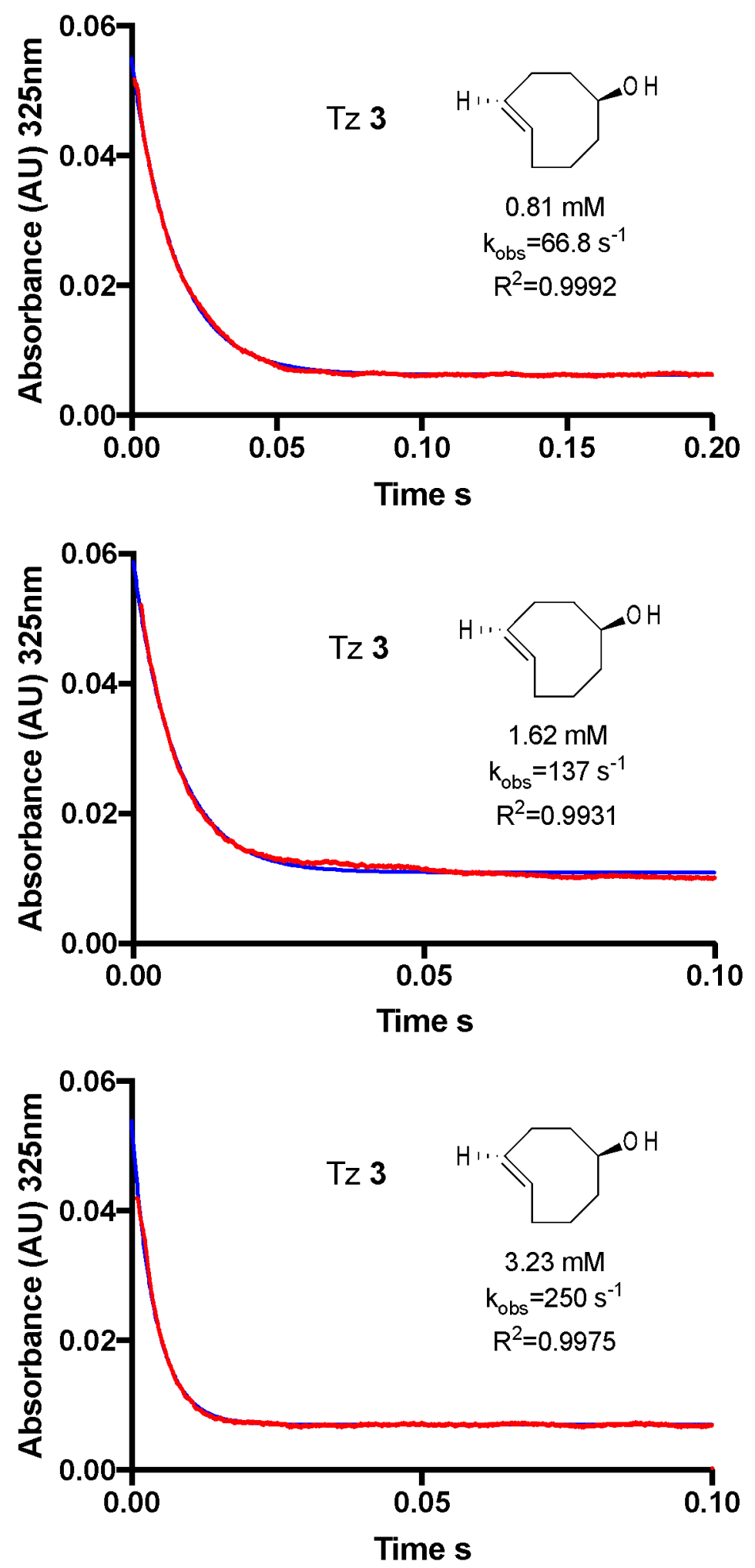

Fig S31. Stopped-flow kinetics of Tz $3(0.1 \mathrm{mM})$ and ax-5-hydroxy-trans-cyclooctene (0.81 mM (top), $1.62 \mathrm{mM}$ (center), $3.23 \mathrm{mM}$ (bottom)). The data was shown as red dots, and the fitted curve generated by Prism software was shown in blue. 


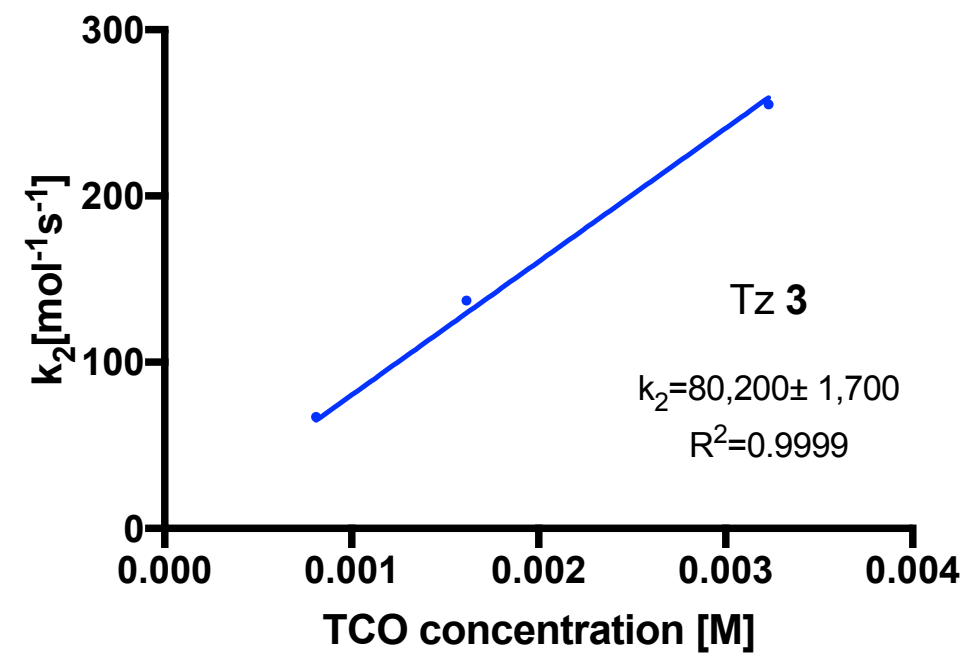

Fig S32. Bimolecular rate determination of Tz 3 and 5-OH TCO by plotting kobs vs ax-5hydroxy-trans-cyclooctene concentration. 


\section{Part III: Oscillatory Rheology}

\subsection{Experimental Set-up}

The viscoelastic properties of the hydrogel were measured using a stress-controlled rheometer (AR-G2, TA Instruments, New Castle, DE) with an $8 \mathrm{~mm}$ parallel plate geometry. The pre-hydrogel mixture was loaded on to the quartz plate within 2 min after mixing and the geometry was lowered to a gap size of $100 \mu \mathrm{m}$ before applying mineral oil around the sample circumference to minimize water evaporation. A $660 \mathrm{~nm}$ light source was connected to the quartz plate of the rheometer via an optical cable (Fig S33C). The power density at the surface of the quartz plate was measured as $20 \mathrm{~mW} / \mathrm{cm}^{2}$ using a Coherent FieldMax-Top Optical Power Meter equipped with a PM10 sensor. Time sweeps were carried out at a frequency of $1 \mathrm{~Hz}$ and at strains of $1 \%$ for 120 minutes in both the in-situ gelation and control groups. All measurements were performed at room temperature in triplicate and the average storage $\left(G^{\prime}\right)$ and loss ( $\left.G^{\prime \prime}\right)$ moduli are reported. PBS buffer used in rheology experiment was passed through a column of Chelex 100 resin to remove any trace metals. The $\mathrm{pH}$ of the buffer was then adjusted to 7.4 using 1 $\mathrm{M}$ solutions of either $\mathrm{HCl}$ or $\mathrm{NaOH}$. Catalase from bovine liver was purchased from Sigma (C1345-1G).

\subsection{In-situ gelation (Results displayed in Fig 6C)}

The hydrogel precursor solution was prepared in PBS (HA-dTCO: $4.4 \mathrm{mg} / \mathrm{mL}, 2.5 \mathrm{mM}$ for dTCO; HA-DHTz: $8.8 \mathrm{mg} / \mathrm{mL}, 2 \mathrm{mM}$ for DHTz; SiR catalyst $1 \mathrm{~d}$ : $40 \mu \mathrm{M}$; catalase: 2.5 $\mathrm{mg} / \mathrm{mL}, 10 \mu \mathrm{M})$. Then $40 \mu \mathrm{L}$ of the solution was loaded onto the geometry and a 2-h time sweep experiment was performed, with light turned on at $t=5 \mathrm{~min}$.

\subsection{Oscillatory rheological measurement on hydrogel precursor solution without light}

The precursor solution was prepared as described in S3.2. Then $40 \mu \mathrm{L}$ of the solution was loaded onto the geometry, and a 10-h time sweep experiment was conducted in the dark without the light.

\subsection{Oscillatory rheological measurement on hydrogel precursor solution without photocatalyst}

The precursor solution was prepared as described in S3.2, but without the SiR catalyst. Then $40 \mu \mathrm{L}$ of the solution was loaded onto the geometry and a 2-h time sweep experiment was conducted, with light turned on at $t=5 \mathrm{~min}$. 
A

B
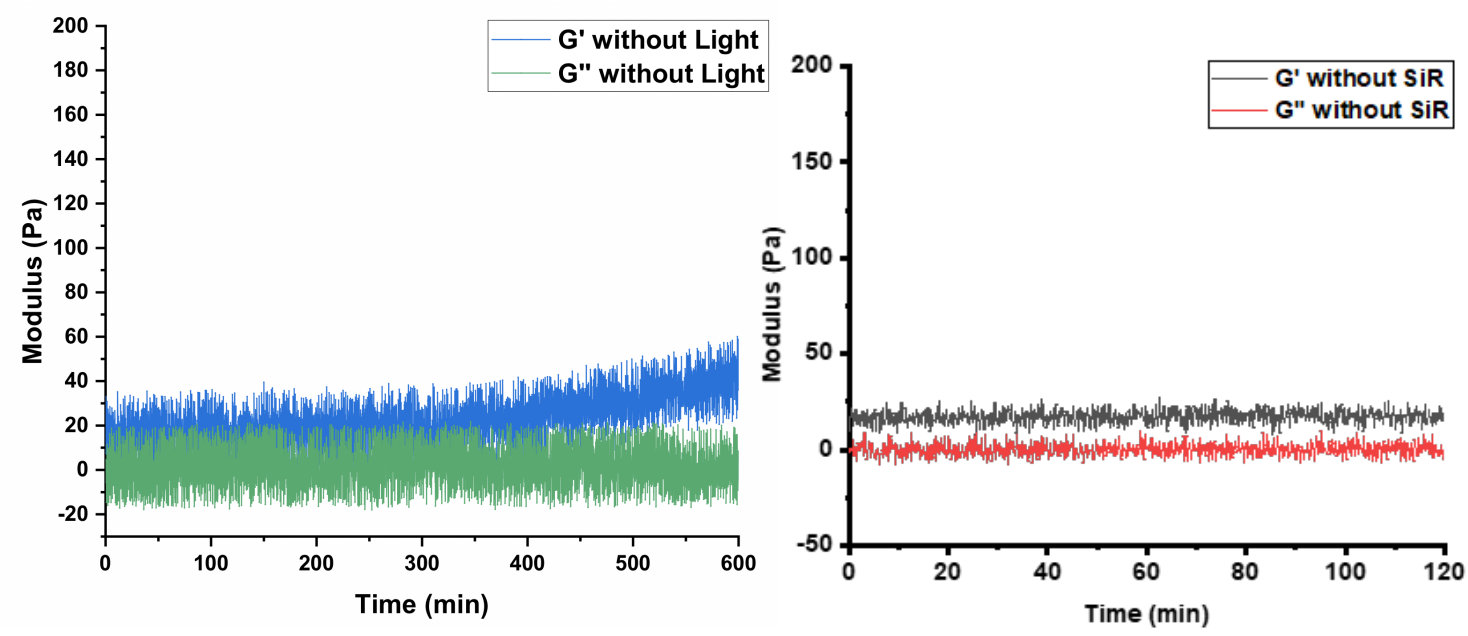

C

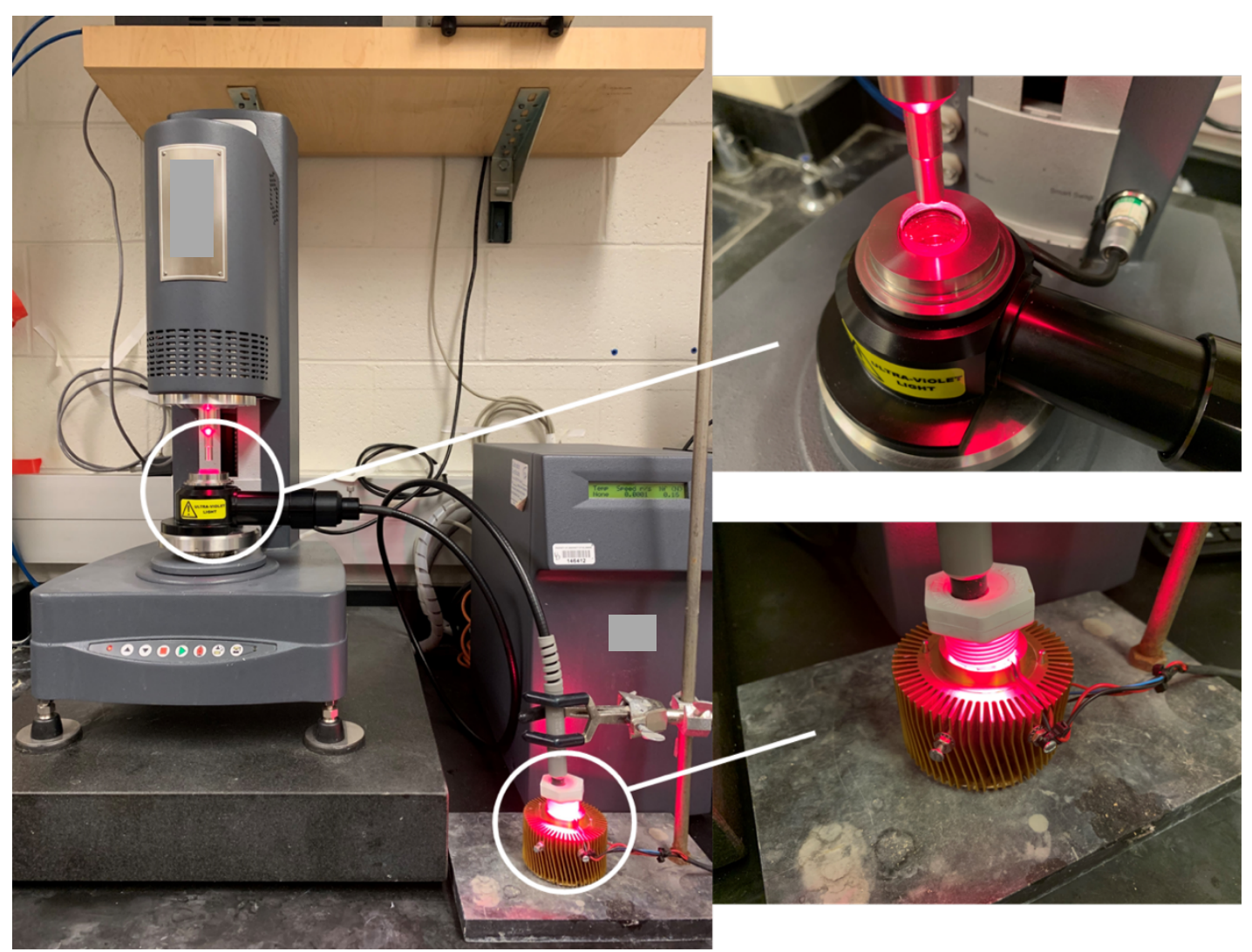

Fig S33. Time sweep experiments on pre-hydrogel solution (A) without light and (B) with light but without photocatalyst. (C) Experimental setup for oscillatory rheometry. The 660 $\mathrm{nm}$ red light was introduced to the rheometer through a fiber optic cable. 


\section{Part IV: 3D cell encapsulation study}

\subsection{General considerations}

The far-red/NIR light source for cell culture experiments was introduced using a custom light source displayed in Fig S34, which is configured to carry out up to six cell culture experiments with simultaneous irradiation. The light source was constructed from six 'deep red' Cree XLamp XP-E "3 up" High Power LED Star (CREEXPE-DRD-3) that were purchased from LED Supply (https://www.ledsupply.com/leds/cree-xlamp-xpe-highpower-led-star). Also purchased from LED Supply were the heat sink (https://www.ledsupply.com/led-heatsinks/makersled-heatsink-kit) and driver (1000ma wired version: https://www.ledsupply.com/led-drivers/mean-well-ldd-h-series-cc-stepdown-mode). For cell culture experiments, petri dishes were located $10 \mathrm{~cm}$ from the light source. The light intensity $10 \mathrm{~cm}$ from the light source was measured to be $180 \mathrm{~mW} / \mathrm{cm}^{2}$ with a Coherent FieldMax-Top Optical Power Meter equipped with a PM10 sensor.

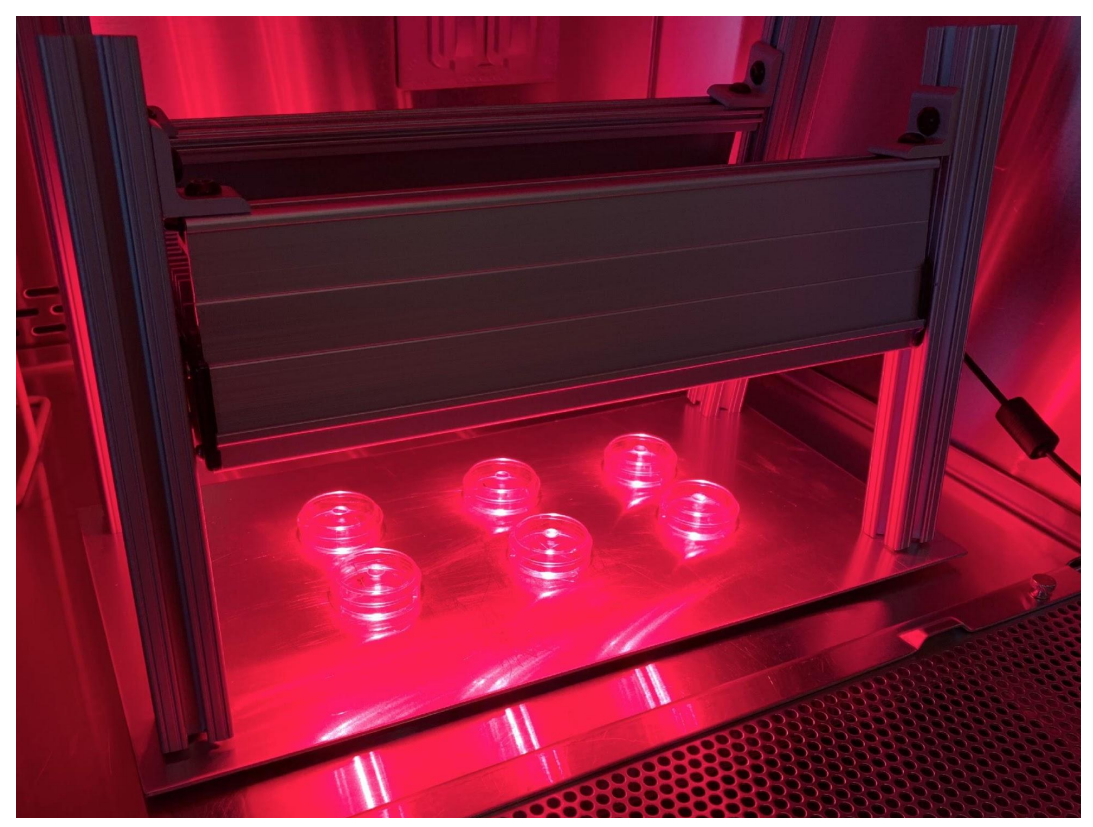

Fig S34. Experimental setup for cell encapsulation (described in S4.3).

\subsection{Preparation of cell spheroids:}

'LNCaP PCa cells were obtained from American Type Culture Collection (ATCC, Manassas, VA). Cells were seeded onto two $75-\mathrm{cm}^{2}$ tissue culture flasks (Celltreat) at a density of $1 \times 10^{6}$ cells $/ \mathrm{mL}$ and maintained in cell culture media (RPMI-1640, ATCC) supplemented with $5 \%(\mathrm{v} / \mathrm{v})$ fetal bovine serum (FBS) and $100 \mu \mathrm{g} / \mathrm{mL}$ streptomycin sulfate in $0.085 \%(\mathrm{v} / \mathrm{v})$ saline $(\mathrm{P} / \mathrm{S})$ at $37{ }^{\circ} \mathrm{C}$ with $5 \% \mathrm{CO}_{2}$. Media was changed every other day. At $75 \%$ confluency, cells were trypsinized with $0.25 \%(\mathrm{w} / \mathrm{v})$ trypsin containing ethylenediaminetetraacetic acid (EDTA.4Na). $2 \mathrm{~mL}$ of cell suspension was aliquoted to each well of an agarose microwell plate (0.02 wt\%, Fisher Scientific), prepared as previously described, ${ }^{2}$ at a concentration of $1.6 \times 10^{5} \mathrm{cells} / \mathrm{mL}$. After 2-3 days, spheroids 
with a diameter around $100 \mu \mathrm{m}$ were observed. The agarose hydrogel replicas containing the spheroids were then turned upside down inside the wells of a 12-well plate and tapped gently to recover spheroids from the microwells. The contents of every 6 wells of the 12well plate were transferred to a $15 \mathrm{~mL}$ centrifuge tube and spheroids were let to settle down for 5 min.

\subsection{Cell encapsulation (Results displayed in Fig 6A, Fig S34)}

The spheroids pellets were resuspended into a media (161 $\mu \mathrm{L}, \mathrm{RPMI}-1640$, ATCC) solution of HA-dTCO $(7.8 \mathrm{mg} / \mathrm{mL})$, SiR $(71 \mu \mathrm{M})$, and catalase $(50 \mathrm{mg} / \mathrm{mL})$. This cell suspension was then mixed with a PBS solution of HA-DHTz $(127 \mu \mathrm{L})$ to result in final concentrations of HA-dTCO $(4.4 \mathrm{mg} / \mathrm{mL}), \mathrm{HA}-\mathrm{DHTz}(8.8 \mathrm{mg} / \mathrm{mL}), \operatorname{SiR}(1 \mathrm{~d})(40 \mu \mathrm{M})$ and catalase $(2.5 \mathrm{mg} / \mathrm{mL})$. The suspension was transferred to glass-bottom dishes ( $40 \mu \mathrm{L} / \mathrm{dish})$ (Cat \#P35G-1.5-7-C, MatTek) and then exposed to far-red light $\left(660 \mathrm{~nm}, 180 \mathrm{~mW} / \mathrm{cm}^{2}\right)$ for 10 minutes (the dish was flipped after the $1^{\text {st }}$ minute of irradiation to prevent spheroid settle down) to initiate gelation before adding cell culture medium. Media changes were performed after first 30 minutes and then every other day.

\subsection{Cell viability assay (Results displayed in Fig 6E, Fig S35-37)}

Cell-laden hydrogels were stained with a commercially available cell viability staining kit according to manufacturer's protocol (LIVE/DEAD, Thermo Fisher Scientific) on days 1, 7 and 14 . A mixture containing $4 \mu \mathrm{M}$ of both calcein-AM and ethidium homodimer-1 in PBS (1x) was added to the MatTek dish and the cells were incubated at $37^{\circ} \mathrm{C}$ for 15 min then washed 3 times with PBS (1x). Confocal microscopy images were taken of three biological replicates using a Zeiss LSM 880 confocal microscope with a 10X Plan Apochromat (N.A. 0.7) objective. Maximum intensity projections were created using ZEN Software (ZEISS ZEN, Peabody, MA). Maximum projection images were imported into ImageJ for live/dead quantification. The excitation/emission wavelengths for Calcein-AM were $488 / 515 \mathrm{~nm}$, and for Ethidium homodimer-1 were 528/671 nm. The red and green channels were isolated and the fluorescence intensity was measured for each channel separately. Viability was quantified based on the calcein positive cell number using ImageJ software. 


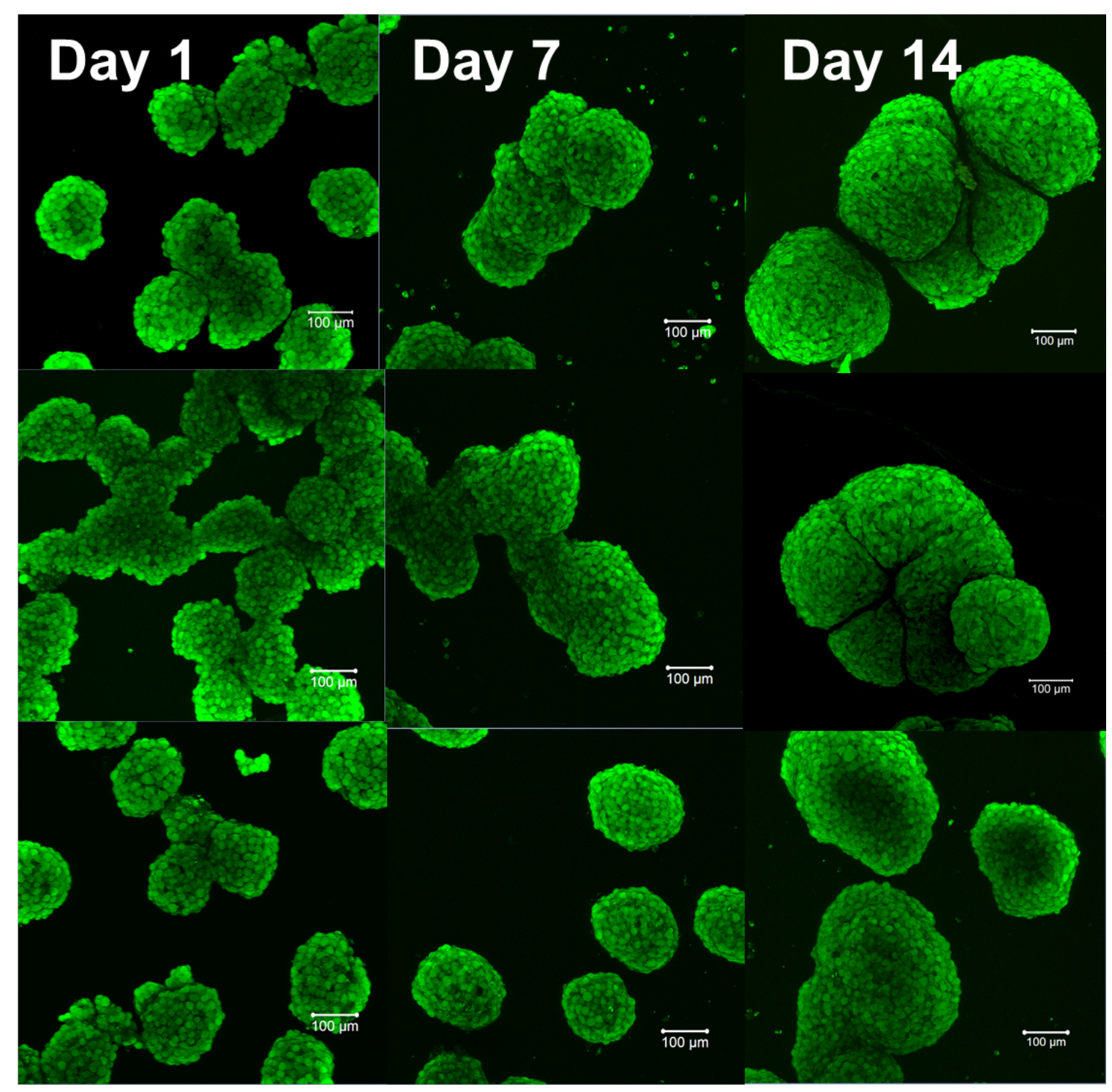

Fig S35. Live/dead assay of LnCaP spheroids (repeat 1, acquired with Airyscan) 


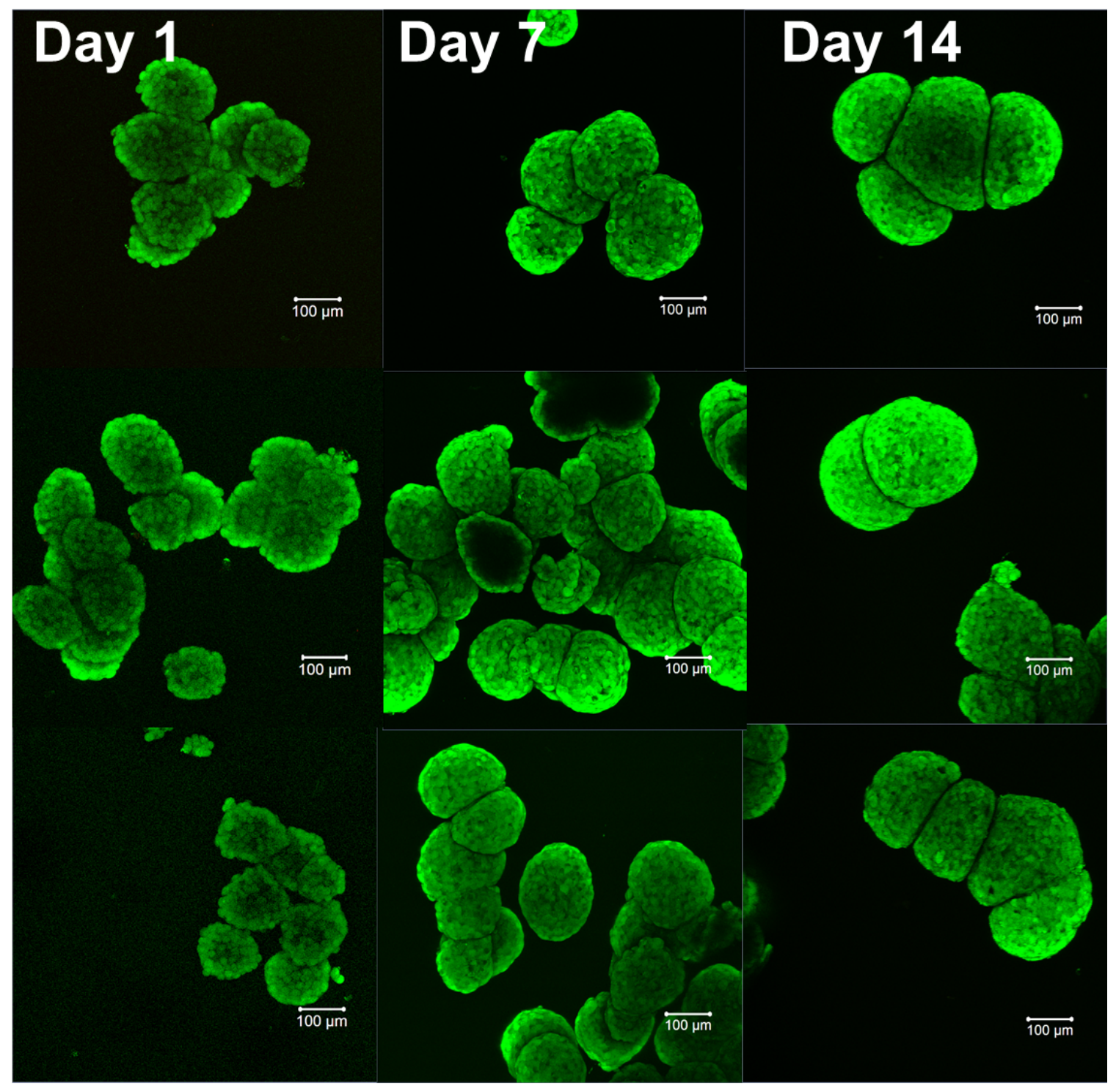

Fig S36. Live/dead assay of LnCaP spheroids (repeat 2, acquired with Airyscan). 


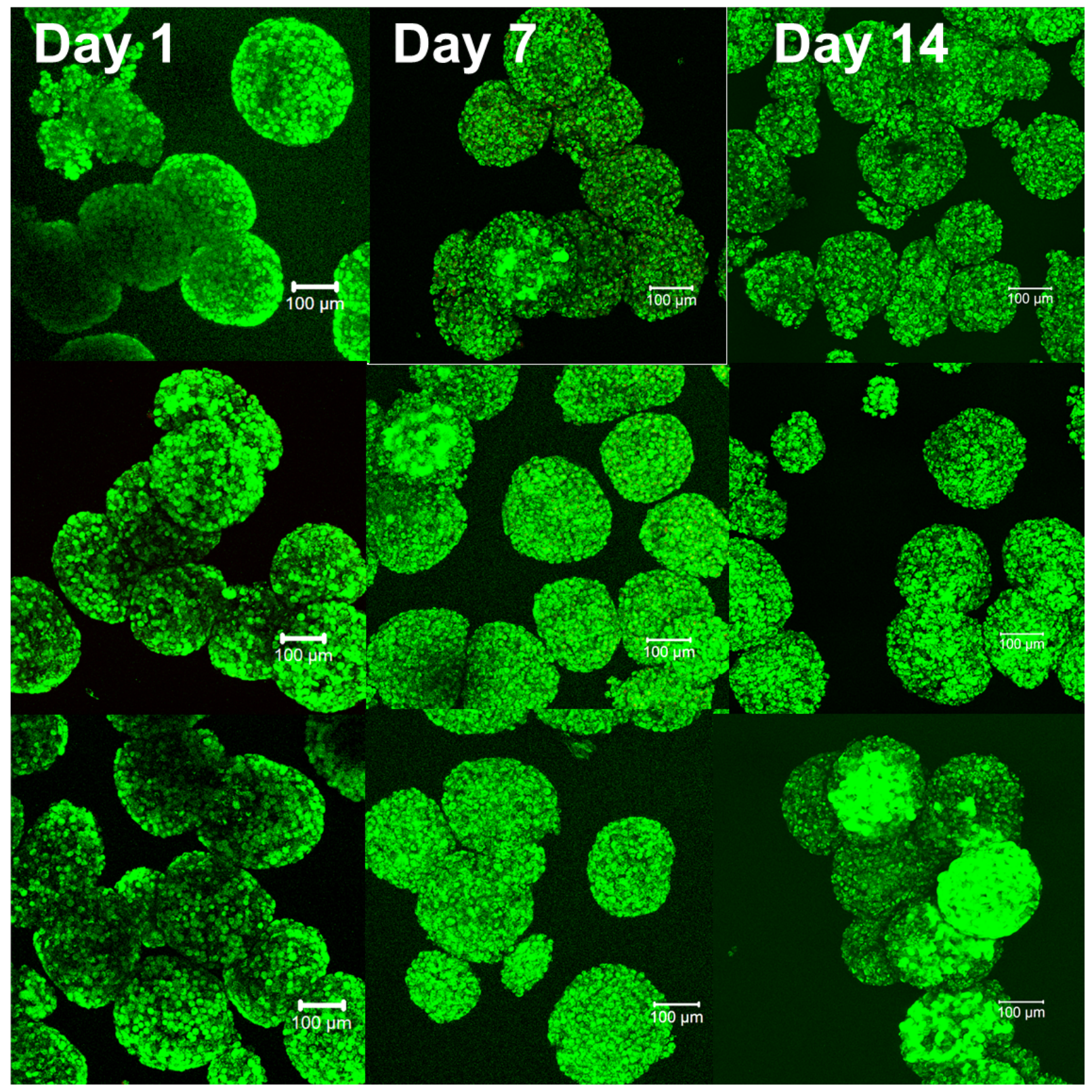

Fig S37. Live/dead assay of LnCaP spheroids (repeat 3, acquired without Airyscan, thus image resolution different from Fig $\mathbf{S 3 5}, \mathbf{3 6}$ ) 
Fig S38. Separate display of green (live) and red (dead) channels for LnCaP spheroids stained with Calcein AM (Excitation/emission 488/515 nm) and ethidium homodimer-1 (528/671 nm).

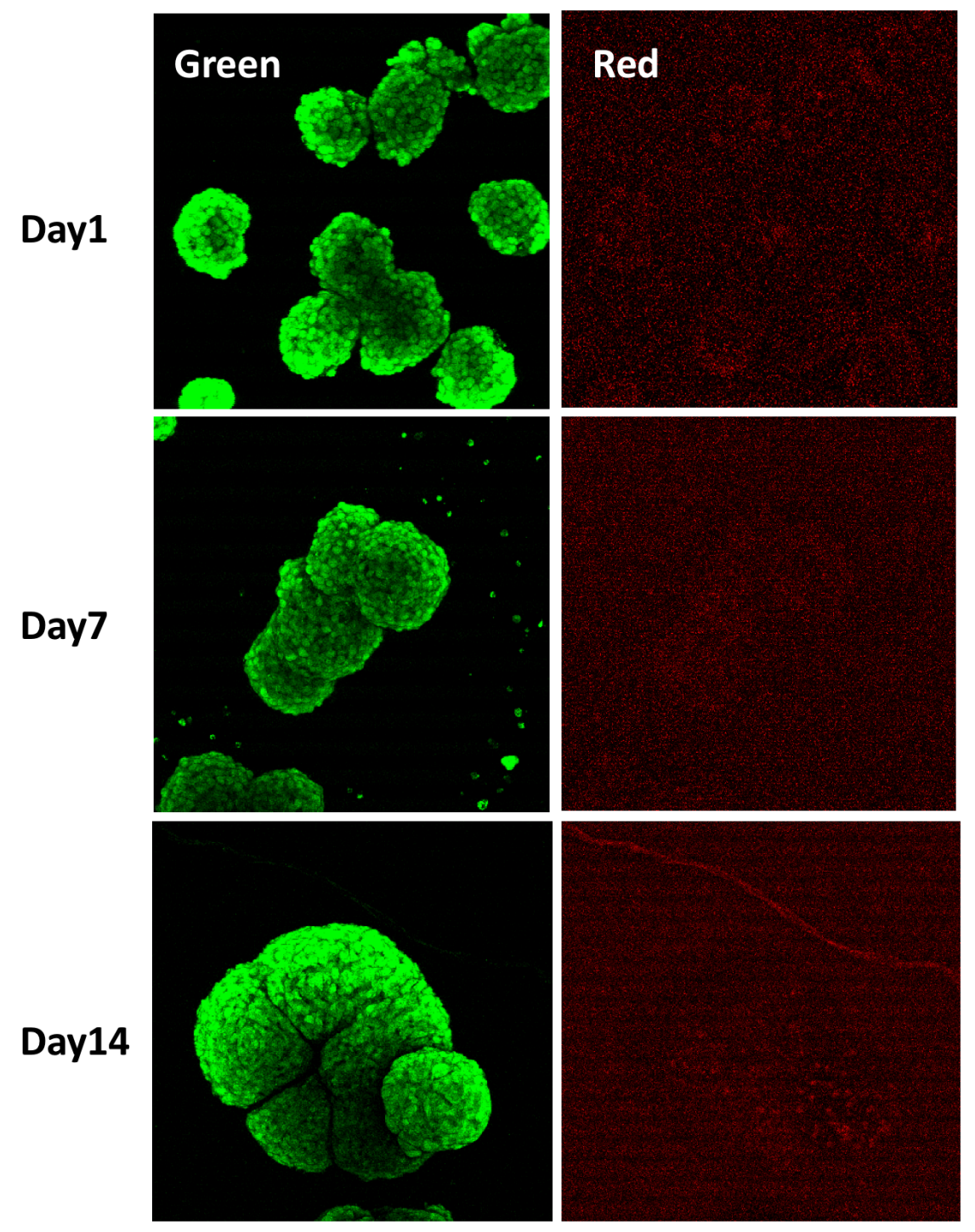




\section{Part V: Hydrogelation studies in live mice}

\subsection{General consideration}

All the fluorescent total radiant efficiency images were measured using IVIS Spectrum in vivo imaging system (PerkinElmer Model\# 124262). The imaging acquisition parameters were kept the same for all the imaging experiments $(\mathrm{Ex} / \mathrm{Em}=757 \mathrm{~nm} / 781 \mathrm{~nm}$; exposure time $=2 \mathrm{~s})$. Female nude mice $(4-6$ weeks old $)$ were used in all in vivo experiments.

\subsection{Preparation of hydrogel precursor solution}

HA-dTCO (0.42 mg) was dissolved in PBS buffer $(42 \mu \mathrm{L})$ at $37^{\circ} \mathrm{C}$ overnight on thermomixer (Eppendorf, $600 \mathrm{rpm})$. Cy7-Methyltetrazine $(6 \mu \mathrm{g}$, Click Chemistry Tools, Scottsdale, AZ) was added into the HA-dTCO PBS solution and incubated for $1 \mathrm{~h}$ to yield a solution of Cy7-HA-dTCO. Then a hydrogel precursor solution was prepared with the desired concentration of each component: Cy7-HA-dTCO $(4.4 \mathrm{mg} / \mathrm{mL}, 2.5 \mathrm{mM}$ for dTCO, $50 \mu \mathrm{M}$ for Cy7), HA-DHTz (8.8 mg/mL, $2 \mathrm{mM}$ for DHTz), SiR catalyst $1 \mathrm{~d}(40 \mu \mathrm{M})$ and catalase $(2.5 \mathrm{mg} / \mathrm{mL}, 10 \mu \mathrm{M})$.

\subsection{Study of the fluorescence signal change before and after in vitro gelation}

The fluorescent signal before and after light-induced gelation was measured using IVIS Spectrum in vivo imaging system. In brief, $40 \mu \mathrm{L}$ hydrogel precursor solution described in S5.2 was added into a 96 black strip plate (Thermo Scientific), divided into two groups and the fluorescence signal was measured. One group $(n=3)$ was irradiated with far$\mathrm{red} / \mathrm{NIR}$ light $\left(660 \mathrm{~nm}, 530 \mathrm{~mW} / \mathrm{cm}^{2}, 5 \mathrm{~min}\right)$, while the other was kept in dark. All the samples were then kept in dark for another $15 \mathrm{~min}$ and fluorescence signal was measured. The results were presented as the average total radiant efficiency of three wells. The fluorescent signal of the wells in two groups was compared using paired t-test. 

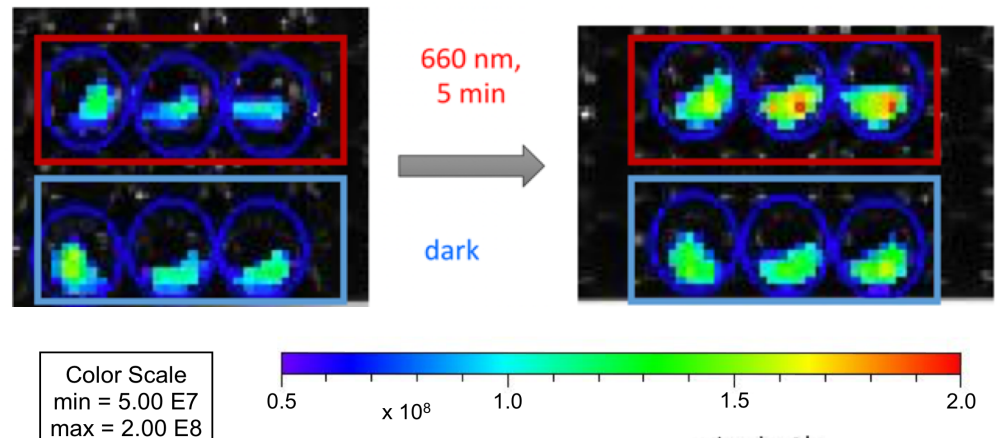

0.5

$\max =2.00 \mathrm{E} 8$

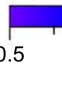

$\times 10^{8}$

1.0

Radiant Efficiency

1.5

$\left(\frac{p i s e c i \mathrm{~cm}^{2} / \mathrm{sy}}{\mu \mathrm{w} / \mathrm{cm}^{2}}\right.$

Fig S39. Fluorescent images of the hydrogel precursor solution $(n=3)$ before (upper left) and after far-red/NIR light irradiation (upper right). The fluorescent signal from the same amount of hydrogel precursor solutions $(n=3)$ that were kept in dark without light irradiation was also measured in parallel as control (lower panel). All the images were displayed using the same color scale. The results were presented as the average total radiant efficiency of three wells.

Paired $t$ test data of plate data

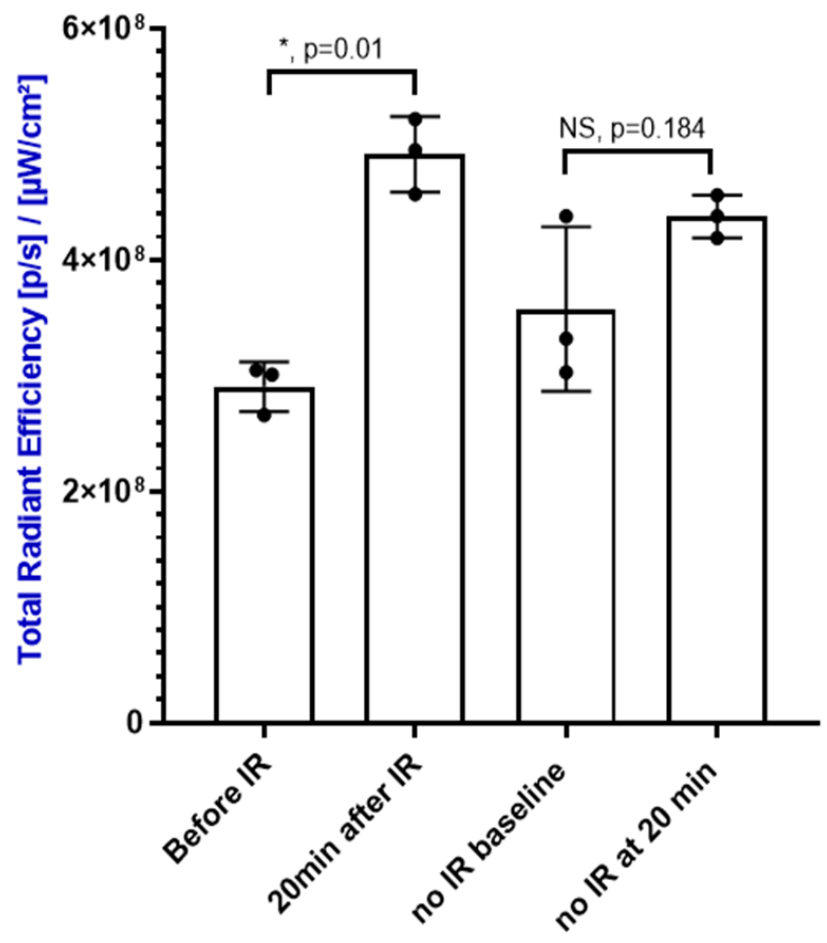

Fig S40. The change of the fluorescent signal intensity in the light-induced gelation of hydrogel precursor solution. When the hydrogel precursor solution was irradiated with farred light, the gelation and accompanying increase of fluorescent signal $(p=0.01)$ were 
observed. In contrast, the hydrogel precursor solutions that were kept in dark for 20min had no gelation and fluorescent signal change observed $(p=0.184)$.

\subsection{Study of in vivo gelation}

\subsubsection{The baseline correction before the injection of $\boldsymbol{I n}$ vivo gelation experiments}

Before administration into mice, the syringes each with $40 \mu \mathrm{L}$ hydrogel precursor solution described in S5.2 were imaged using the IVIS Spectrum in vivo imaging system. The image and the quantitative analysis of the total radiant efficiency of each syringe demonstrated that a similar amount of Cy7-HA-dTCO was injected into each of the mice.
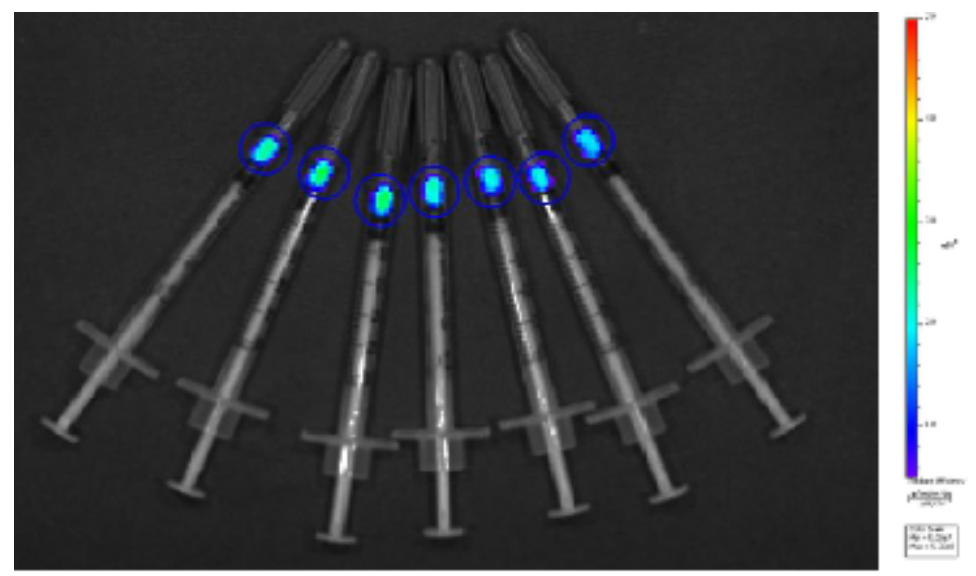

\begin{tabular}{|cc|}
\hline syringe & $\begin{array}{c}\text { Total Radiant } \\
\text { Efficiency } \\
{[\mathrm{p} / \mathrm{s}] /\left[\mu \mathrm{W} / \mathrm{cm}^{2}\right]}\end{array}$ \\
1 & $7.30 \mathrm{E}+08$ \\
2 & $8.07 \mathrm{E}+08$ \\
3 & $7.99 \mathrm{E}+08$ \\
4 & $7.01 \mathrm{E}+08$ \\
5 & $6.12 \mathrm{E}+08$ \\
6 & $5.96 \mathrm{E}+08$ \\
7 & $6.45 \mathrm{E}+08$ \\
\hline
\end{tabular}

Fig S41. (Left) Syringes containing the hydrogel precursor solutions described in $\mathbf{S 5 . 2}$ were analyzed using IVIS Spectrum in vivo imaging. (Right) The total radiant efficiency for the solutions loaded into syringes was similar across the study, indicating that a similar amount of hydrogel solution was injected into the different mice in this study.

\subsubsection{Time-course imaging experiment:}

The hydrogel precursor solutions described in $\mathbf{S 5 . 2}(40 \mu \mathrm{L})$ were injected into the subcutaneous space at the midline of the lower back of 3 different mice. After injection, the fluorescent signal at the injection site was measured by IVIS Spectrum in vivo imaging and recorded as the pre-IR value. The injection area was then irradiated with far-red/NIR light $\left(660 \mathrm{~nm}, 530 \mathrm{~mW} / \mathrm{cm}^{2}, 5 \mathrm{~min}\right)$. Then the fluorescent signal of the injection site was monitored at different time points over 72 hours. 
Time course in-vivo gelation
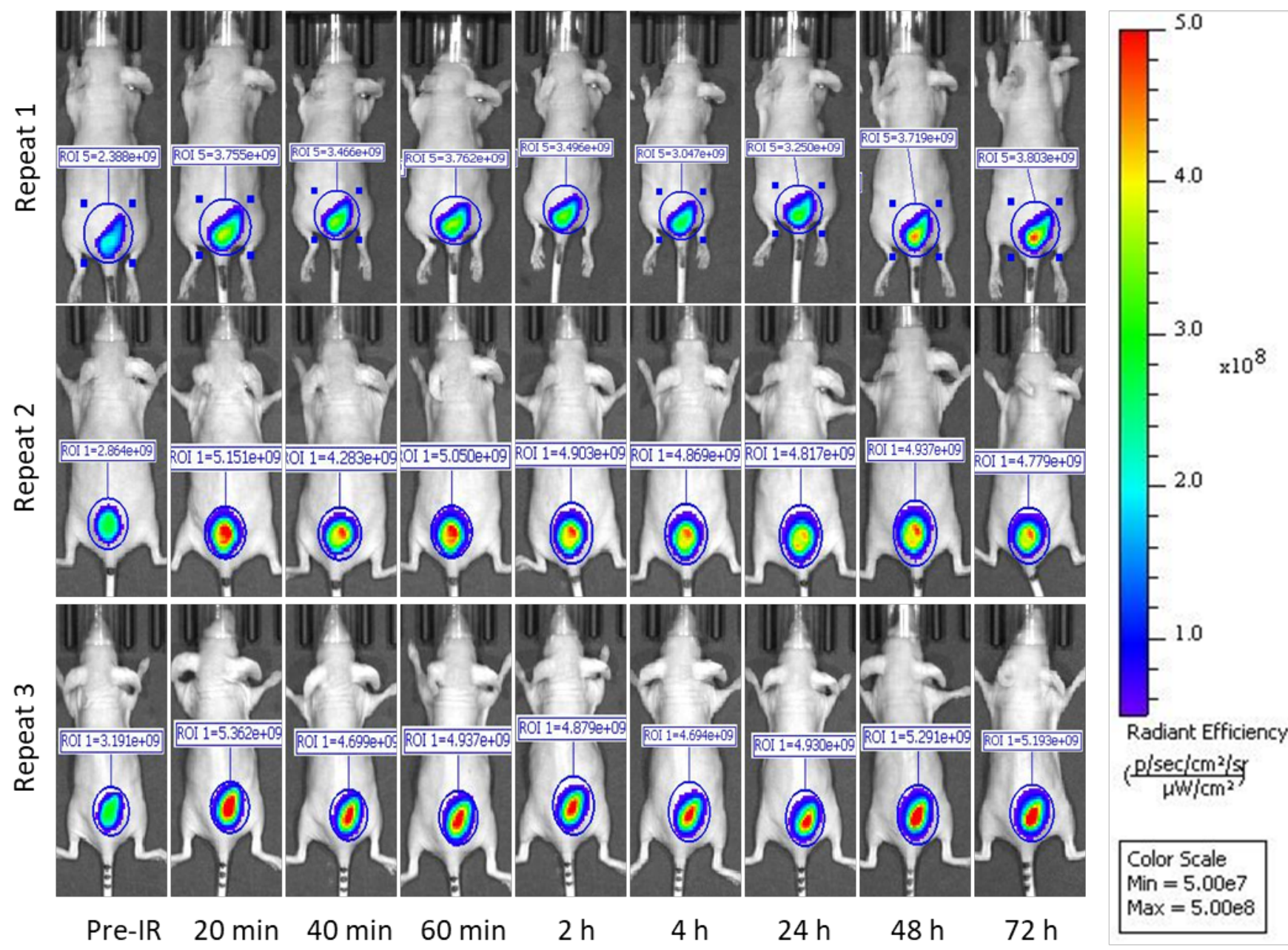

Fig S42. Serial fluorescent imaging experiment showed the change of fluorescent intensity of the injection site over 72 hours. 


\subsubsection{Control experiment without light:}

The hydrogel precursor solutions described in S5.2 $(40 \mu \mathrm{L})$ were injected into the subcutaneous space at the midline of the lower back of 3 different mice. After injection, the fluorescent signal at the injection site was measured and continuously monitored at different time points for 72 hours.

Control without light
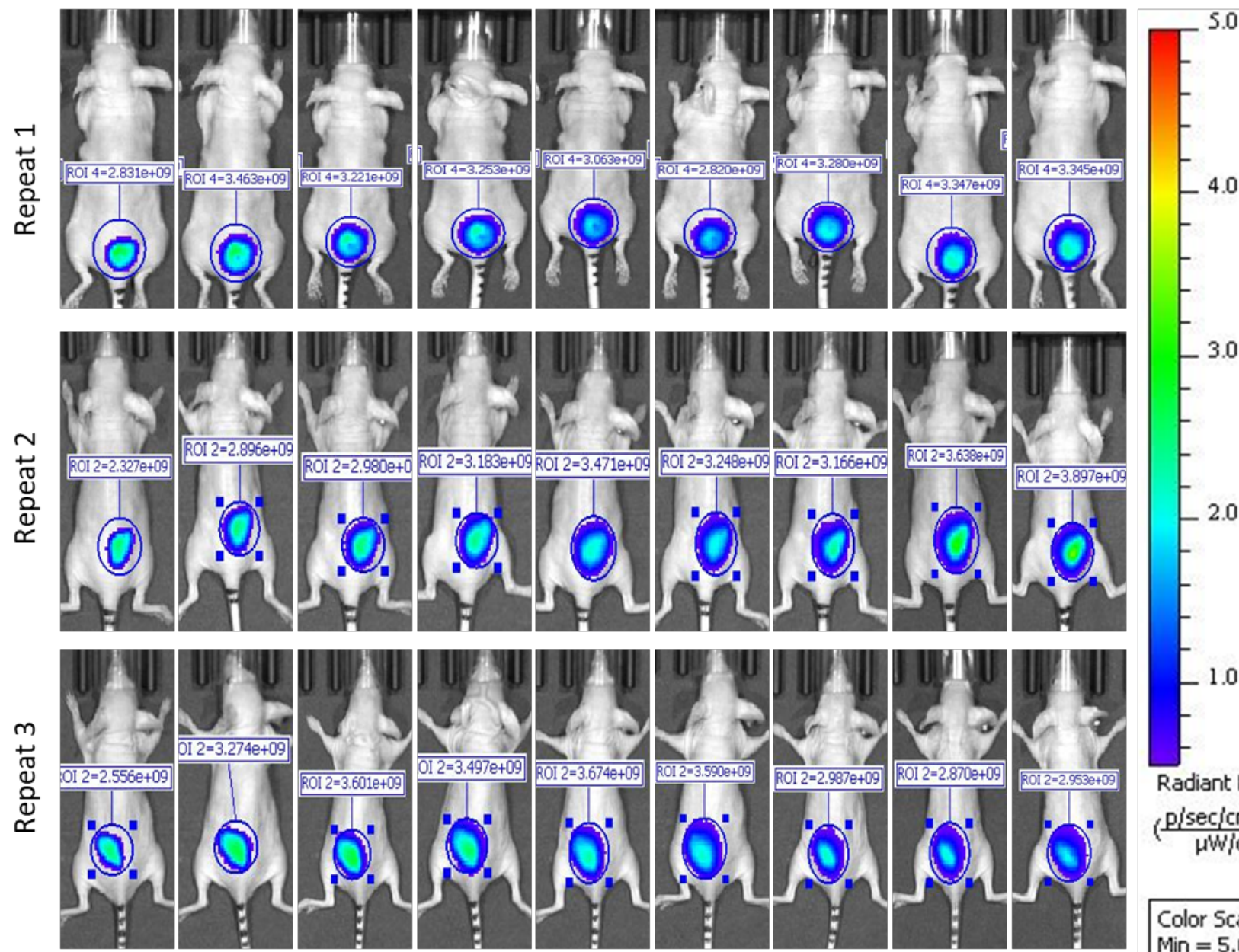

Pre-IR $20 \mathrm{~min} \quad 40 \mathrm{~min} \quad 60 \mathrm{~min}$

$2 \mathrm{~h}$

$4 \mathrm{~h}$

$24 \mathrm{~h}$

$48 \mathrm{~h}$

$72 \mathrm{~h}$

Fig S43. Serial fluorescent imaging results showed the change of fluorescent intensity of the injection site (no light irradiation) over 72 hours. 


\subsubsection{Control experiment injecting Cy7-HA-dTCO only:}

A PBS solution of Cy7-HA-dTCO ( $8.8 \mathrm{mg} / \mathrm{mL}, 2.5 \mathrm{mM}$ for dTCO, $50 \mu \mathrm{M}$ for Cy7, $40 \mu \mathrm{L}$ ) was injected into the subcutaneous space at the midline of the lower back. After injection, the fluorescence signal at the injection site was measured by IVIS Spectrum in vivo imaging and recorded as pre-IR value. The injection area was then irradiated with far$\mathrm{red} / \mathrm{NIR}$ light $\left(660 \mathrm{~nm}, 530 \mathrm{~mW} / \mathrm{cm}^{2}, 5 \mathrm{~min}\right)$. Then the fluorescence signal of the injection site was monitored at different time points for 72 hours.

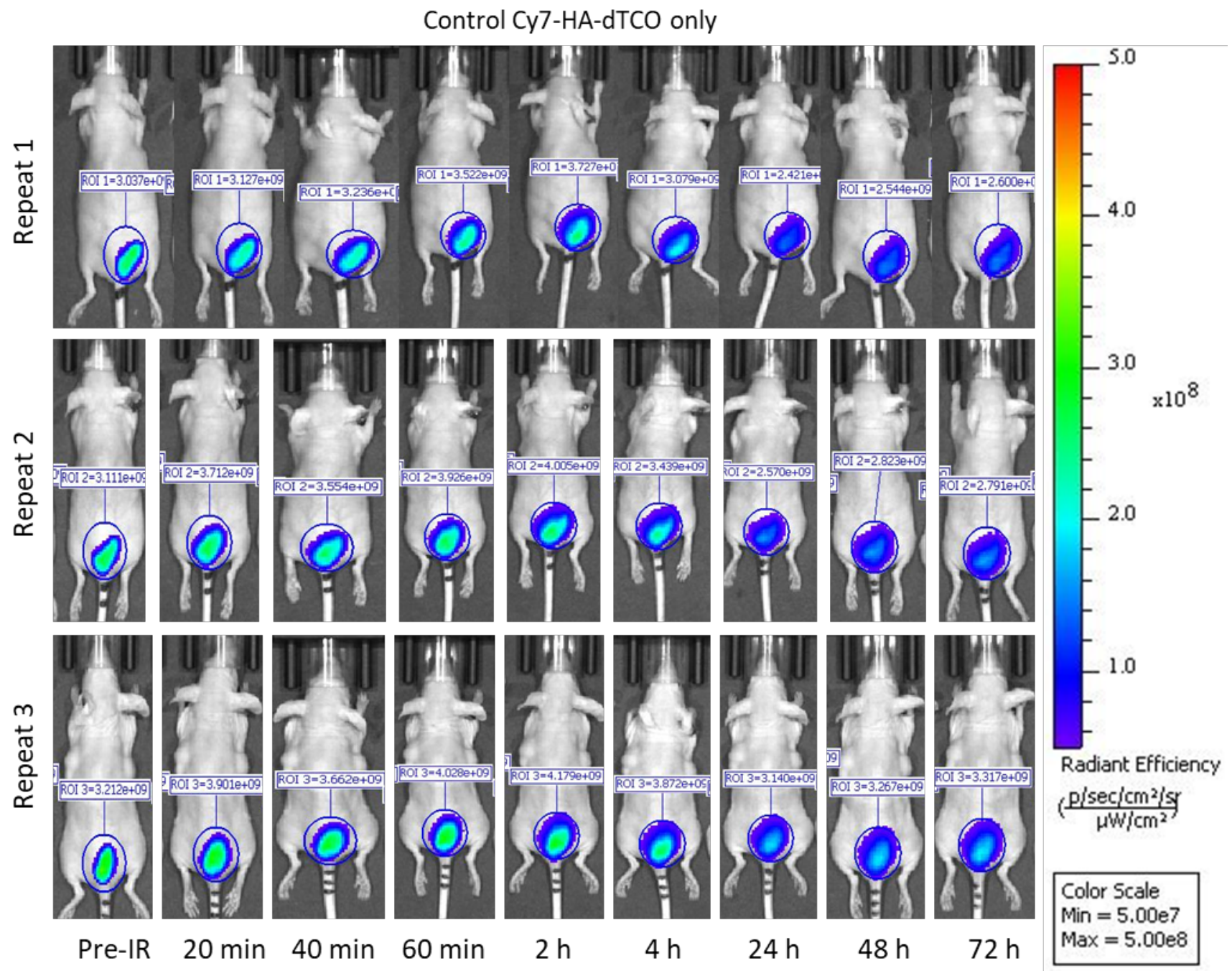

Fig S44. Serial fluorescent imaging results showed the change of fluorescent intensity of the injection site with Cy7-HA-dTCO only in the presence of light irradiation over 72 hours. 

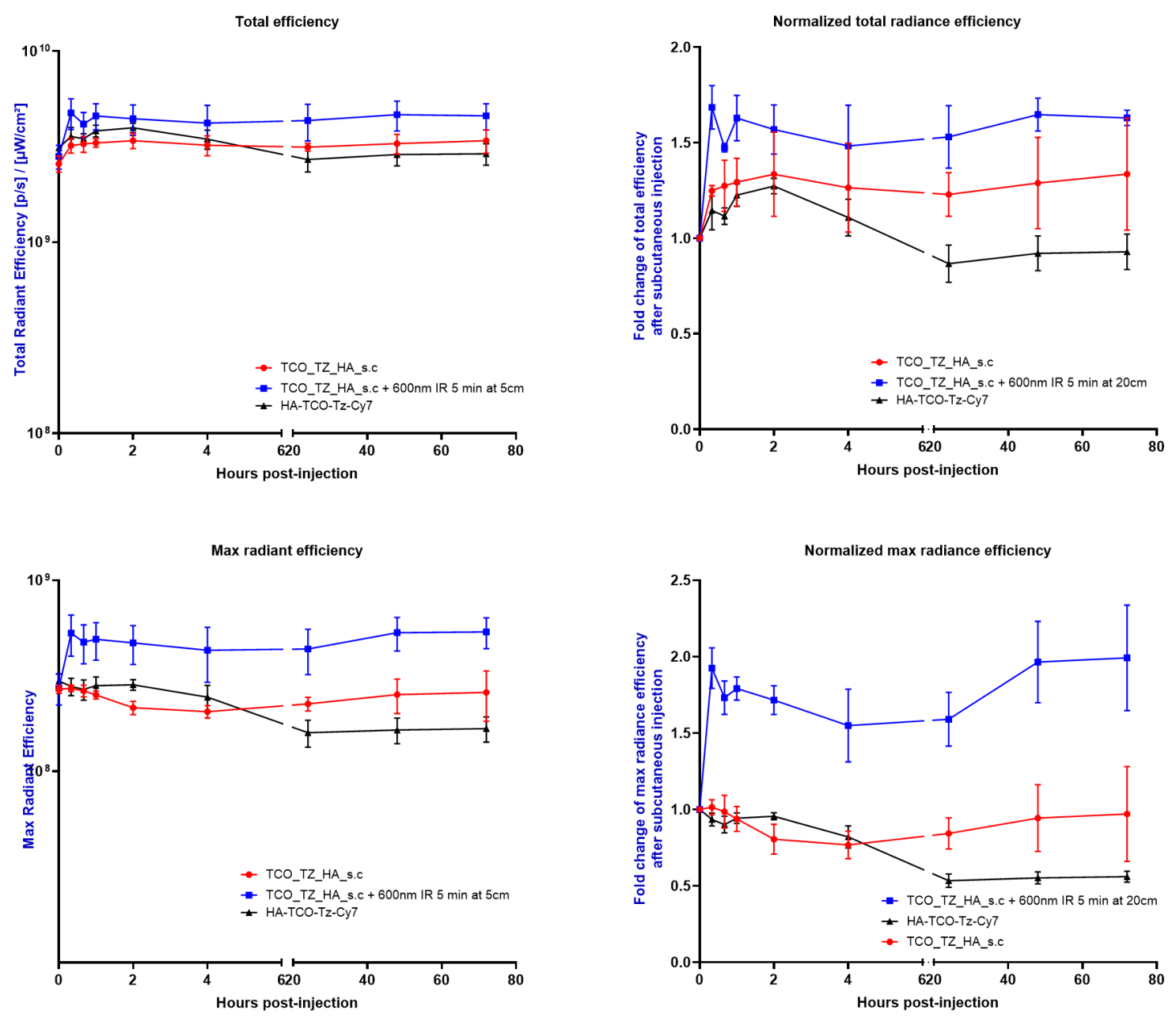

Fig S45. Quantitative analysis of serial fluorescence imaging results. For data normalization, the measured radiant efficiency at different time points was normalized to that of the pre-irradiation value (total or max), and expressed as fold-change. 


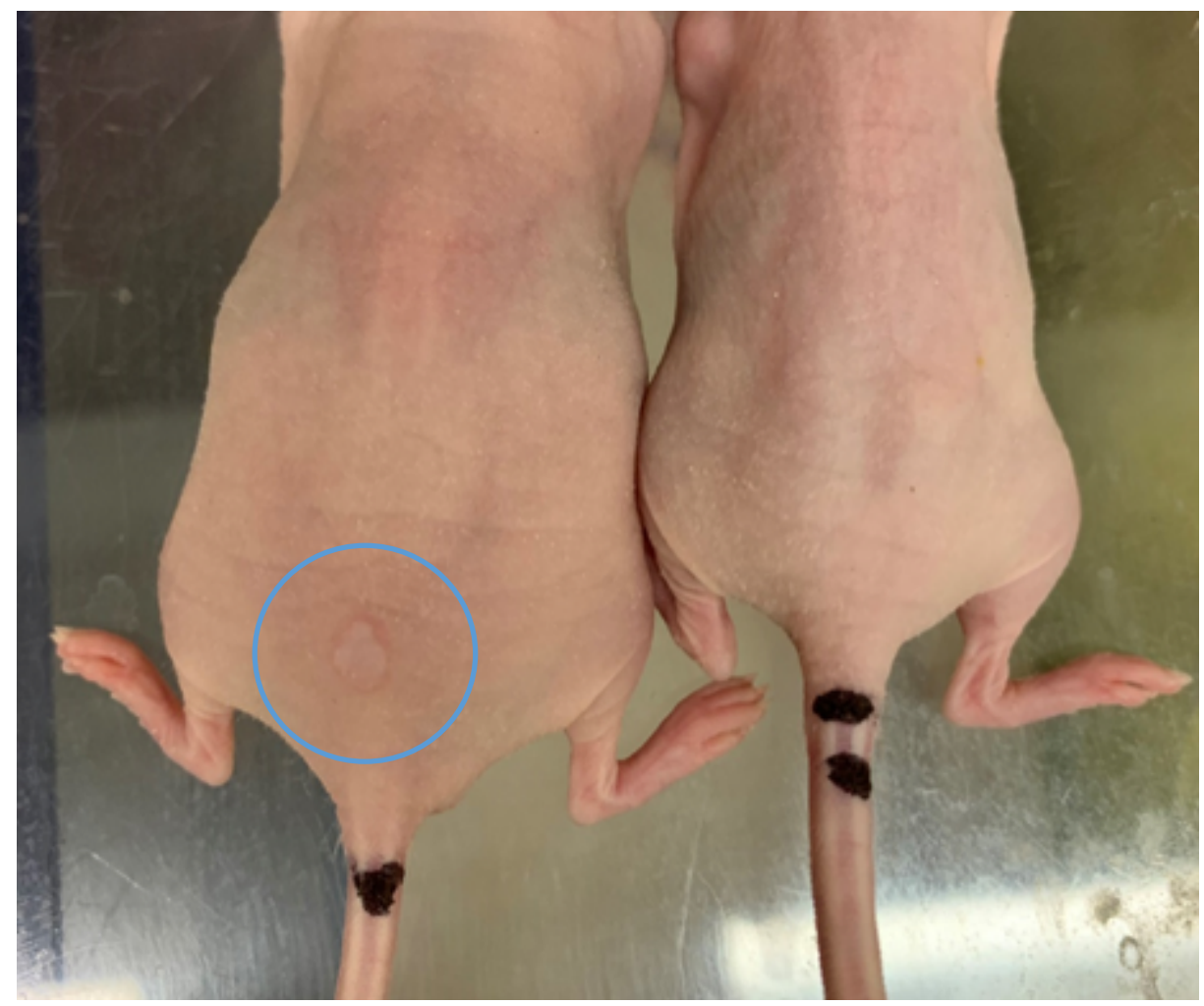

Fig S46. A bump was visible due to the hydrogel formation in experiment described in S5.5.1 (left), but not in experiment described in S5.5.2 (right, control without light). 


\subsection{Fluorescent imaging guided surgical experiments}

\subsubsection{Removal of the light-induced hydrogel}

The hydrogel precursor solutions described in $\mathbf{S 5 . 2}$ was subcutaneously injected into the mouse $(40 \mu \mathrm{L})$. After far-red/NIR light irradiation $\left(660 \mathrm{~nm}, 530 \mathrm{~mW} / \mathrm{cm}^{2}, 5 \mathrm{~min}\right)$ and another 15 min waiting period without irradiation to allow gel formation, the mouse was euthanized. Guided by fluorescence imaging as described in 5.1 , the gel was surgically recovered from the subcutaneous space. The mouse and the harvested gel were imaged as described.

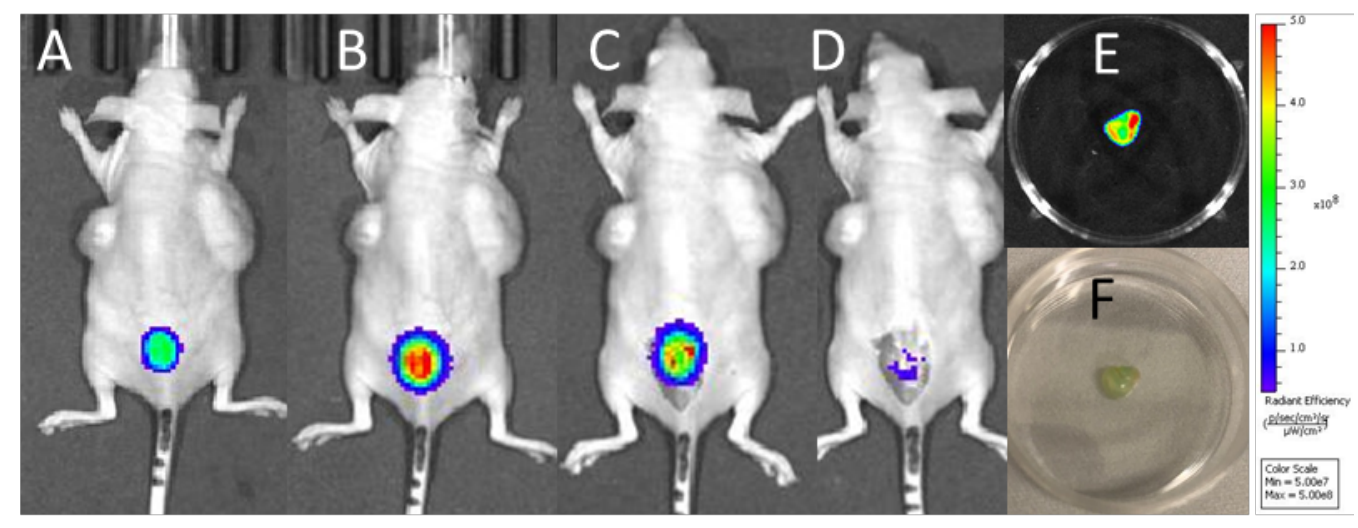

Fig S47. Fluorescent image of the mouse (A) Immediately after the hydrogel precursor solution injection. (B) after 5 min light treatment and another 15 min waiting period without irradiation(20 min post-injection). The fluorescent signal intensity increased due to gel formation. (C) After the skin removed. (D) After the hydrogel removed from the tissue. A faint fluorescence signal was detected in the tissue. (E) The fluorescence signal of the gel recovered from the mouse. $(F)$ The bright- field image of the gel recovered from the mouse. 


\subsubsection{Surgical experiments for control without light}

The hydrogel precursor solutions described in \$5.2 was subcutaneously injected into the mouse $(40 \mu \mathrm{L})$. The mouse was then euthanized 20 minutes post injection, and the skin was cut open. The surgery was performed in a similar way as described in S5.6.1. The tissue sample was then imaged by IVIS Spectrum in vivo imaging system.

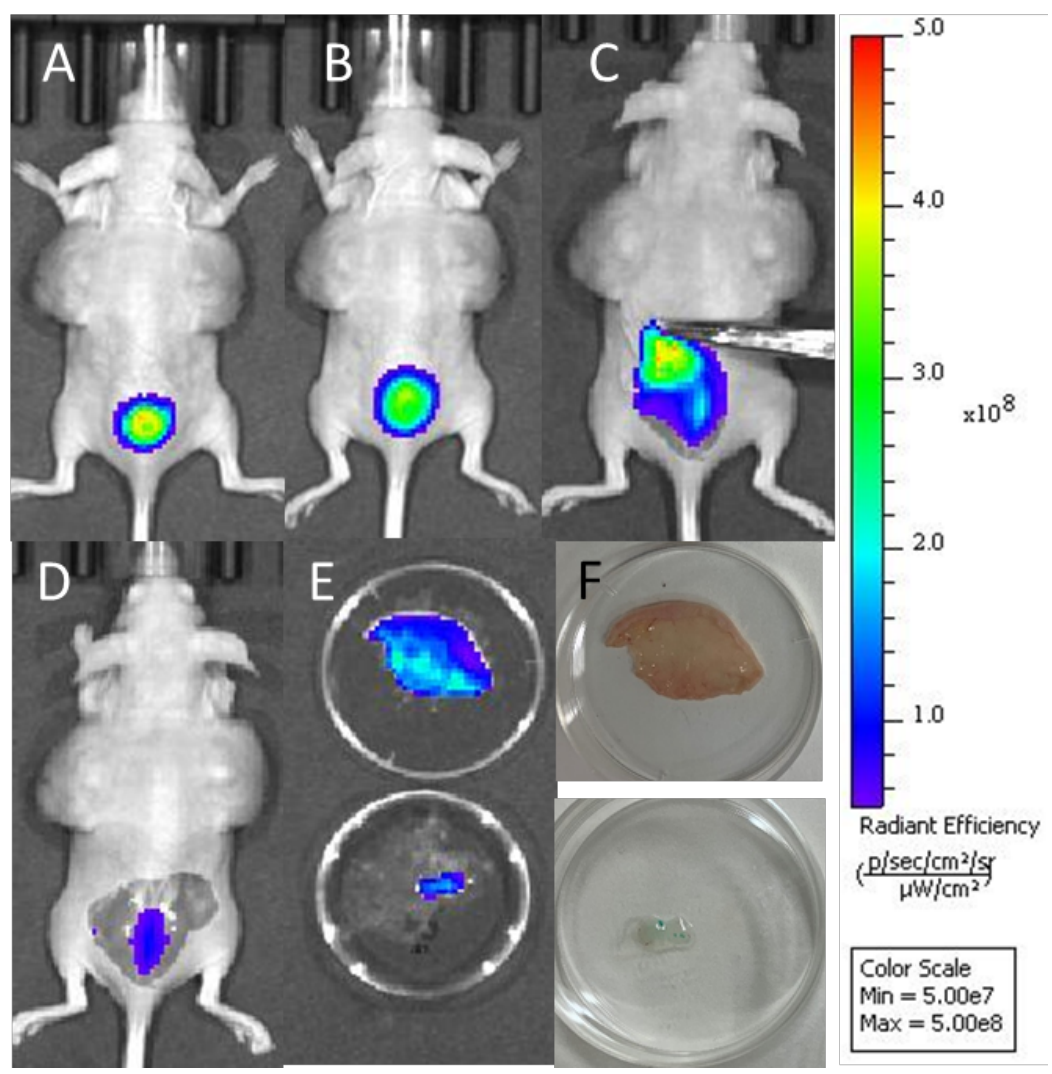

Fig S48. Fluorescent image of the mouse $(A)$ immediately after the hydrogel precursor solution injection and (B) 20 min after injection without light treatment. The fluorescent signal intensity did not increase significantly because there was minimal gel formation. (C) After the skin was removed. (D) After the tissue at the injected area was removed. A faint fluorescence signal was detected in the tissue. (E) The fluorescence signal of the tissue and injected material recovered from the mouse. (F) The bright-field image of the tissue and recovered material from the mouse after injection. 


\section{Part VI: Mechanistic study of the oxidation of DHT 6 catalyzed by SiR 1d}

\subsection{Relative rates of photocatalyzed oxidation of DHTz and oxidation of ABDA by singlet oxygen using SiR 1d vs methylene blue.}

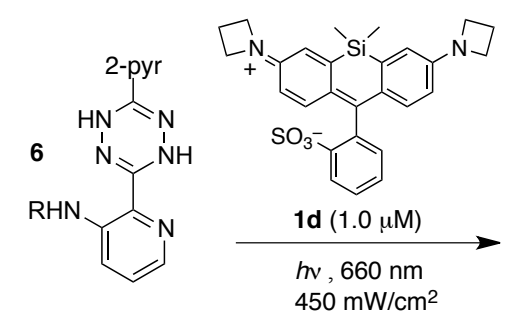

SiR-catalyzed oxidation of DHTz 6 . In a cuvette, a PBS solution $(2 \mathrm{~mL})$ of DHTz $6(35 \mu \mathrm{M})$ and $\operatorname{SiR} 1 \mathbf{d}(1 \mu \mathrm{M})$ was prepared from stock solutions. A LED source described in $\mathbf{S 2 . 1}$ $\left(660 \mathrm{~nm}, 450 \mathrm{~mW} / \mathrm{cm}^{2}\right)$ was used to irradiate from the top of the cuvette. The oxidation of DHTz 6 to Tz 7 was monitored by recording the absorbance at $354 \mathrm{~nm}$ every 10 seconds.
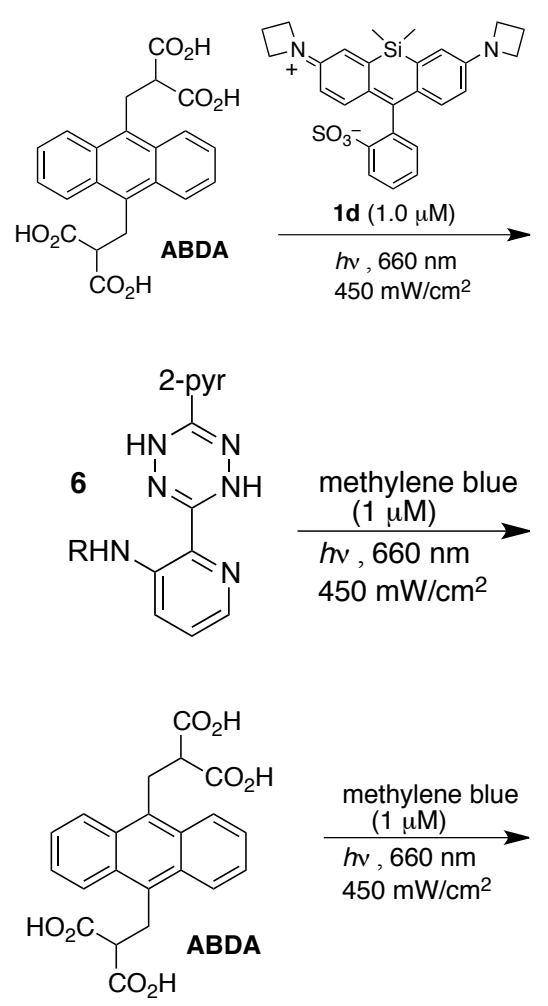

SiR-catalyzed reaction of ABDA. In a cuvette, a PBS solution $(2 \mathrm{~mL})$ of 9,10-Anthracenediyl-bis(methylene)dimalonic acid (ABDA) $(35 \mu \mathrm{M})$ and SiR 1d $(1 \mu \mathrm{M})$ was prepared from stock solutions. A LED source described in S2.1 (660 nm, 450 $\mathrm{mW} / \mathrm{cm}^{2}$ ) was used to irradiate from the top of the cuvette. The oxidation of ABDA was monitored by recording the absorbance at $402 \mathrm{~nm}$ every 10 seconds.

MB-catalyzed oxidation of DHTz 6 . In a cuvette, a PBS solution $(2 \mathrm{~mL})$ of DHTz $6(35 \mu \mathrm{M})$ and $\mathrm{MB}(2 \mu \mathrm{M})$ was prepared from stock solutions. A LED source described in $\mathbf{S 2 . 1}(660 \mathrm{~nm}$, $450 \mathrm{~mW} / \mathrm{cm}^{2}$ ) was used to irradiate from the top of the cuvette. The oxidation of DHTz 6 to Tz 7 was monitored by recording the absorbance at $354 \mathrm{~nm}$ every 2 seconds.

MB-catalyzed reaction of ABDA.In a cuvette, a PBS solution $(2 \mathrm{~mL})$ of 9,10-Anthracenediyl-bis(methylene)dimalonic acid (ABDA) $(35 \mu \mathrm{M})$ and $\mathrm{MB}(2 \mu \mathrm{M})$ was prepared from stock solutions. A LED source described in S2.1 $(660 \mathrm{~nm}, 450$ $\mathrm{mW} / \mathrm{cm}^{2}$ ) was used to irradiate from the top of the cuvette. The oxidation of ABDA was monitored by recording the absorbance at $402 \mathrm{~nm}$ every 2 seconds. 

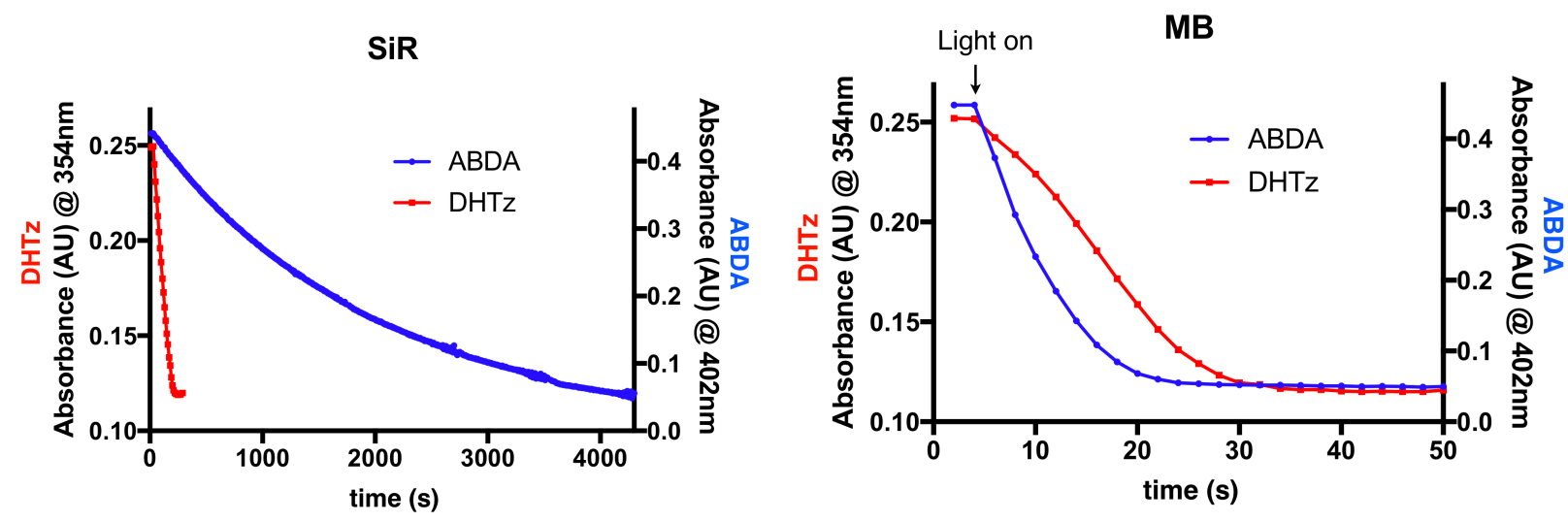

Fig S49. Relative rates of (left) SiR- and (right)-MB catalyzed oxidation of DHTz and ABDA.

\subsection{Effect of SiR concentration on the rate of DHTz oxidation.}

In a cuvette, a series of PBS solutions $(2 \mathrm{~mL})$ of DHTz $6(35 \mu \mathrm{M})$ and SiR 1d $(0.5,1,2$ $\mu \mathrm{M}$ respectively) were prepared from stock solutions. A LED source described in S2.1 $\left(660 \mathrm{~nm}, 450 \mathrm{~mW} / \mathrm{cm}^{2}\right)$ was used to irradiate from the top of the cuvette. The oxidation of DHTz 6 to Tz 7 was monitored by recording the absorbance at 354 nm every 10 seconds.

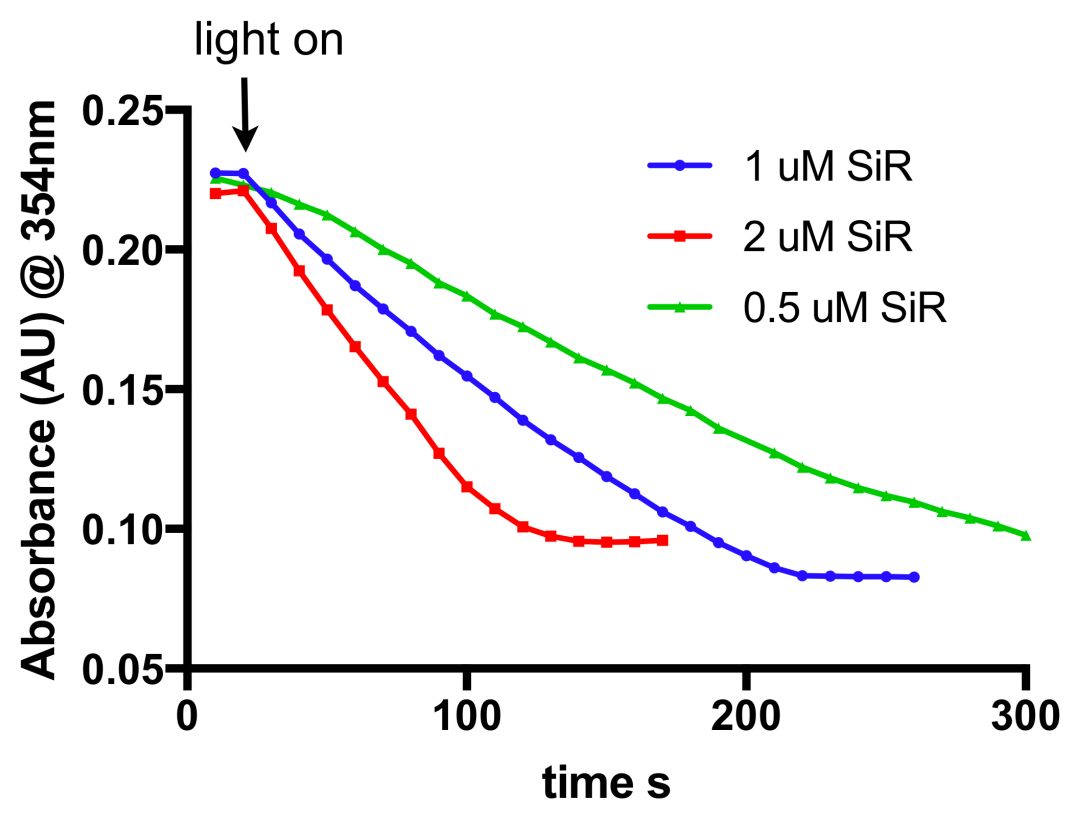

Fig S50. Effect of photocatalyst concentration on the rate of DHTz oxidation. 


\subsection{Effect of light power density on the rate of DHTz oxidation}

In a cuvette, PBS solutions $(2 \mathrm{~mL})$ of DHTz $6(35 \mu \mathrm{M})$ and SiR $1 \mathrm{~d}(1 \mu \mathrm{M})$ were prepared from stock solutions. The LED source described in S2.1 was distanced from the cuvette to deliver $660 \mathrm{~nm}$ light of different intensities $\left(18,45,90,180,315,450 \mathrm{~mW} / \mathrm{cm}^{2}\right.$ respectively, measured using an optical power meter) by irradiating the top of the cuvette. The oxidation of DHTz 6 to Tz 7 was monitored by recording the absorbance at $354 \mathrm{~nm}$ every 10 seconds.

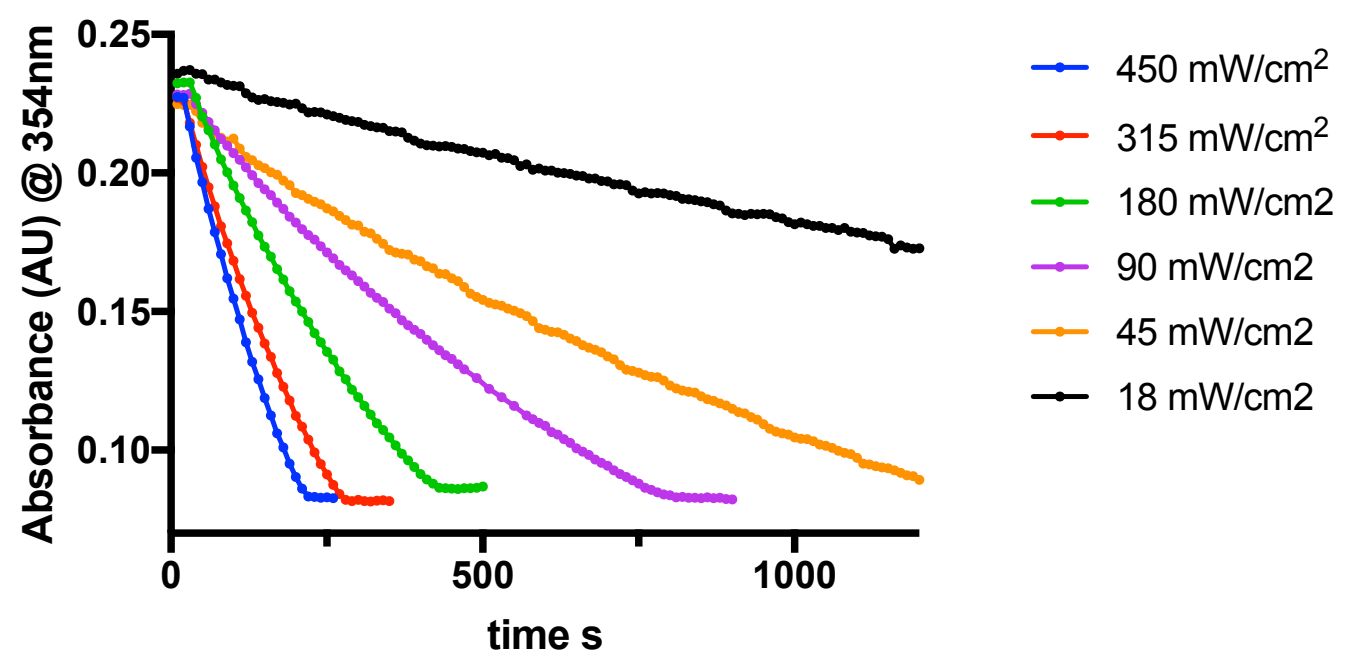

Fig S51. Effect of light power density on the rate of SiR-catalyzed DHTz oxidation. 


\subsection{Effect of DHTz concentration on rate.}

In cuvettes, a series of PBS solutions $(2 \mathrm{~mL})$ of differing concentrations of DHTz 6 and SiR 1d were prepared from stock solutions. The LED source described in $\mathbf{S 2 . 1}(660 \mathrm{~nm}$, $450 \mathrm{~mW} / \mathrm{cm}^{2}$ ) was used to irradiate from the top of the cuvette. The oxidation of DHTz 6 to Tz 7 was monitored by recording the absorbance at $354 \mathrm{~nm}$ every 10 seconds.

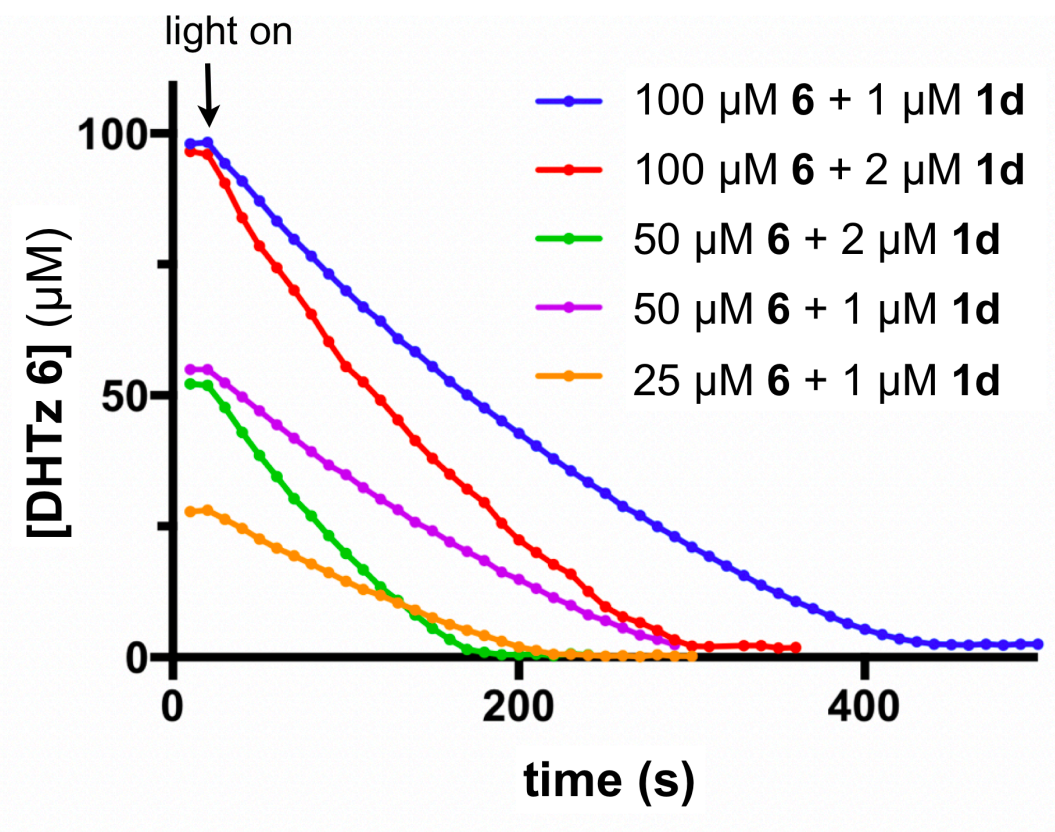

Fig S52. Effect DHTz concentraion on the rate of SiR-catalyzed DHTz oxidation. 


\subsection{UV-vis spectra of SiR 1d in the presence and absence of DHTz 6}

The UV-Vis spectra were recorded for a PBS solutions of SiR $1 \mathrm{~d}(8 \mu \mathrm{M}, 0.8 \mathrm{~mL})$, and $\mathrm{DHTz} 6$ was then added portion-wise to the solution to reach the concentration of $0.4,1.2$, 2.0 and $2.8 \mathrm{mM}$. UV-Vis spectra were recorded each time DHTz 6 was added. The UVVis spectra of a PBS solution of DHTz $6(0.8 \mathrm{mM}, 0.8 \mathrm{~mL})$ was also recorded for comparison.

\section{8 uM SiR 1d with DHT added}

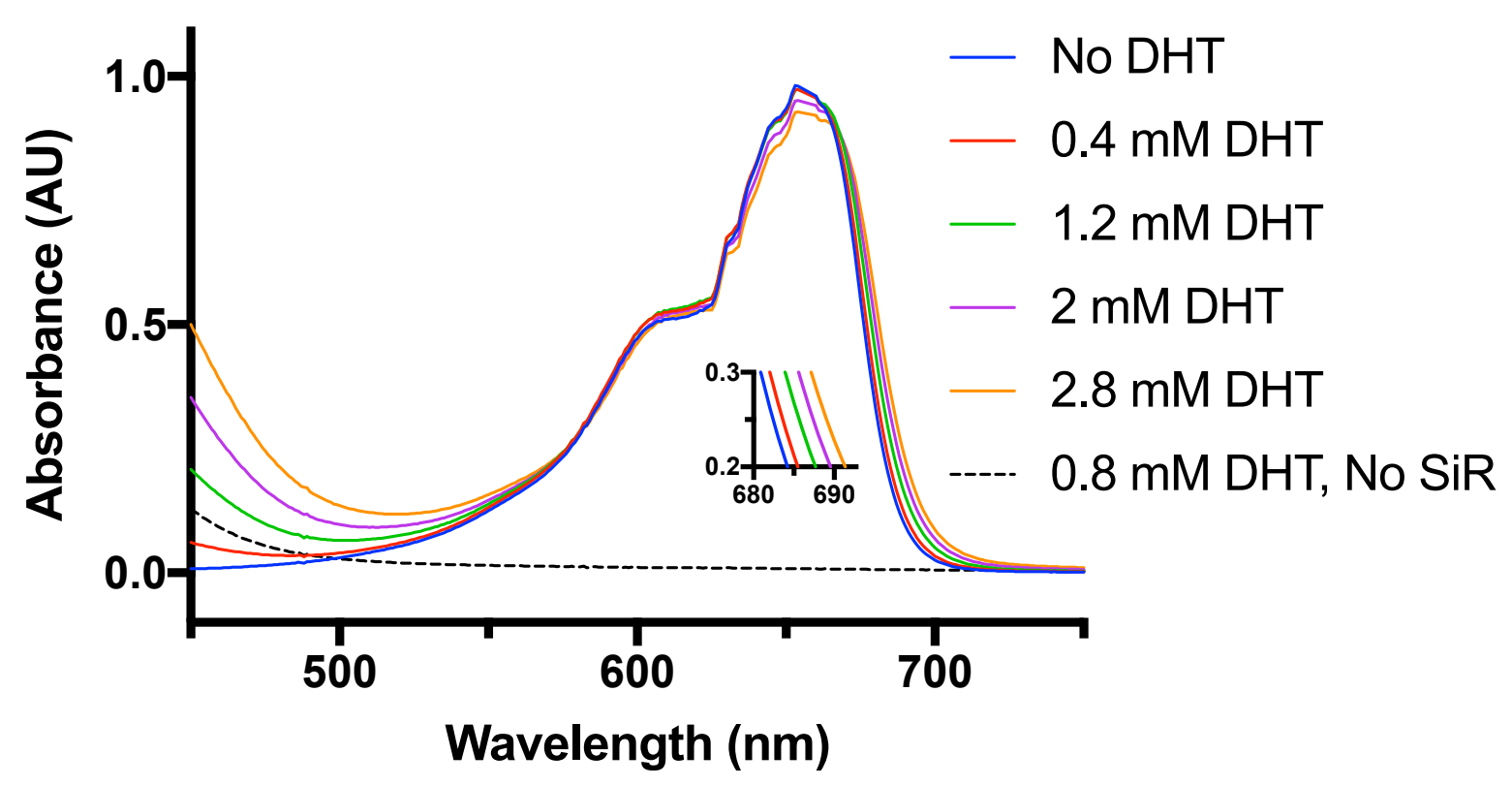

Fig S53. Spectra of solutions of SiR 1d $(8 \mu \mathrm{M})$ (blue spectrum), DHTz $6(0.8 \mathrm{mM}$, black dashed line) and of SiR 1d $(8 \mu \mathrm{M})$ containing varied amounts of DHTz $6(0.4 \mathrm{mM}-2.8$ $\mathrm{mM})$. 


\subsection{Effect of tetrazine or peroxide on DHTz oxidation rate.}

In cuvettes, PBS solutions $(2 \mathrm{~mL})$ of DHTz $6(35 \mu \mathrm{M})$ and SiR 1d $(1 \mu \mathrm{M})$ were prepared without additive or with $\mathrm{Tz} 7(200 \mu \mathrm{M}), \mathrm{H}_{2} \mathrm{O}_{2}(70 \mu \mathrm{M})$, or with both $7(35 \mu \mathrm{M})$ and $\mathrm{H}_{2} \mathrm{O}_{2}$ $(35 \mu \mathrm{M})$. An LED source described in $\mathbf{S 2 . 1}\left(660 \mathrm{~nm}, 450 \mathrm{~mW} / \mathrm{cm}^{2}\right)$ was used to irradiate from the top of the cuvette. The oxidation of DHTz 6 to Tz 7 was monitored by recording the absorbance at $354 \mathrm{~nm}$ every 10 seconds.

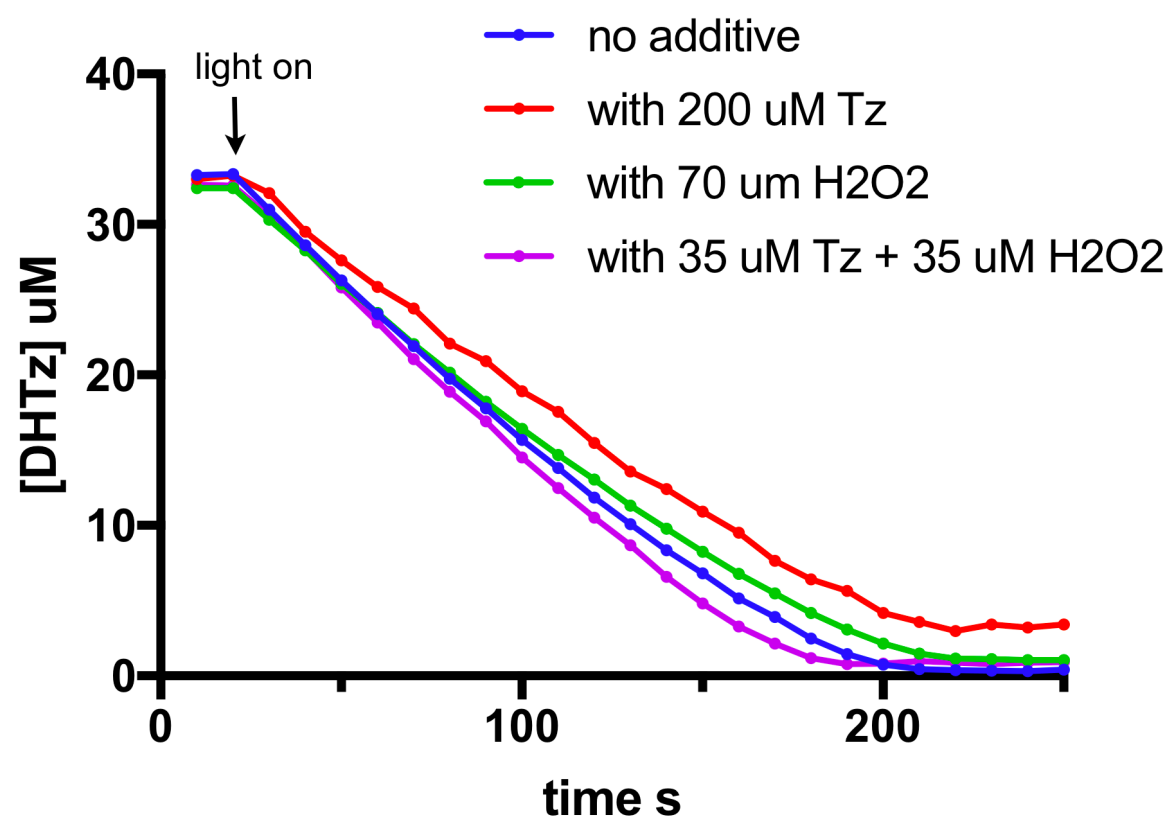

Fig S54. Tz 7 and $\mathrm{H}_{2} \mathrm{O}_{2}$ do not influence the rate of $\mathrm{DHTz}$ oxidation. 


\subsection{Effect of oxidation products on DHTz rate}

To determine if the products have an influence on the rate DHTz oxidation, a SiRcatalyzed DHTz oxidation reaction was allowed to go to completion with in situ monitoring of DHTz consumption. The lamp was turned off, and without adding additional catalyst, the mixture was spiked with additional DHTz starting material, the lamp turned on, and the consumption of $\mathrm{DHTz}$ starting material was again monitored. The process was repeated twice, and no change in reaction rate was observed.

Thus, In a cuvette, a PBS solution (2 mL) of DHTz $6(35 \mu \mathrm{M})$ and SiR $1 \mathrm{~d}(1 \mu \mathrm{M})$ was prepared from stock solutions. The LED source described in $\mathbf{S 2 . 1}\left(660 \mathrm{~nm}, 450 \mathrm{~mW} / \mathrm{cm}^{2}\right)$ was used to irradiate from the top of the cuvette. The oxidation of DHTz 6 to Tz 7 was monitored by recording the absorbance at $354 \mathrm{~nm}$ every 10 seconds. After the reaction finished, the light was turned off, more DHTz 6(35 $\mu \mathrm{M})$ was added, and light was turned back on and the reaction again monitored as before. The process was again repeated.

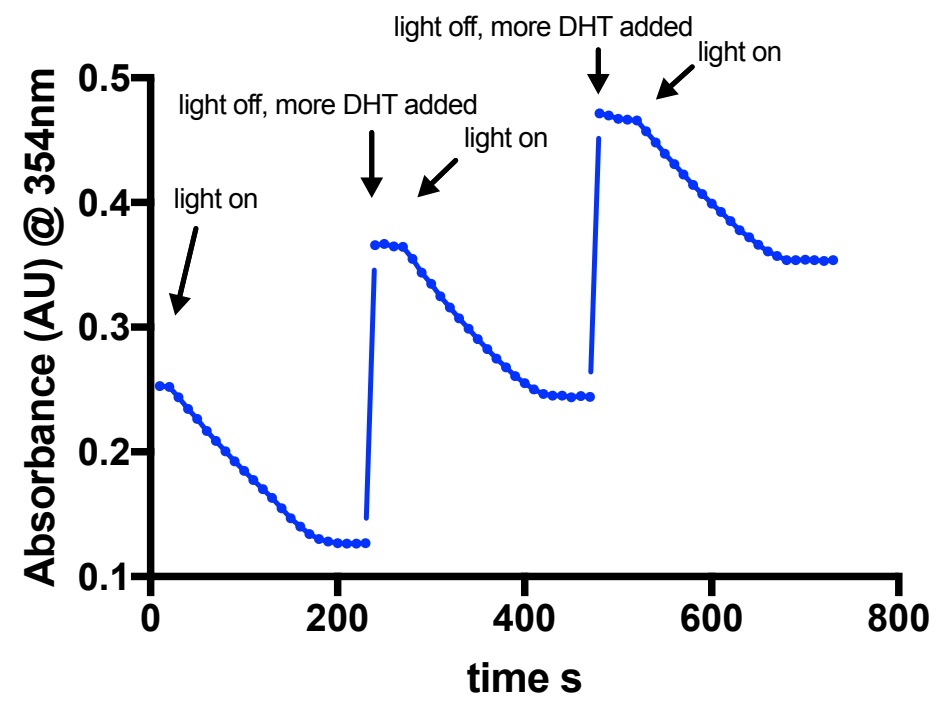

Fig S55. Effect of oxidation products on DHTz rate 


\subsection{Effect of catalase on background DHTz oxidation}

A PBS solution $(2 \mathrm{~mL})$ of DHTz $6(35 \mu \mathrm{M})$ and catalase $(1 \mu \mathrm{M})$ and a PBS solution of DHTz $6(35 \mu \mathrm{M})$ were monitored in ambient light separately by UV-Vis at $354 \mathrm{~nm}$ every 10 seconds. The change in absorbance of the two solutions were similar, indicating catalase is not a catalyst for the oxidation from 6 to 7 . The baseline difference between the two solutions is due to the absorption of catalase at this wavelength.

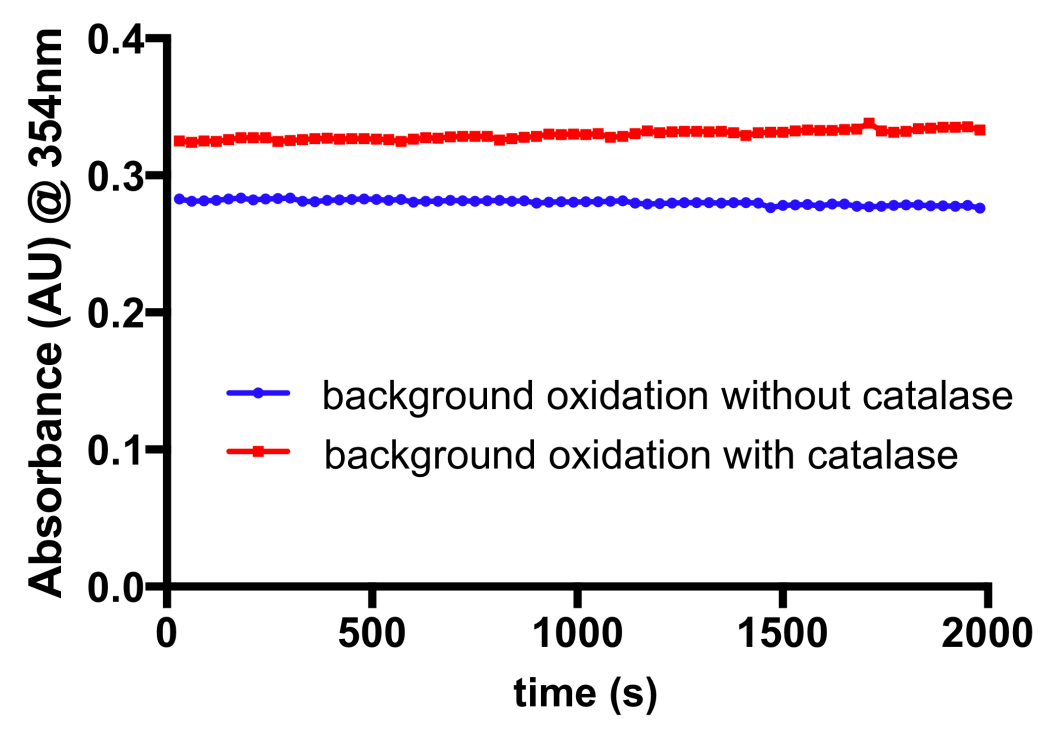

Fig S56. Catalase does not have an effect on the background oxidation of DHTz 6. 


\subsection{Effect of methylene blue and light on proteins}

In a centrifuge tubes $(1.5 \mathrm{~mL})$, PBS solutions $(1 \mathrm{~mL})$ were prepared that contained protein $(25 \mu \mathrm{M})$ or protein and methylene blue $(1 \mu \mathrm{M})$. The solutions were treated with the LED source described in $\mathbf{S 4 . 1}\left(660 \mathrm{~nm}, 180 \mathrm{~mW} / \mathrm{cm}^{2}\right)$ for $4 \mathrm{~min}$, or incubated without light for the same time. The samples were then loaded to LC-MS and gels for analysis.

Protein samples in PBS were prepared as shown in the table and separated on a $4 \%-15 \%$ gradient gel from Bio-Rad (Mini-PROTEAN® TGX ${ }^{\mathrm{TM}}$ Precast Protein Gels, 15-well, $15 \mu \mathrm{l}$ ) alongside a molecular weight ladder (Precision Plus Protein ${ }^{\mathrm{TM}}$ Dual Color Standards). Proteins were stained with Coomassie and gel was de-stained before imaging.

Mass spectra for TrX are displayed in the manuscript. MS for ribonuclease A and lysozyme are displayed below.

\section{Ribonuclease A}

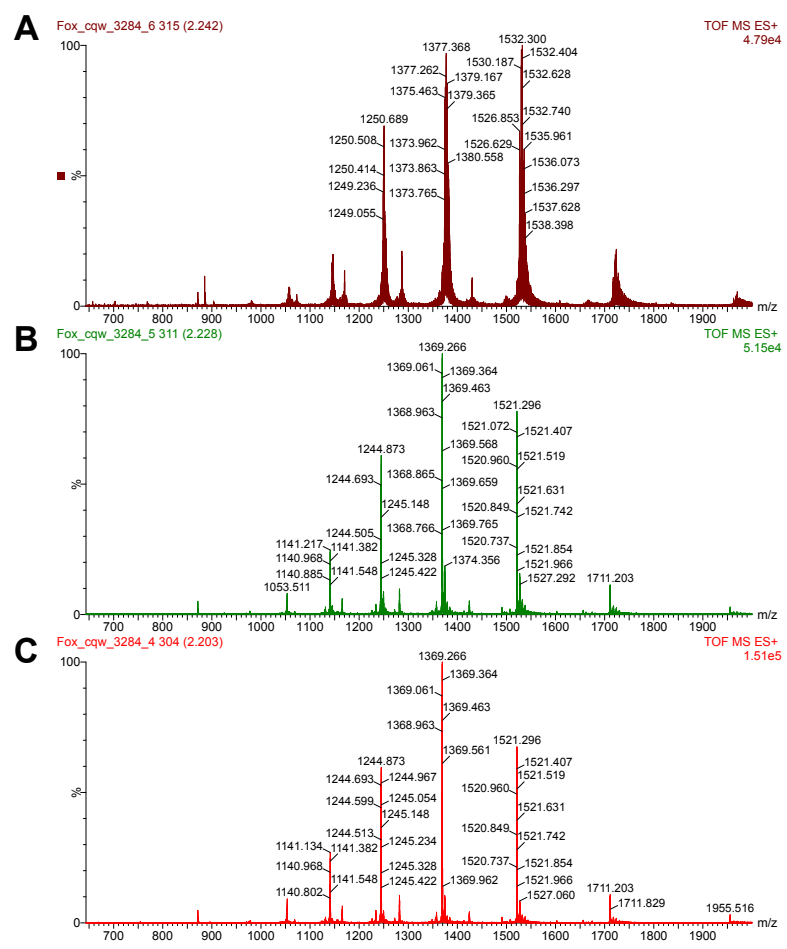

Lysozyme

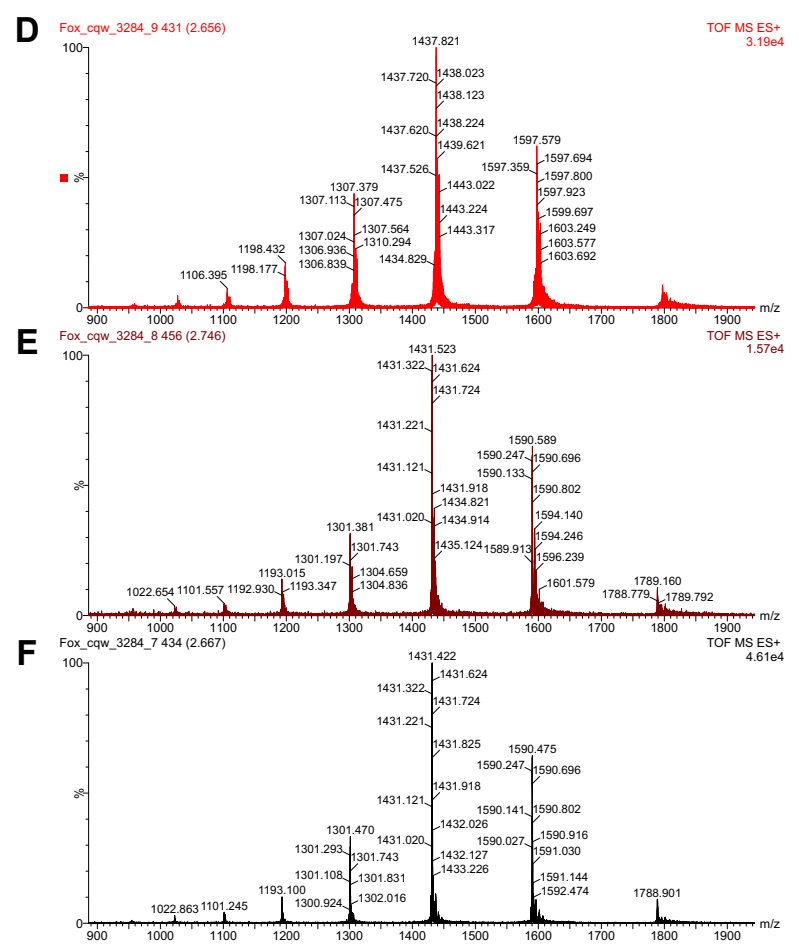

Fig S57. Ribonuclease A $(25 \mu \mathrm{M})$ : raw ESI mass spectra $(A)$ after 4 min irradiation (660 $\mathrm{nm})$ with $\mathrm{MB}(1 \mu \mathrm{M}),(\mathrm{B})$ after incubation with $\mathrm{MB}(1 \mu \mathrm{M})$ without light $(\mathrm{C})$ after 4 min irradiation $(660 \mathrm{~nm})$ without MB. Lysozyme $(25 \mu \mathrm{M})$ : raw ESI mass spectra (D) after 4 min irradiation $(660 \mathrm{~nm})$ with $\mathrm{MB}(1 \mu \mathrm{M}),(\mathrm{E})$ after incubation with $\mathrm{MB}(1 \mu \mathrm{M})$ without light $(\mathrm{F})$ after 4 min irradiation $(660 \mathrm{~nm})$ without $\mathrm{MB}$. 
While MB/light causes degradation by mass spectrometry, significant changes were not observed by gel electrophoresis.

Fig S58. Gel electrophoresis for proteins that were treated with light and methylene blue, light only, or methylene blue only.

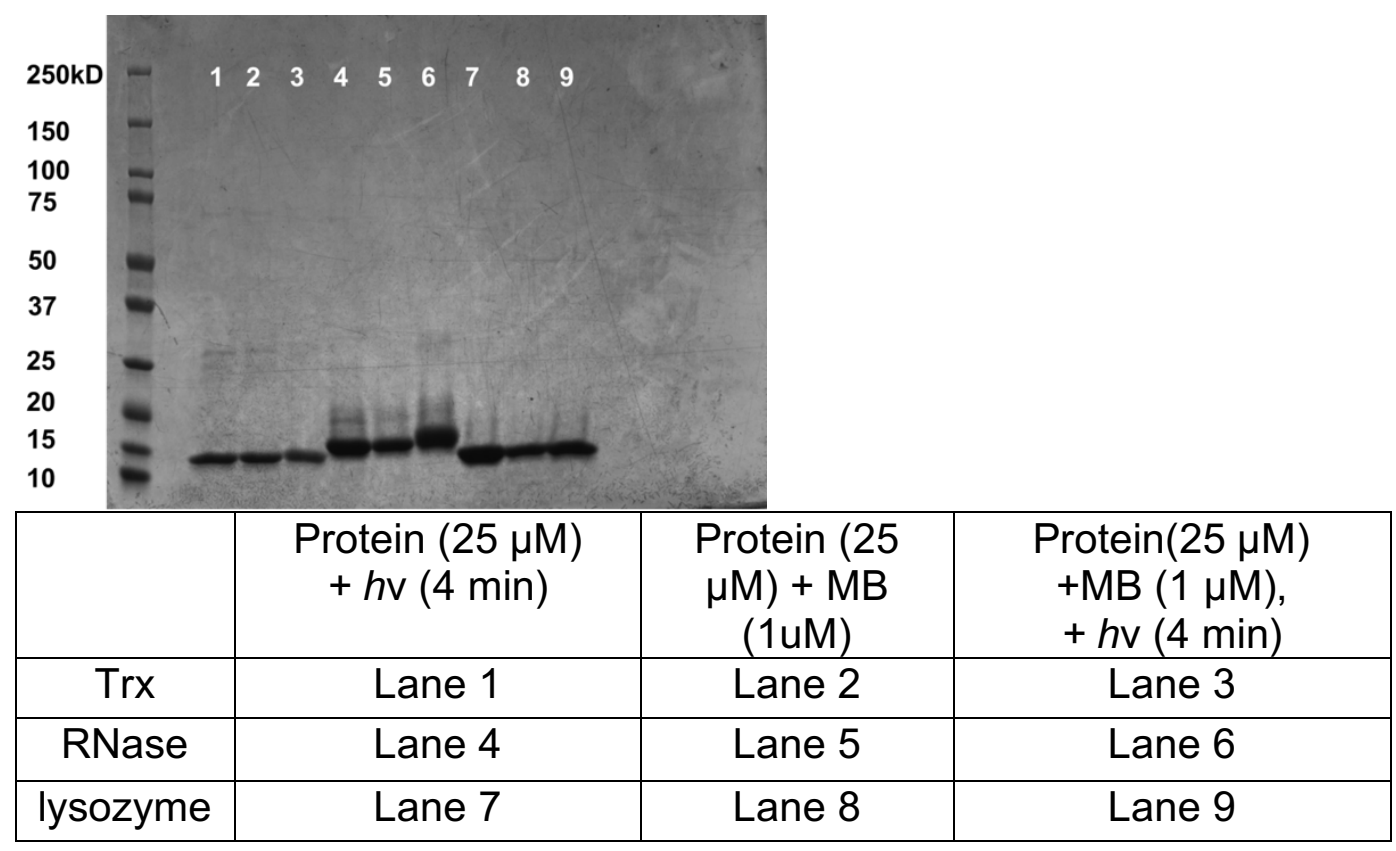


Part VII: Mechanistic studies showing that peroxide is a product of DHTz oxidation

\subsection{Oxygen Electrode Experiment (Results displayed in Fig 2B)}

Solutions of DHTz $2(180 \mu \mathrm{M})$ in PBS were prepared from concentrated stock solutions $(1 \mathrm{mM})$. The DHTz solution $(180 \mu \mathrm{M}, 4 \mathrm{~mL})$ was added to a stirring, water jacketed Clark Oxygen Electrode, the chamber was sealed and the oxygen saturation calibrated to $100 \%$. The dissolved oxygen concentration was recorded once every second throughout the experiment. Rose bengal was added through the injection port as a concentrated stock ( $1.5 \mathrm{mM}$ ) to give a final concentration of $20 \mu \mathrm{M}$. A green LED (528 $\mathrm{nm}$ ) was used to irradiate the solution for 140 seconds before switching it off. Catalase was then added from a $10 \mu \mathrm{M}$ stock solution to give a final enzyme concentration of 120 $\mathrm{nM}$. After the catalase-induced increase in dissolved oxygen, the LED was switched on for another two minutes before switching it off again and concluding the experiment.

\subsection{Formation of $\mathrm{H}_{2} \mathrm{O}_{2}$ in methylene blue and SiR-photocatalyzed DHTz oxidation.}

In centrifuge tubes $(1.5 \mathrm{~mL})$, PBS solutions $(1 \mathrm{~mL})$ were prepared containing $(\mathrm{A}) \mathrm{DHTz} 6$ $(30 \mu \mathrm{M})$ with SiR catalyst 1d $(1 \mu \mathrm{M}),(B) \mathrm{DHTz} 6(35 \mu \mathrm{M})$ with MB $(1 \mu \mathrm{M}),(\mathrm{C}) \operatorname{SiR} 1 \mathbf{d}(1$ $\mu \mathrm{M})$ alone, and (D) MB (1 $\mu \mathrm{M})$ alone. The LED source described in S2.1 (660 nm, 450 $\mathrm{mW} / \mathrm{cm}^{2}$ ) was used to irradiate from the side of the tube. The $\mathrm{H}_{2} \mathrm{O}_{2}$ concentration of the solution after 5 min were determined using an amplex red hydrogen peroxide assay kit (Sigma-Aldrich, MAK165-1KT) by monitoring the increase in absorbance at $540 \mathrm{~nm}$.

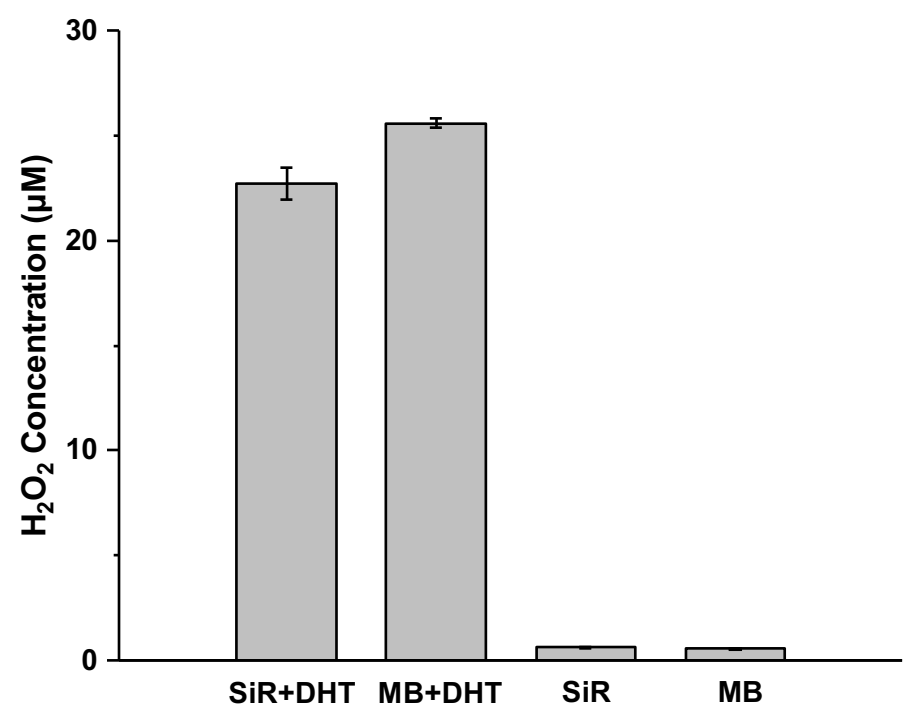

Fig S59. $\mathrm{H}_{2} \mathrm{O}_{2}$ is a product of the SiR and MB catalyzed oxidation of DHTz 6 . 


\subsection{Effect of Catalase on LNCaP Viability After Photocatalytic DHTz Oxidation}

The following study on $\mathrm{LNCaP}$ cells in $2 \mathrm{D}$ cell culture demonstrates the beneficial impact of including catalase during photocatalytic DHTz oxidation in a cellular experiment.

LNCaP PCa cells were obtained from American Type Culture Collection (ATCC, Manassas, VA). Cells were seeded onto two $75-\mathrm{cm}^{2}$ tissue culture flasks (Celltreat) at a density of $1 \times 10^{6}$ cells $/ \mathrm{mL}$ and maintained in cell culture media (RPMI-1640, ATCC) supplemented with $5 \%(\mathrm{v} / \mathrm{v})$ fetal bovine serum (FBS) and $100 \mu \mathrm{g} / \mathrm{mL}$ streptomycin sulfate in $0.085 \%(\mathrm{v} / \mathrm{v})$ saline $(\mathrm{P} / \mathrm{S})$ at $37{ }^{\circ} \mathrm{C}$ with $5 \% \mathrm{CO}_{2}$. Media was changed every other day. At $75 \%$ confluency, cells were trypsinized with $0.25 \%(\mathrm{w} / \mathrm{v})$ trypsin containing ethylenediaminetetraacetic acid (EDTA $4 \mathrm{Na})$.

The cell suspension was centrifuged at $450 \mathrm{rpm}$ for $5 \mathrm{~min}$ and a total of $450 \mathrm{k}$ cells were resuspended into media (193 $\mu \mathrm{L}, \mathrm{RPMI}-1640$, ATCC) and then mixed with a PBS solution of DHTz (6), SiR (1d), catalase and $\mathrm{H}_{2} \mathrm{O}_{2}$ at a desired final concentration for each component:
A. Catalase: $2 \mathrm{mM} \mathrm{6,} 40 \mu \mathrm{M} 1 \mathrm{~d}, 2.5 \mathrm{mg} / \mathrm{mL}$ catalase

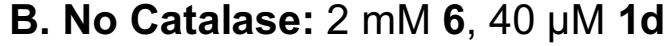
C. $\mathrm{H}_{2} \mathrm{O}_{2}: 2 \mathrm{mM} \mathrm{H}_{2} \mathrm{O}_{2}$.
D. Media: no additional reagent.

Each suspension was transferred to glass-bottom 48 -well plate $(200 \mu \mathrm{L} /$ well, $150 \mathrm{k}$ cells per well) (Cat: P48G-1.5-6-F Mattek) and then exposed to far-red light (660 nm, 180 $\mathrm{mW} / \mathrm{cm}^{2}$ ) for 10 minutes. LNCaP cells were then incubated with components mentioned above in each condition for $24 \mathrm{hrs}$ at $37^{\circ} \mathrm{C}$ and then replaced with fresh media.

Cells were stained with a commercially available cell viability staining kit according to manufacturer's protocol (LIVE/DEAD, Thermo Fisher Scientific) on day 3. A mixture containing $4 \mu \mathrm{M}$ of both calcein-AM and ethidium homodimer-1 in PBS (1x) was added to the 48 well plate and the cells were incubated at $37^{\circ} \mathrm{C}$ for 10 min then washed 3 times with PBS (1x). Confocal microscopy images were taken of three biological replicates using a Zeiss LSM 880 confocal microscope with a 10X Plan Apochromat (N.A. 0.45) objective. Viability was quantified based on the calcein positive cell number using Image J software.
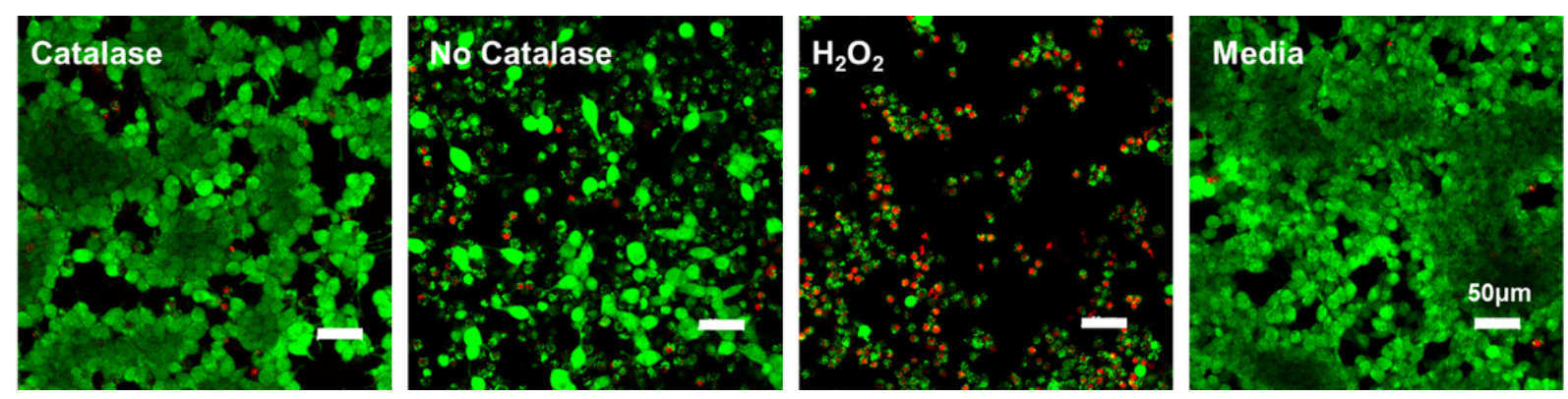

Fig S60. Live/dead assay of LnCaP cells treated with $660 \mathrm{~nm}$ light $\left(180 \mathrm{~mW} / \mathrm{cm}^{2}, 10 \mathrm{~min}\right)$ and (A) Catalase: $2 \mathrm{mM} \mathrm{6,} 40 \mu \mathrm{M}$ 1d, $2.5 \mathrm{mg} / \mathrm{mL}$ catalase (B) No Catalase: $2 \mathrm{mM} \mathrm{6,} 40$ $\mu \mathrm{M}$ 1d, (C) $\mathrm{H}_{2} \mathrm{O}_{2}: 2 \mathrm{mM} \mathrm{H}_{2} \mathrm{O}_{2}$, (D) Media: no additional reagents. 


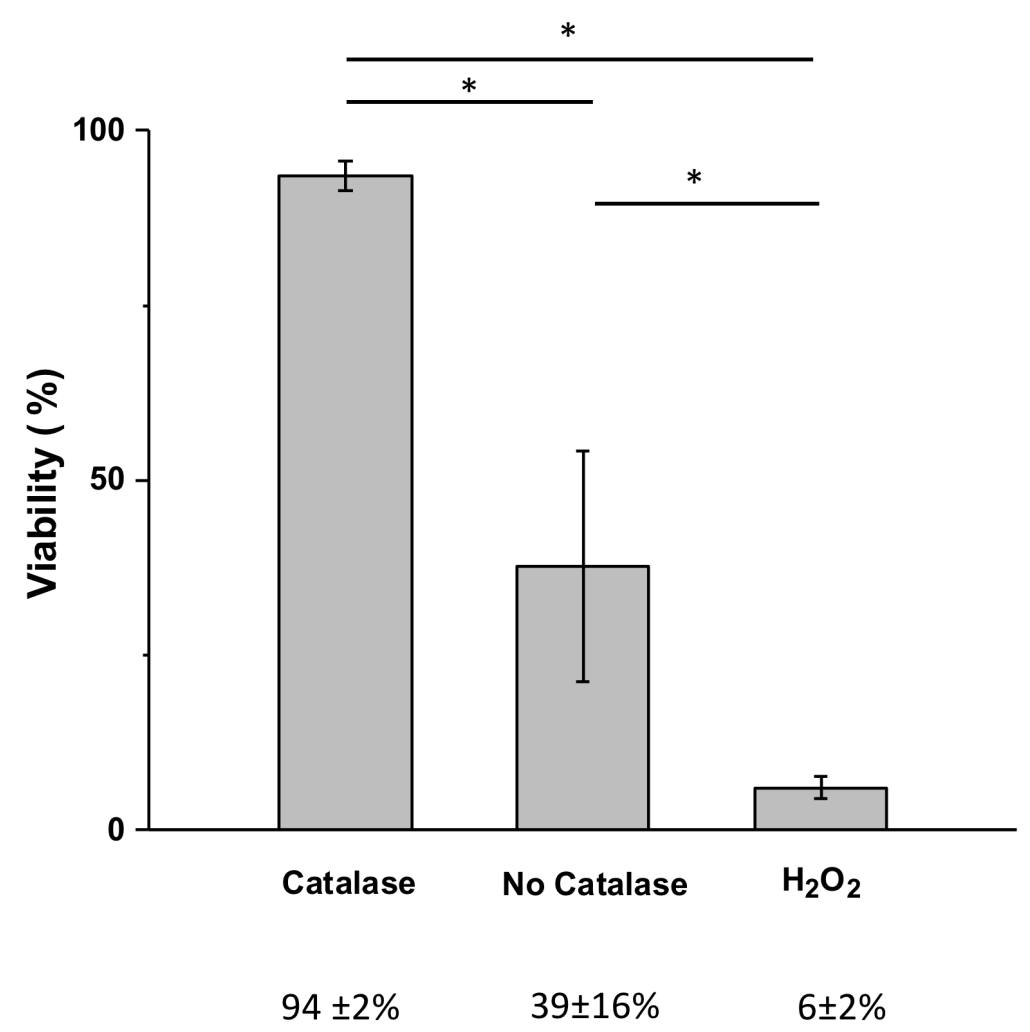

Fig S61. Quantification of cell viability of LnCaP cells treated with $660 \mathrm{~nm}$ light (180 $\mathrm{mW} / \mathrm{cm}^{2}, 10 \mathrm{~min}$ ) and (A) Catalase: $2 \mathrm{mM} \mathrm{6}, 40 \mu \mathrm{M} \mathrm{1d}, 2.5 \mathrm{mg} / \mathrm{mL}$ catalase (B) No Catalase: $2 \mathrm{mM}$ 6, $40 \mu \mathrm{M}$ 1d, (C) $\mathrm{H}_{2} \mathrm{O}_{2}: 2 \mathrm{mM} \mathrm{H}_{2} \mathrm{O}_{2}$. 


\section{References}

1. Hao, Y.; Song, J.; Ravikrishnan, A.; Dicker, K. T.; Fowler, E. W.; Zerdoum, A. B.; Li, Y.; Zhang, H.; Rajasekaran, A. K.; Fox, J. M.; Jia, X., Rapid Bioorthogonal Chemistry Enables in Situ Modulation of the Stem Cell Behavior in 3D without External Triggers. ACS Appl Mater Interfaces 2018, 10 (31), 26016-26027.

2. Ozdemir, T.; Srinivasan, P. P.; Zakheim, D. R.; Harrington, D. A.; Witt, R. L.; FarachCarson, M. C.; Jia, X.; Pradhan-Bhatt, S., Bottom-up assembly of salivary gland microtissues for assessing myoepithelial cell function. Biomaterials 2017, 142, 124-135. 
${ }^{1} \mathrm{H}$ NMR (600 MHz, $\mathrm{CDCl}_{3}$ ) of 3-((2-hydroxyethyl)amino) picolinonitrile<smiles>N#Cc1ncccc1NCCO</smiles>

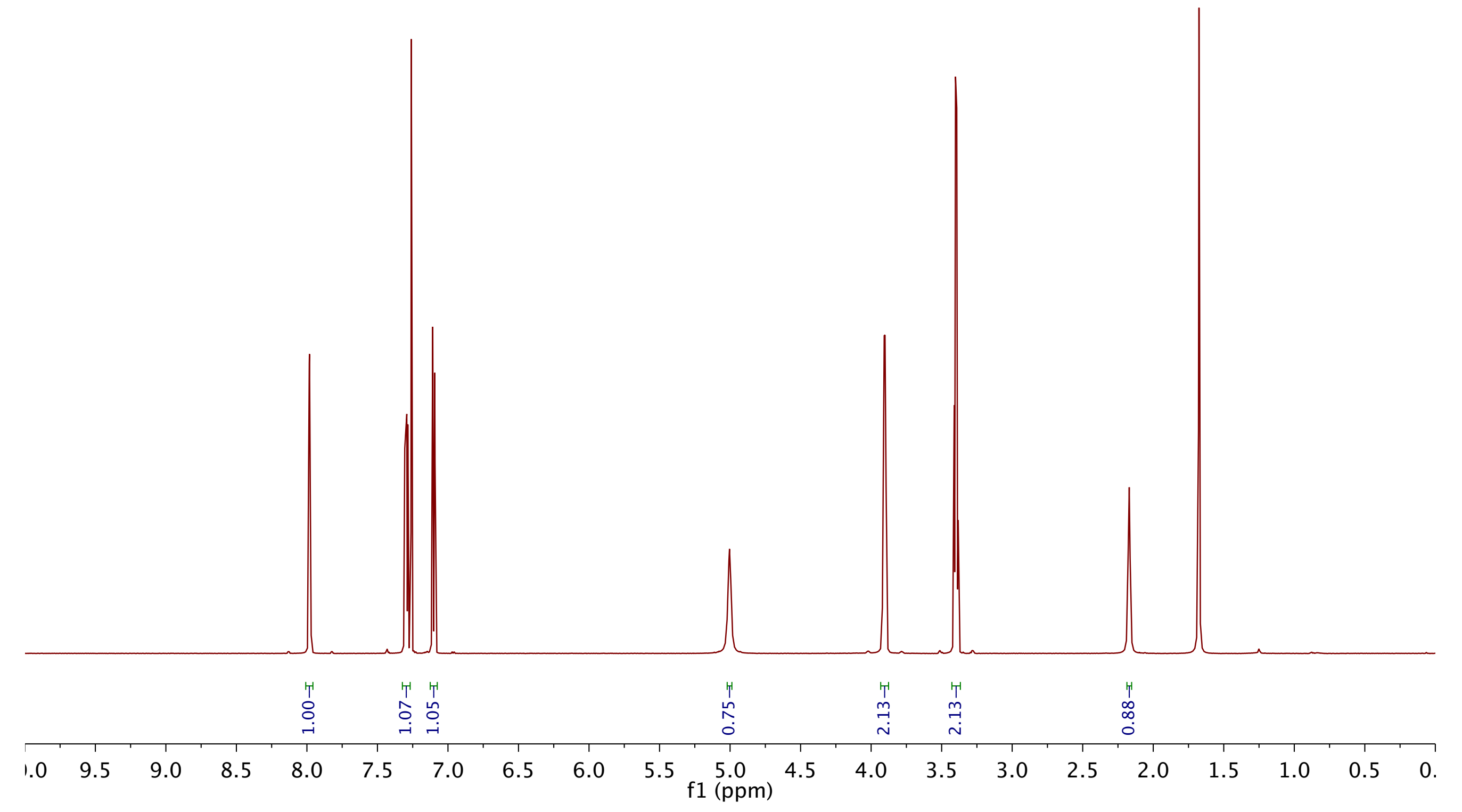


${ }^{13} \mathrm{C}$ NMR (101 MHz, $\left.\mathrm{CDCl}_{3}\right)$ of 3-((2-hydroxyethyl)amino) picolinonitrile<smiles>N#Cc1ncccc1NCCO</smiles>

Inmum

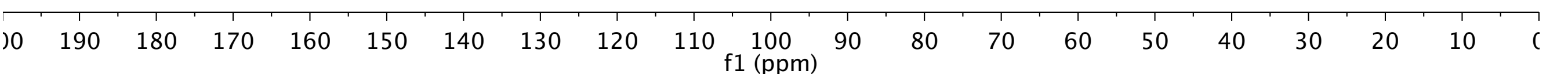


${ }^{1} \mathrm{H}$ NMR $\left(600 \mathrm{MHz}, \mathrm{CDCl}_{3}\right)$ of 2-((2-(6-(pyridin-2-yl)-1,4-dihydro-1,2,4,5-tetrazin-3-yl)pyridin-3yl)amino)ethanol (4)
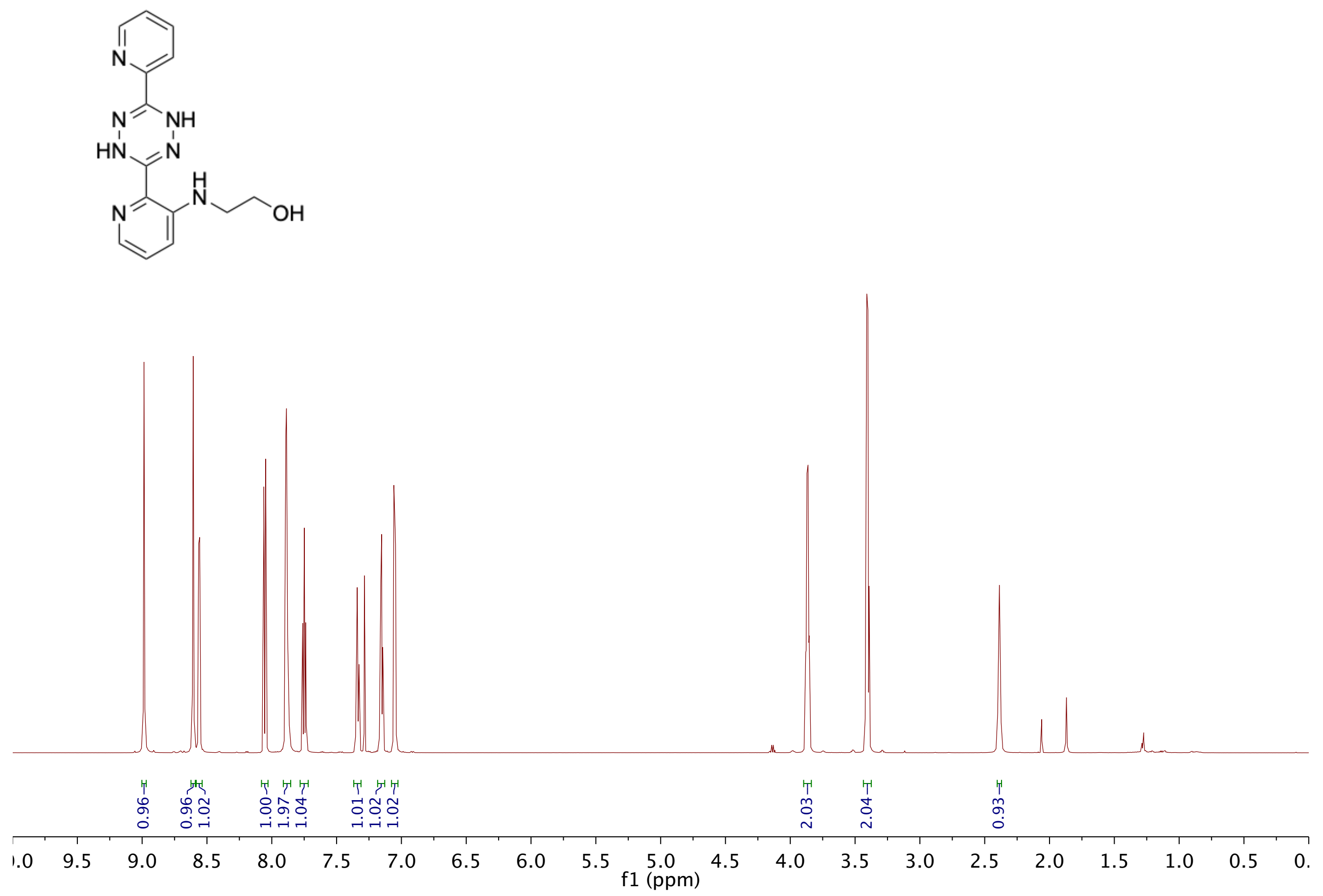


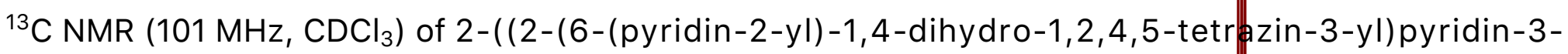
yl)amino)ethanol (4)
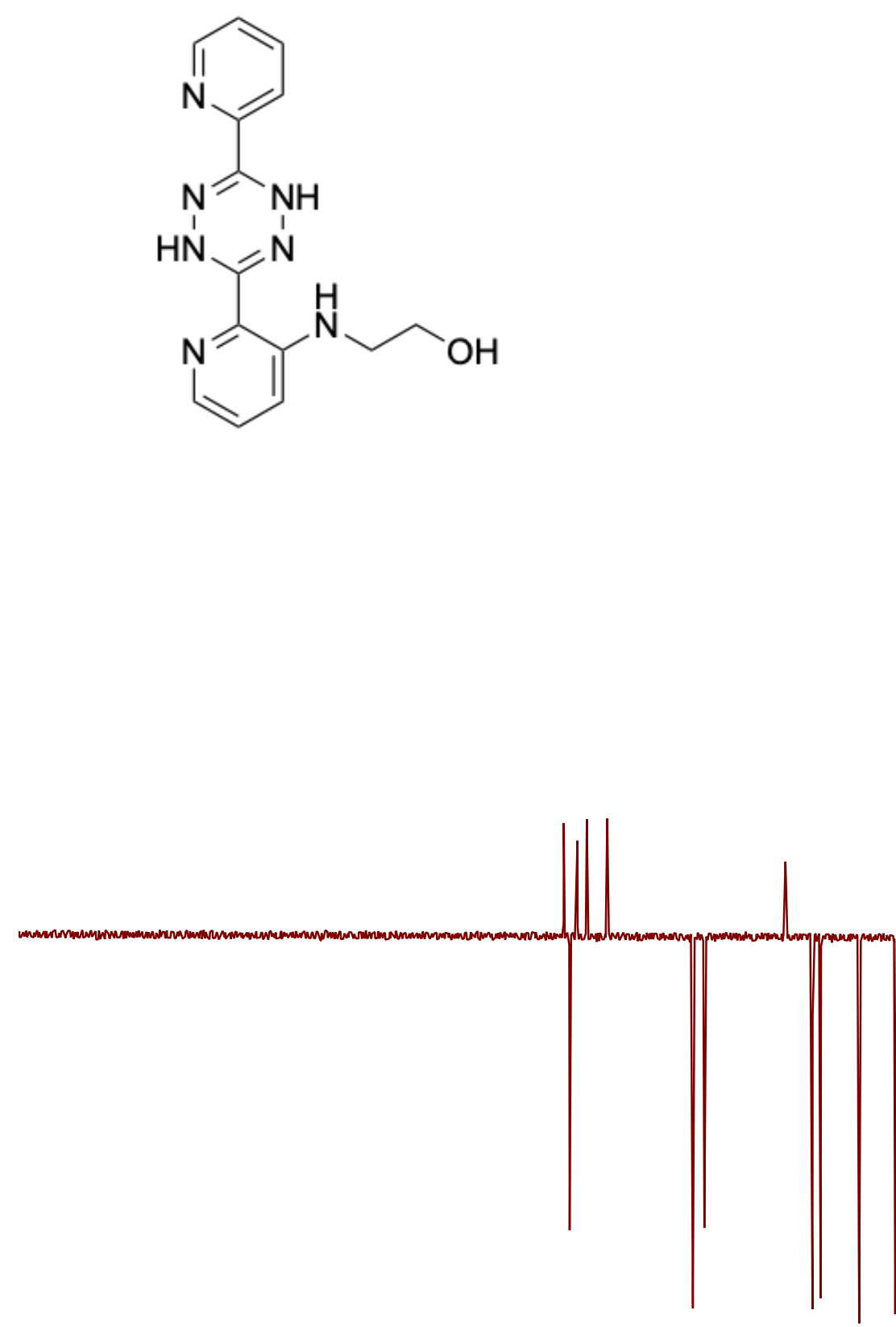

$\begin{array}{llllllll}190 & 180 & 170 & 160 & 150 & 140 & 130 & 120\end{array}$


${ }^{1} \mathrm{H}$ NMR $\left(600 \mathrm{MHz}, \mathrm{CDCl}_{3}\right)$ of 4-nit ophenyl(2-((2-(6-(pyridin-2-yl)-1,4-dihydro-1,2,4,5-tetrazin-3-yl)pyridin-3yl)amino)ethyl)carbonate (5)

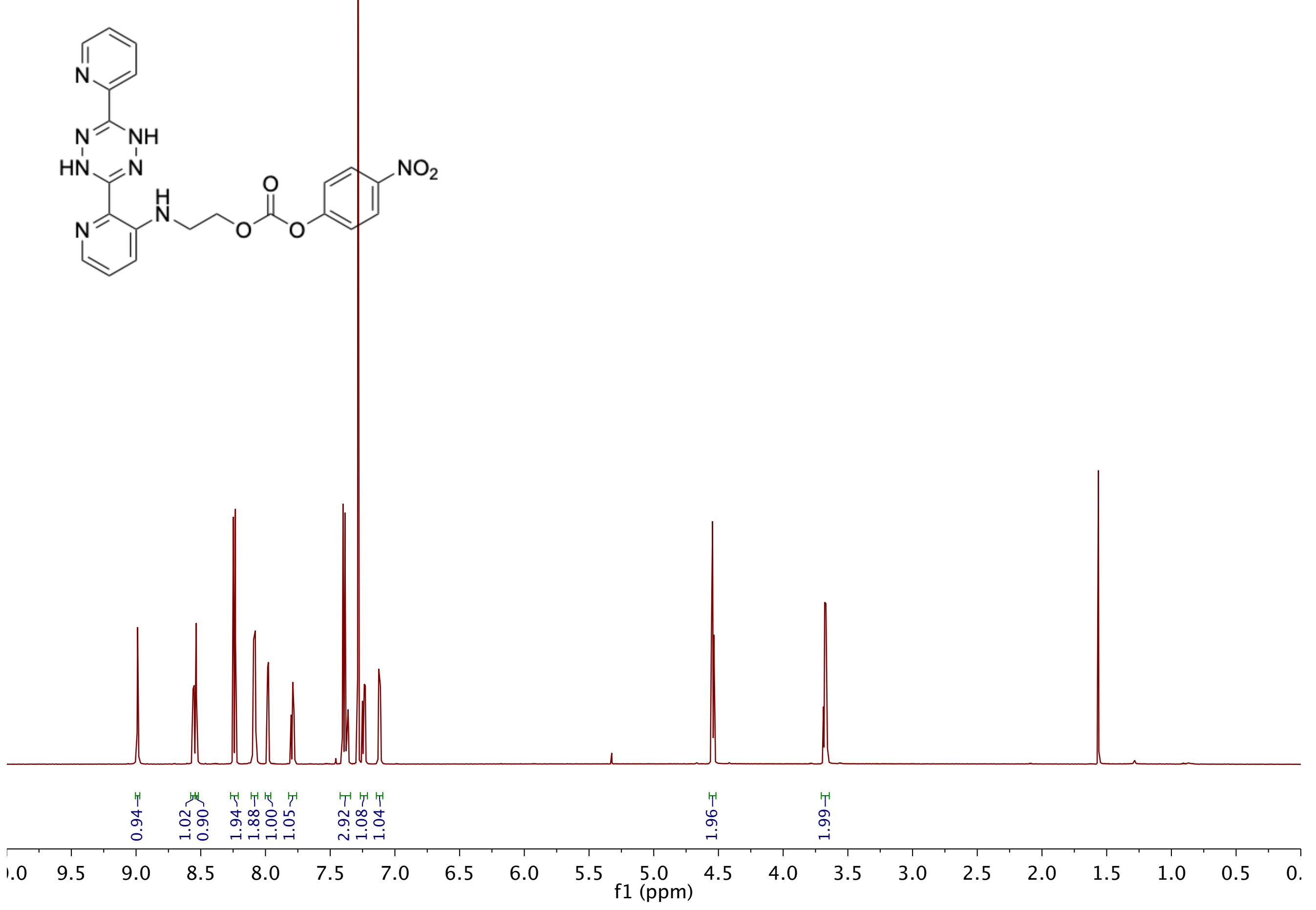


${ }^{13} \mathrm{C} \mathrm{NMR}\left(101 \mathrm{MHz}, \mathrm{CDCl}_{3}\right)$ of 4-nitrophenyl(2-((2-(6-(pyridin-2-yl)-1,4-dihyd|o-1,2,4,5-tetrazin-3-yl)pyridin-3yl)amino)ethyl)carbonate (5)
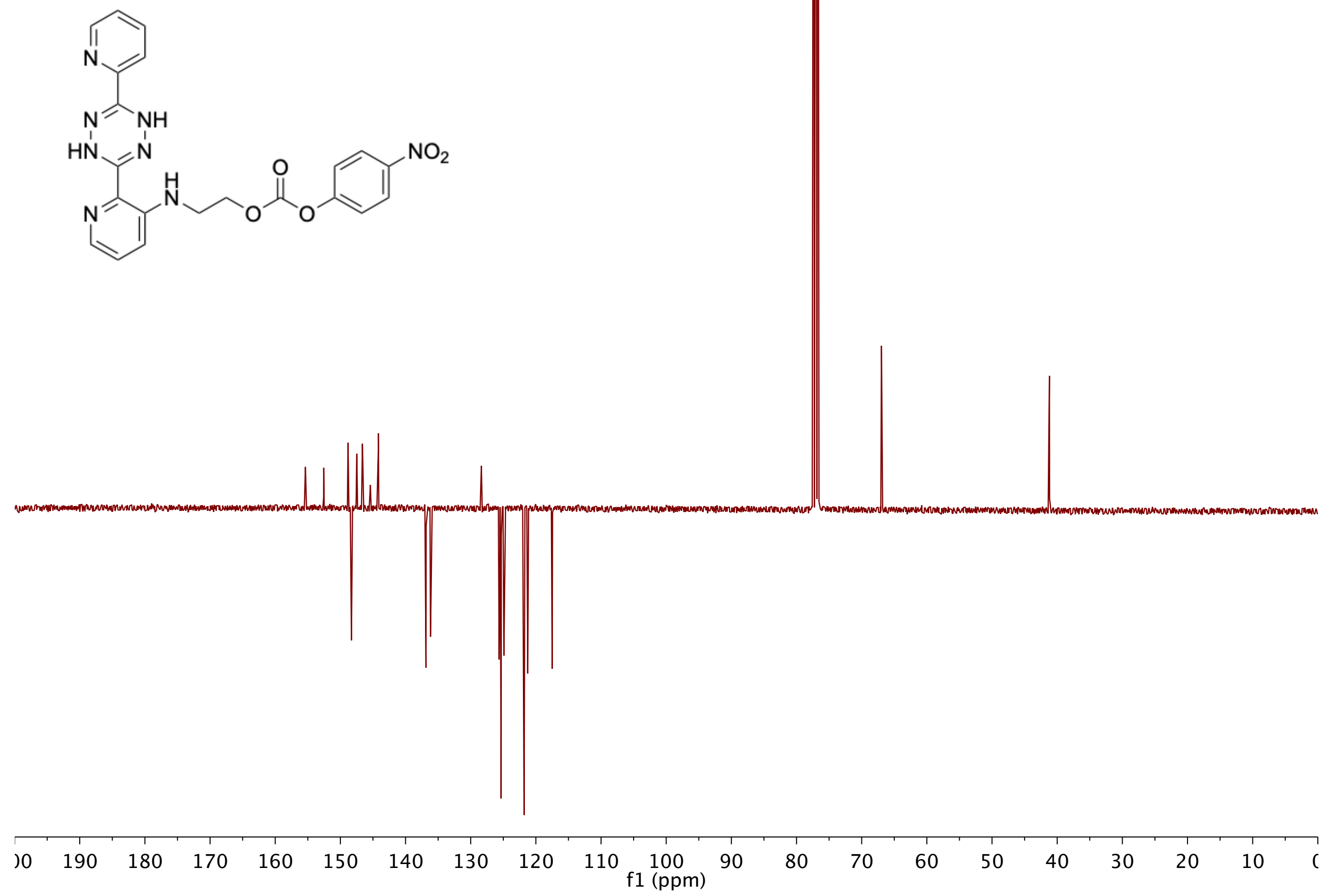
${ }^{1} \mathrm{H}$ NMR $\left(600 \mathrm{MHz}, \mathrm{CDCl}_{3}\right)$ of 2-((2-(6-(pyridin-2-yl)-1,4-dihydro-1,2,4,5-tetrazin-3-yl)pyridin-3yl)amino)ethyl-2,5,8,11,14,17,20,23,26,29,32,35-dodecaoxaheptatriacontan-37-ylcarbamate (6)
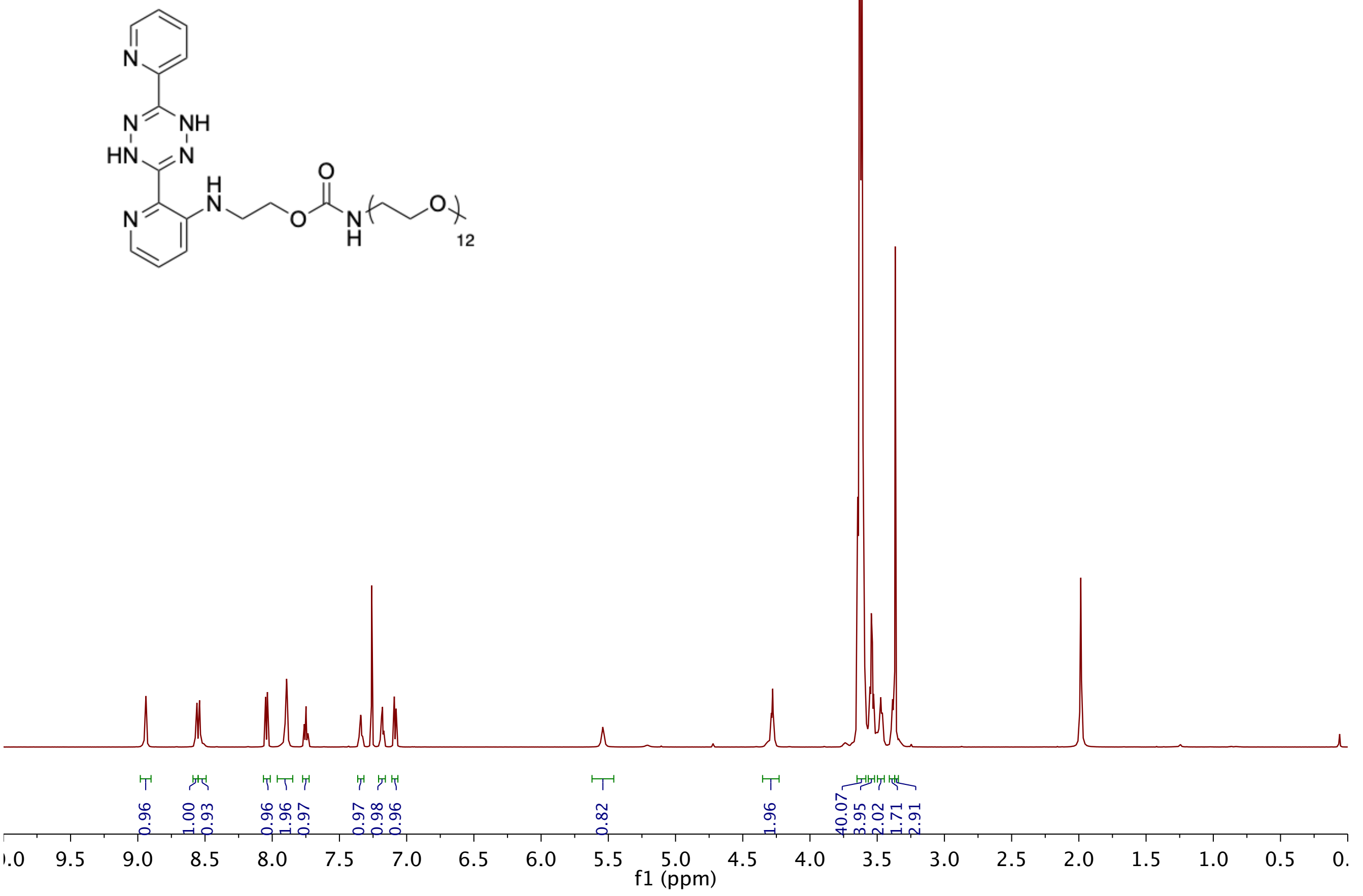
${ }^{13} \mathrm{C}$ NMR $\left(101 \mathrm{MHz}, \mathrm{CDCl}_{3}\right)$ of 2-((2-(6-(pyridin-2-yl)-1, 4-dihydro-1,2,4,5-tetrazin-3-yl)pyridin-3yl)amino)ethyl-2,5,8,11,14,17,20,23,26,29,32,35-dodecaoxaheptatriacontan-37-ylcarbamate (6)
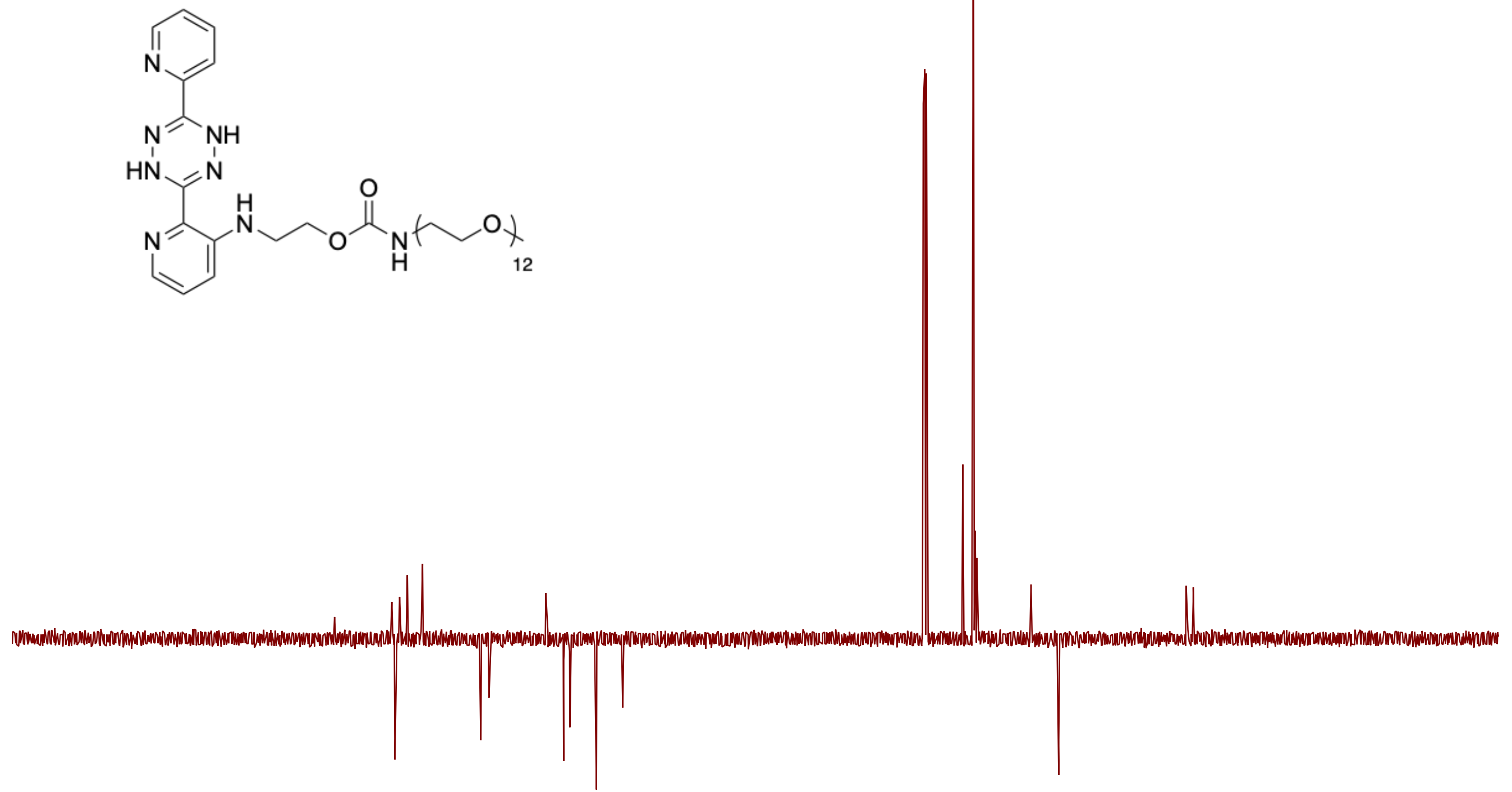

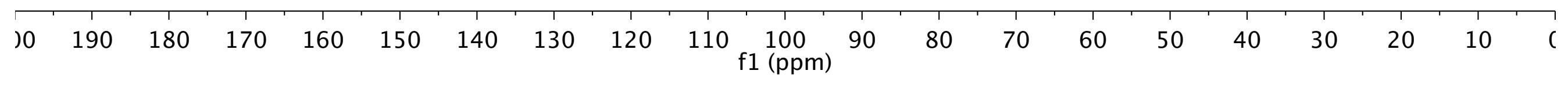


${ }^{1} \mathrm{H}$ NMR $\left(600 \mathrm{MHz}, \mathrm{CD}_{3} \mathrm{CN}\right)$ of 2-((2-(6-(pyridin-2-yl)-1,2,4,5-tetrazin-3-yl)pyridith-3-yl)amino)eth $\mathbf{}$ $2,5,8,11,14,17,20,23,26,29,32,35$-dodecaoxaheptatriacontan-37-ylcarbamate (\$)
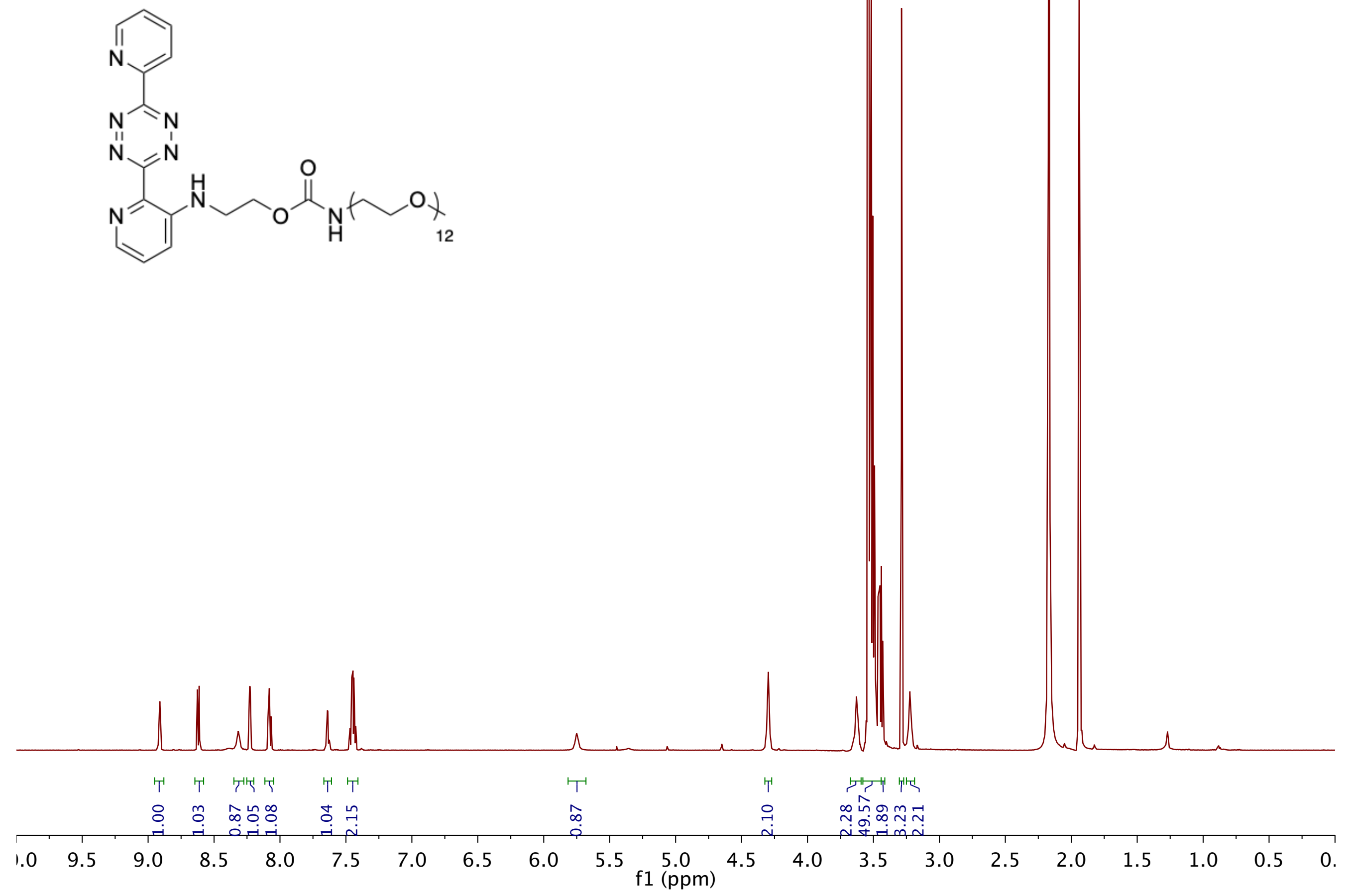
${ }^{13} \mathrm{C}$ NMR $\left(101 \mathrm{MHz}, \mathrm{CD}_{3} \mathrm{CN}\right)$ of 2-((2-(6-(pyridin-2-y|)-1,2,4,5-tetrazin-3-yl) pyridif-3-yl)amino) ethyl $2,5,8,11,14,17,20,23,26,29,32,35$-dodecaoxaheptatriacontan-37-ylcarbamate $(p)$

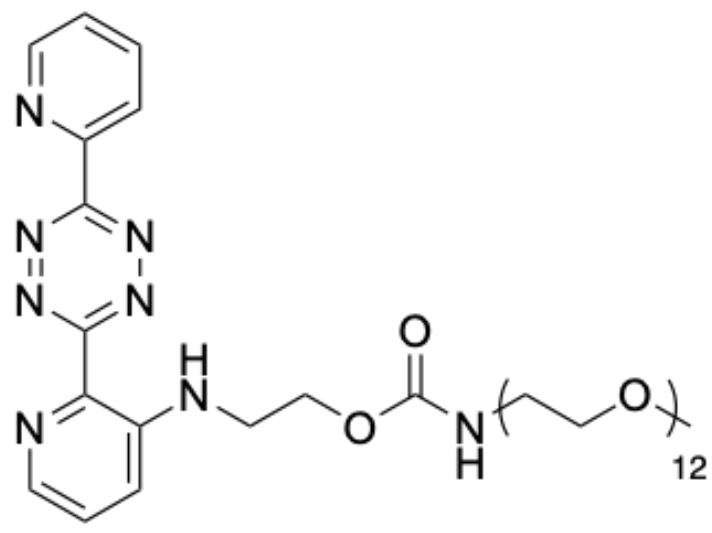

Mint
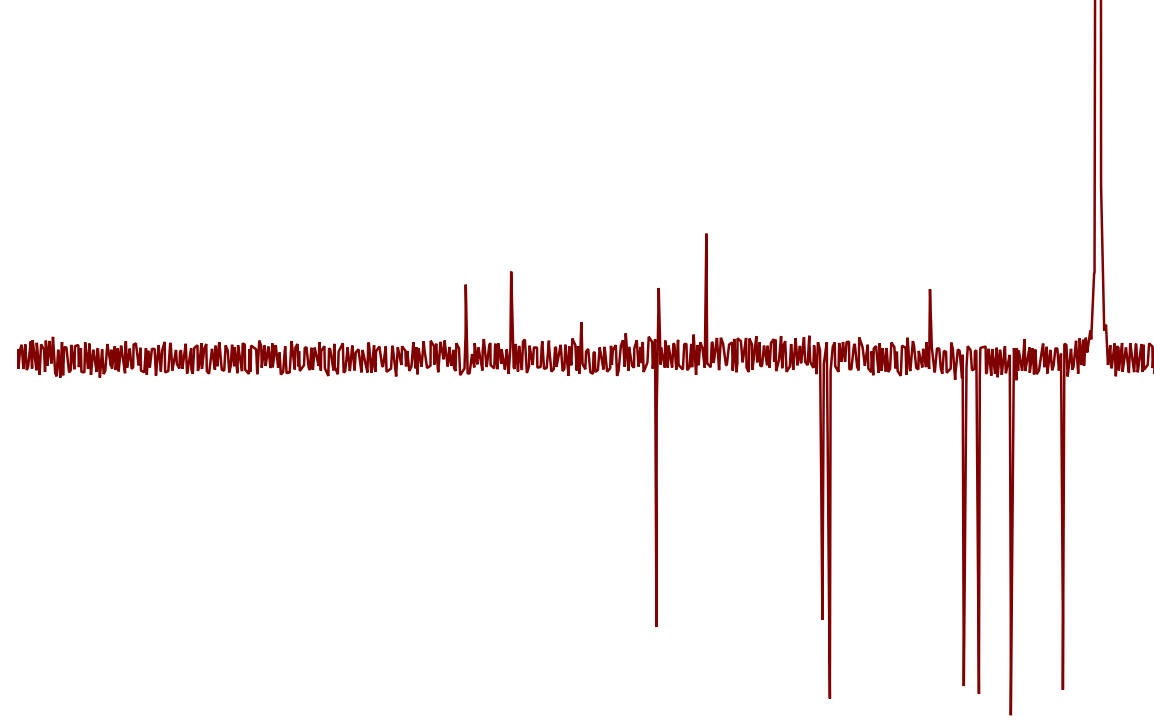

$\begin{array}{llllllll}190 & 180 & 170 & 160 & 150 & 140 & 130 & 120\end{array}$

120110

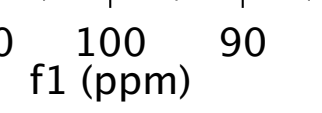

8070


${ }^{1} \mathrm{H}$ NMR $\left(600 \mathrm{MHz}, \mathrm{CDCl}_{3}\right)$ of 2-((2-(6-(pyridin-2-yl)-1,4-dihydro-1,2,4,5-tetrazin-3-yl)pyridin-3-yl)amino) ethyl hydrazinecarboxylate
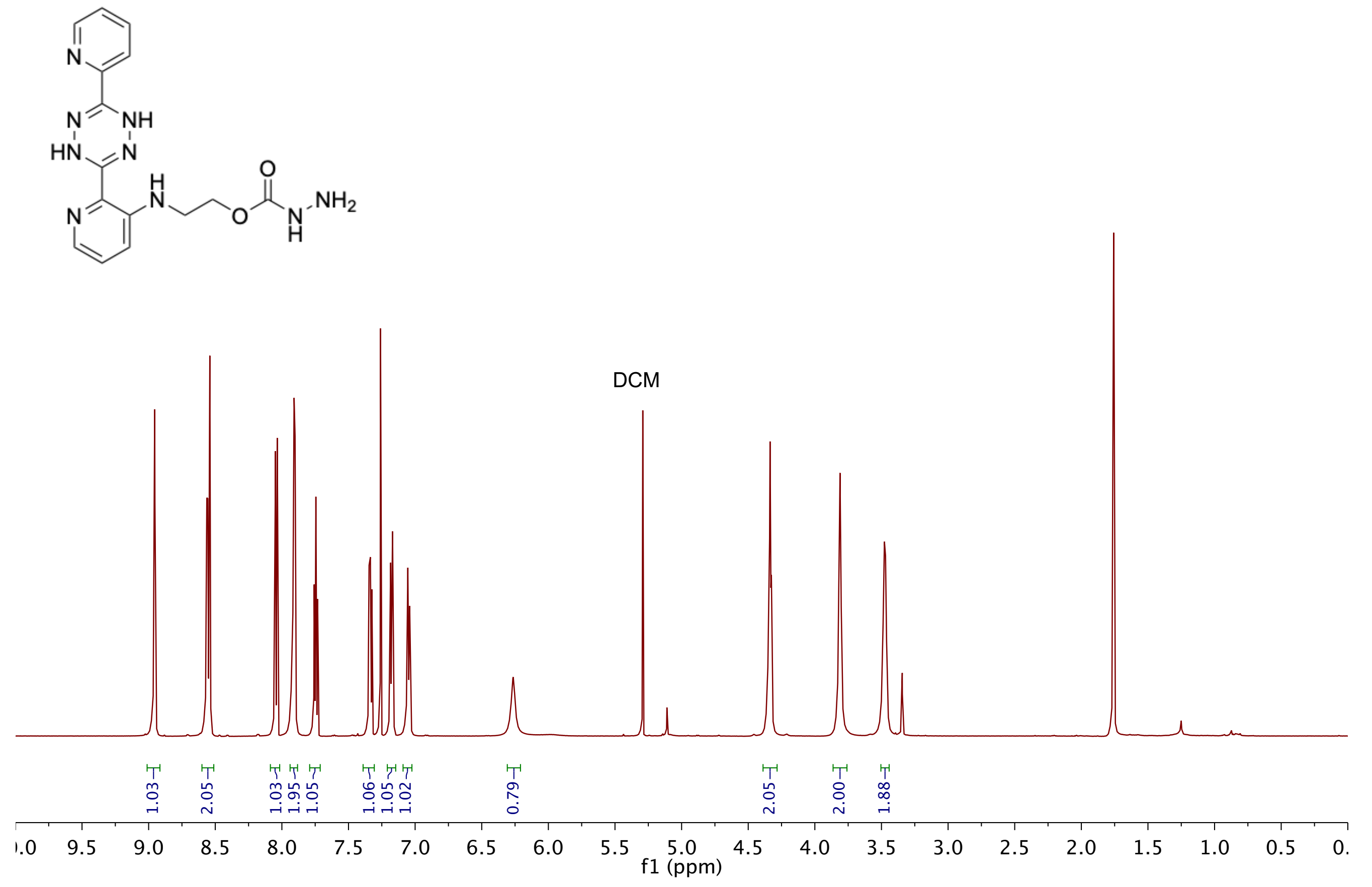
${ }^{13} \mathrm{C}$ NMR $\left(101 \mathrm{MHz}, \mathrm{CDCl}_{3}\right)$ of 2-((2-(6-(pyridin-2-yl)-1,4-dihydro-1,2,4,5-tetr|tzin-3-yl)pyridin-3-yl)amino) ethyl hydrazinecarboxylate

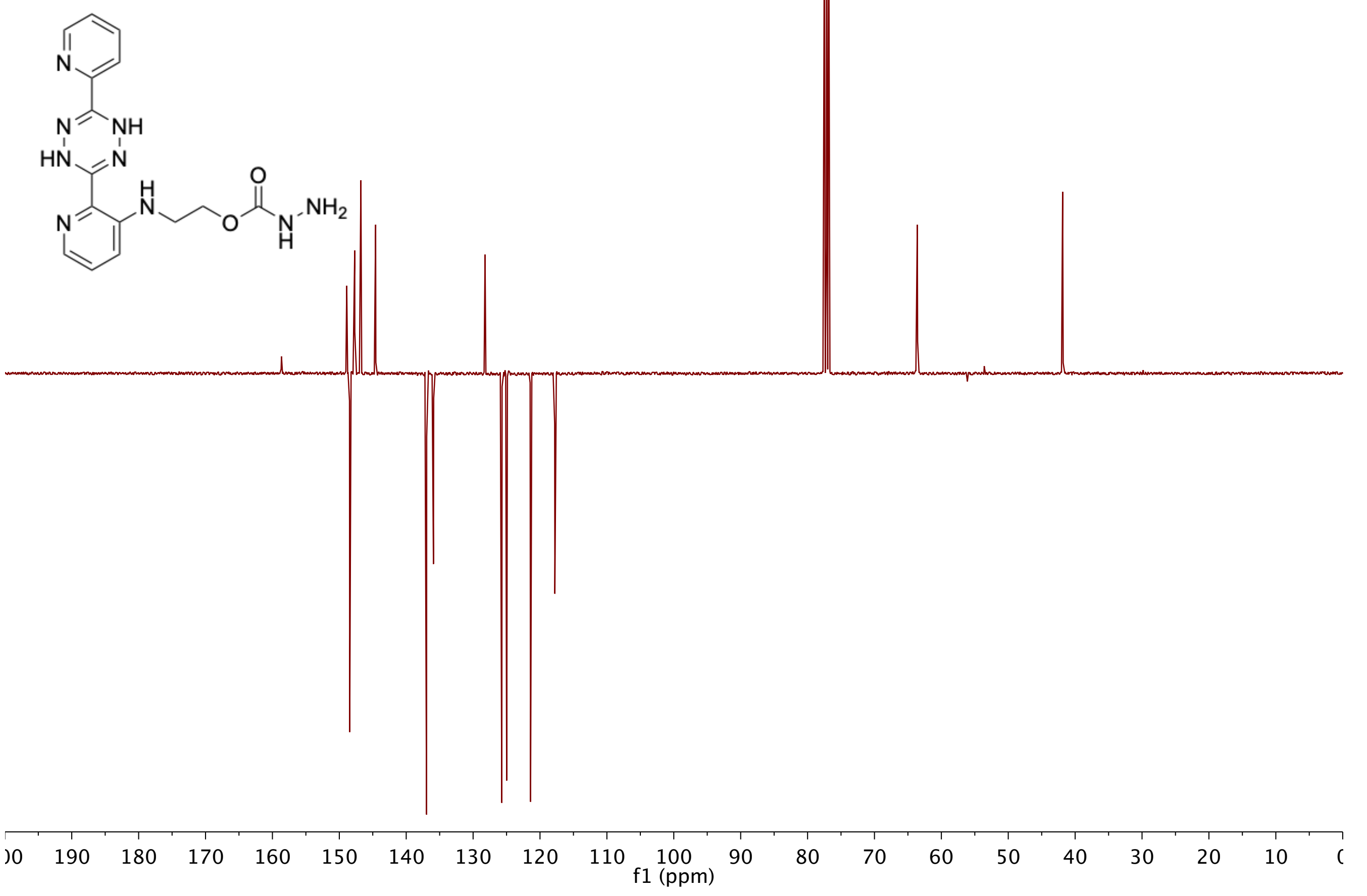


${ }^{1} \mathrm{H}$ NMR $\left(600 \mathrm{MHz}, \mathrm{D}_{2} \mathrm{O}\right)$ of $\mathrm{HA}-\mathrm{DHTz}$
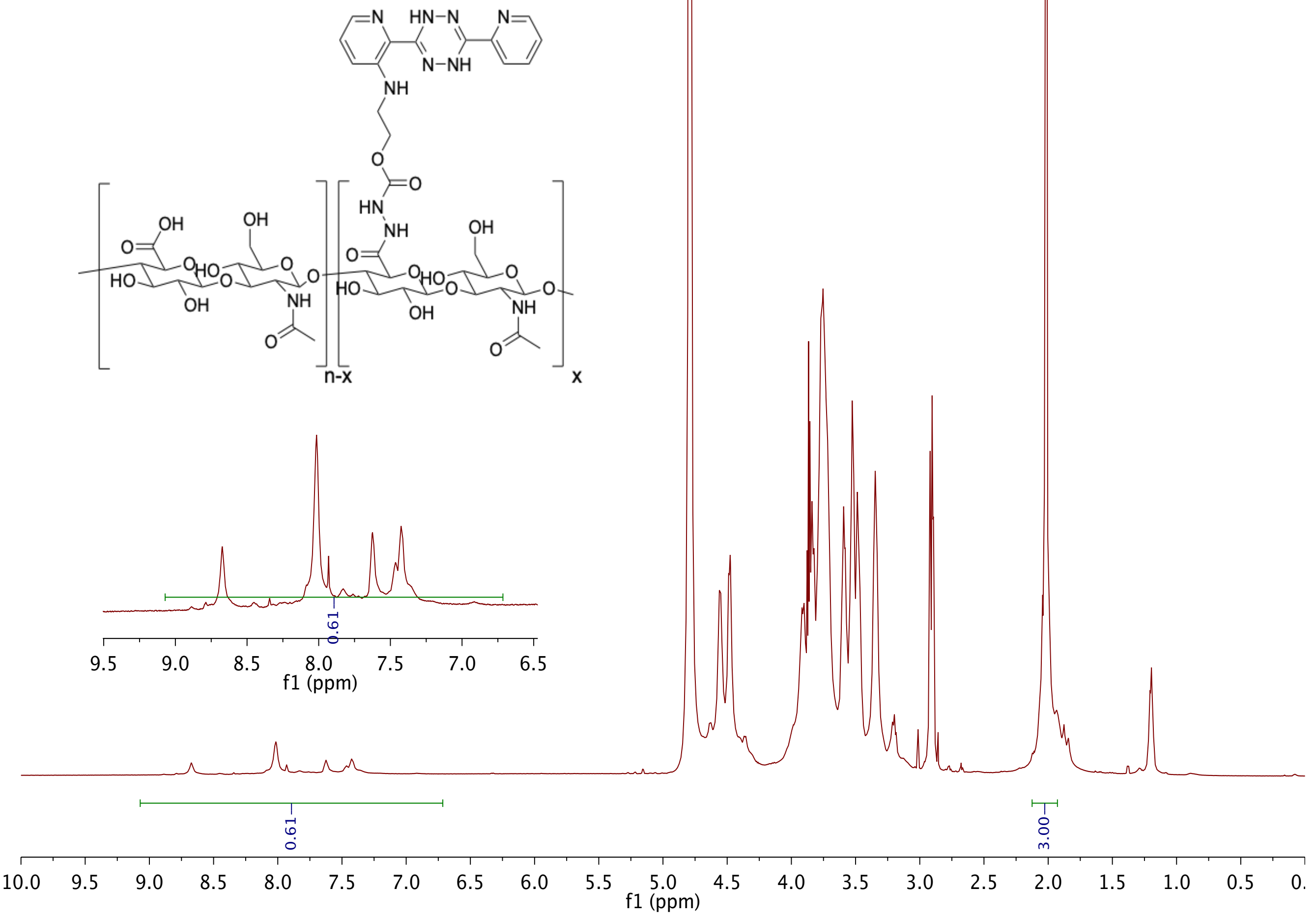
${ }^{1} \mathrm{H}$ NMR $\left(600 \mathrm{MHz}, \mathrm{D}_{2} \mathrm{O}\right)$ of $\mathrm{HA}$-dTCO
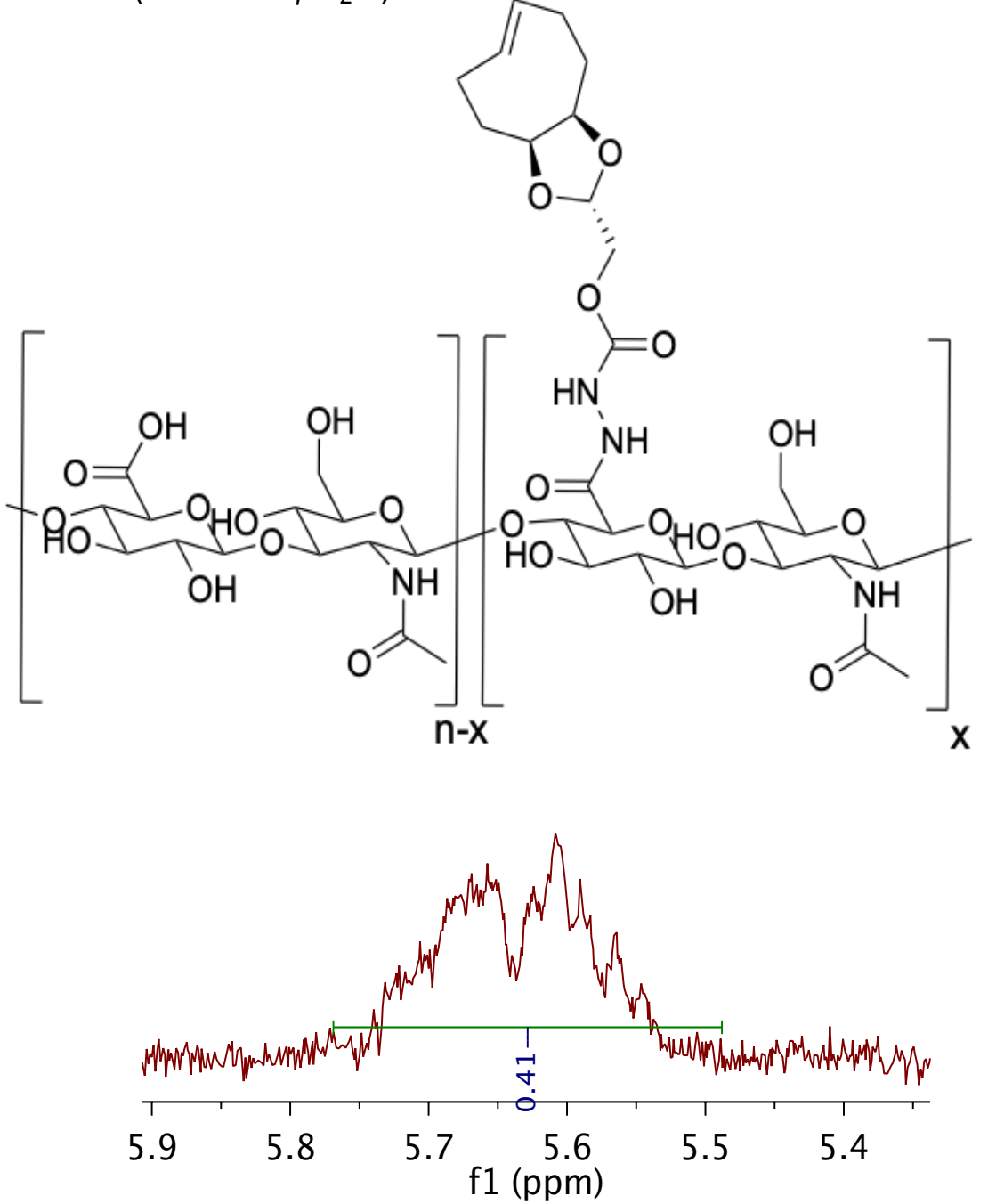

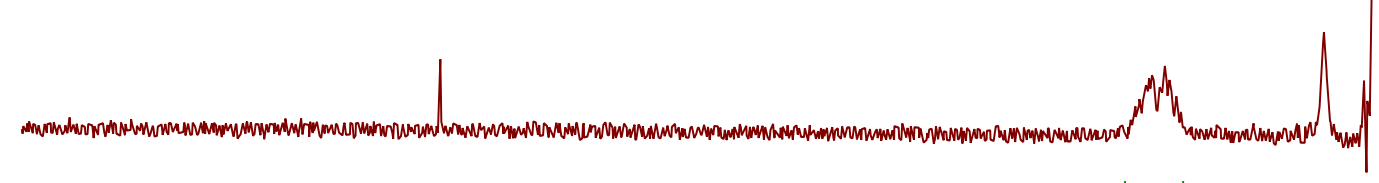

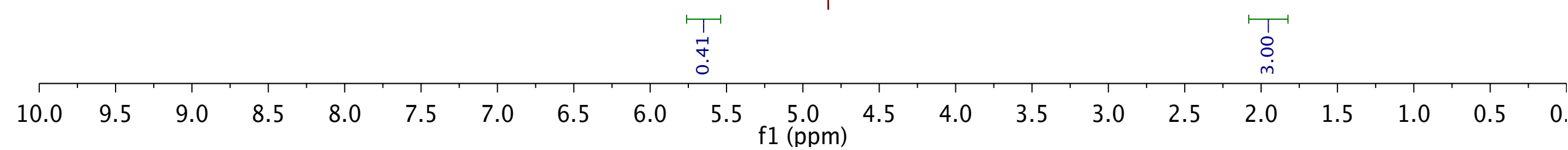

